Maria Fernanda Pistori

\title{
Áreas Protegidas como fonte de serviços ecossistêmicos: conflitos e sinergias com as perspectivas da população
}

Ecosystem services supply by protected areas: conflicts and synergies with the population's perspectives

São Paulo

2020 


\section{Maria Fernanda Pistori}

\section{Áreas Protegidas como fonte de serviços ecossistêmicos: conflitos e sinergias com as perspectivas da população}

Ecosystem services supply by protected areas: conflicts and synergies with the population's perspectives

Dissertação apresentada ao Instituto de Biociências da Universidade de São Paulo, para a obtenção de Título de Mestre em Ciências, na Área de Ecologia.

Orientadora: Profa. Dra. Vânia Regina Pivello

São Paulo 


\section{Ficha Catalográfica}

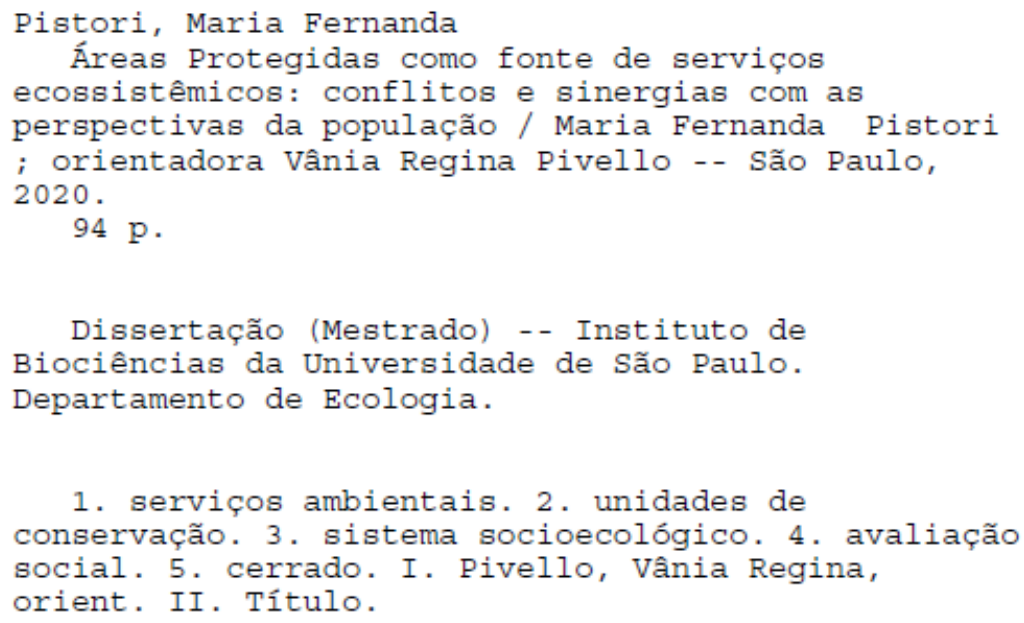

\section{Comissão Julgadora:}

\footnotetext{
$\operatorname{Prof}(a) . \operatorname{Dr}(a)$
}

Prof(a). Dr(a).

Prof(a). Dr(a). 
Dedico essa dissertação às minhas avós, D.Lourdes e D.Sônia, Mulheres fortes que me inspiram com suas trajetórias,

E por todo amor. 
"Na natureza, nada existe sozinho" "In nature, nothing exists alone"

- Rachel Carson, livro Primavera Silenciosa (1962) 
Quando paro para pensar a todos e tudo que devo agradecer para chegar até aqui, me parece impossível, percorre diferentes escalas e interações sem fim. Mas queria deixar uma amostra de toda essa trajetória, de um caminho nem sempre fácil, mas com um saldo enorme de felicidade. Olhando agora, daqui de um pouco mais longe, ele me orgulha e descubro das dores e das delícias da vida, mas ainda há muito para percorrer. E ainda bem. Querendo descobrir mais sobre o mundo, acabo por descobrir mais ainda sobre mim. A decisão de entrar nessa trilha que foi o Mestrado, já foi uma boa prova de coragem e agora posso ver mais do horizonte.

Não poderia deixar de começar a agradecer minha orientadora, Vânia Pivello, por ter me dado o prazer dessa aventura. Pela confiança no meu trabalho e pela liberdade de explorar. Obrigada pelo apoio, críticas e sugestões, e especialmente pela amizade e por ter se tornado minha "mãe acadêmica".

Agradeço a todos os docentes e funcionários do Instituto de Biociências da Universidade de São Paulo por tantas contribuições para o meu crescimento desde a graduação. Agradeço especialmente a todos do Departamento de Ecologia, onde pude lançar meus primeiros voos na vida de cientista, sempre assistida de pessoas que muito contribuíram pro meu crescimento. Não podendo deixar de destacar o papel essencial dos membros da Comissão Coordenadora do Programa, nossa querida Vera e Welington, por fazerem diferença no Programa e na vida dos discentes, especialmente nesse ano de 2020. Assim como agradecer os discentes da pós-graduação, que sempre buscaram contribuir para o melhor coletivamente.

Agradeço à CNPq e CAPES pela bolsa durante o mestrado, assim como pelo fomento para os trabalhos de campo pela verba PROEX da CAPES, assim como o IPT pelo apoio através do programa Novos Talentos. Sem isso não seria possível a execução da pesquisa. Assim também gostaria de agradecer a todos aqueles que lutam pela ciência brasileira. Seguimos juntos.

Aos analistas, técnicos e funcionários do ICMBio do PARNA Brasília por me receberem, especialmente a responsável pelas pesquisa, Cibele, pela pronta disposição em ajudar. Agradeço a todas as pessoas que contribuíram com a pesquisa, participando das entrevistas, oferecendo uma sombra, um copo de água ou cafézinho. O tempo de vocês foi precioso. É muito satisfatório o poder da gentileza.

Agradeço aos membros do meu comitê, Alexandre Igari e Leandro Tambosi, pelas excelentes contribuições para minha pesquisa e meu desenvolvimento, dedicando algumas boas horas de intenso aprendizado. Não deixando de agradecer a Prof. Rozely Ferreira dos Santos pelas críticas, sugestões e ensinamentos durante o início do projeto.

Agradeço também à pesquisadora Caroline Almeida Souza que me orientou no IPT através do Programa Novos Talentos, por todo aprendizado e sugestões e pela oportunidade de experimentar como o planejamento funciona na prática. Muito obrigada.

Aos queridos do LEPAC, sintam-se todos representados, pela convivência, reuniões, aprendizados, cafezinhos e cervejinhas, enfim, por esses anos de compartilhamento. Tenho muito orgulho de ter feito parte desse laboratório que se esforça em fazer uma incrível contribuição científica. 
Agradeço aos amigos da Ecologia, em especial aos membros da comissão do EcoEncontros, projeto que me dediquei durante todo o mestrado e que muito aprendi. Também agradeço o trabalho dos colegas nas outras comissões: PROEX, Café Existencial, EcoEscola, sei que tudo é feito com muita dedicação e carinho.

Agradeço também meus amigos queridos que acompanharam e compartilharam de perto essa jornada: Mariana Mendes, Vítor Zago e, a irmã que a vida deu, Bruna Soares (e o pequeno Ícaro). É sempre ótimo ter vocês para compartilhar minha jornada, é sempre mais fácil carregar o fardo em grupo e mais gostoso quando o riso ecoa.

Às minhas amigas que acompanham há tanto tempo meus passos: Bruna Watzeck, Adriane Polito, Ana Malavasi, Ingra Nolasco e Marcela Grigoleto. É sempre bom ter algumas certezas na vida. Obrigada por torcerem, mesmo às vezes sem entender, por acompanharem minhas andanças, mudanças e sumiços, sempre com reencontros reconfortantes.

Agradeço aos meus novos vizinhos, Bruno Gios e Carla Pavone, que nos recebeu tão bem nessa grande decisão de mudar de cidade e ainda juntar as trouxinhas. Pelas risadas, conselhos e contribuições nas correções. É uma felicidade compartilhar a vida com vocês.

Ao meu companheiro de vida, Leonardo Rezende, que compartilha e participa (alias, obrigada pelo campo!), que incentiva e acolhe. Compartilhar a vida com você é um presente todos os dias, nossa caminhada ao longo desses anos tem sido incrível. Enfim, obrigada por todo seu amor. E ainda de quebra ganhei uma família maravilhosa no pacote, obrigada pelo apoio da minha sogra Maria Sueli, meu sogro André e meu cunhado Marco.

Agradeço imensamente à minha família, grandes entusiastas e apoiadores sem limites. Tudo isso é sobre amor. Aos meus pais, Edmir e Andrea, por tanto, que não caberia aqui, mas especialmente pelo apoio sem fronteiras, por sempre me darem coragem e abrirem meus horizontes, com muito afeto. Ao meu irmão Renato e a cunhada Giulia, pelo apoio, especialmente nas minhas aventuras mundo a fora. À minha irmã, Ana Flávia pela inspiração e torcida de sempre e pela alegria de ter minhas sobrinhas Gabriela e Lavínia. Obrigada família, por me darem segurança ao saber que estão olhando meus voos e por saber que tenho sempre pra onde retornar.

Assim, encerro por aqui meus agradecimentos, e mesmo o que não foram citados por algum esquecimento, saiba que se você fez parte de tudo isso, com certeza têm um pedaço especial por aqui. Obrigada!! Que venham os próximos capítulos. Vida longa aos nossos mares e florestas. 


\section{ÍNDICE}

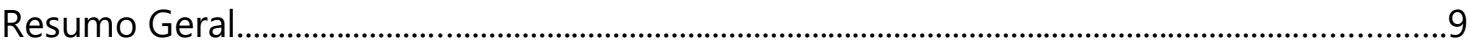

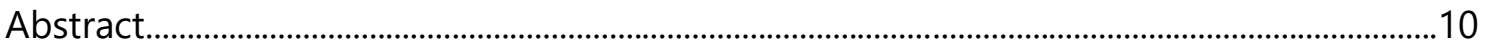

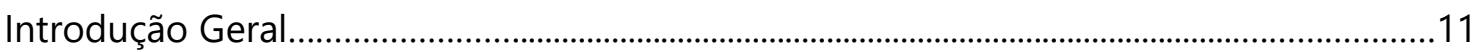

Capítulo 1: Conflitos e sinergias entre áreas protegidas e provisão de serviços ecossistêmicos: uma revisão da literatura................................................................................16

Material Suplementar S1 Capítulo 1....................................................................................................

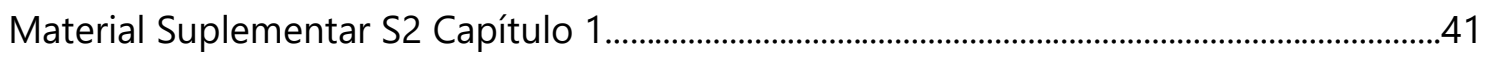

Capítulo 2: Aspectos socioculturais e a percepção sobre os serviços ecossistêmicos: um estudo do Parque Nacional de Brasília.

Material Suplementar S1 Capítulo 2:..........................................................................................

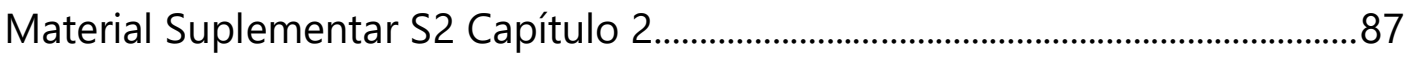

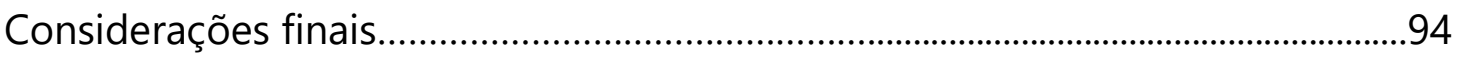


A Ciência da Conservação atualmente centra-se no debate da interface ciênciaprática, buscando maior integração entre a sociedade e natureza para alcançar soluções viáveis para os atuais problemas ambientais. A criação de áreas protegidas tem sido uma das principais estratégias de conservação da biodiversidade, no entanto, a ausência de capacidade efetiva de gerenciamento resulta, em muitos casos, no não cumprimento de metas e objetivos. As chances de se obter uma proteção ambiental bem-sucedida podem ser aumentadas se as metas de proteção forem compartilhadas e apoiadas pela população local. A abordagem de "serviços ecossistêmicos (SE)" pode ser uma importante estratégia ao estender os objetivos da conservação, englobando os valores sociais, econômicos e culturais. Essa dissertação tem o objetivo geral de explorar as percepções, usos e preferências da população em relação aos SE fornecidos por áreas protegidas. No capítulo 1, apresento uma revisão sistemática de 75 artigos para analisar o estado da arte dos estudos que investigam a relação entre o fornecimento de serviços ecossistêmicos e pessoas dentro de áreas protegidas. Esse campo de pesquisa é recente e está em expansão, principalmente nos últimos anos. Dentre os estudos que exploraram a percepção sobre os SE fornecidos por áreas protegidas, nossa análise mostrou que os SE mais valorizados são, de forma geral, compatíveis com os objetivos de conservação. Mas ainda é notável a presença da dependência de comunidades em relação a muitos tipos de serviços ecossistêmicos de provisão, destacando ainda um desafio a ser enfrentado. As características socioculturais e econômicas, além do contexto geográfico, parecem ser importantes fatores relacionados à preferência das pessoas pelos serviços ecossistêmicos. No capítulo 2, apresento um estudo de caso para avaliar a percepção de diferentes grupos de beneficiários em relação aos SE fornecidos pelo Parque Nacional de Brasília (PARNA Brasília), uma importante área protegida de Cerrado, adjacente a um importante centro urbano. Foram realizadas 58 entrevistas com diferentes grupos de stakeholders. O PARNA Brasília é valorizado em grande parte pelos seus objetivos de criação (provisão de habitat, lazer e valor de existência). No entanto, puderam ser identificados alguns trade-offs com serviços ecossistêmicos de provisão, valor que mais diferenciou os grupos de interesse. Houve uma alta correlação entre o valor de importância conferido ao SE e sua percepção de declínio. Dessa forma, a abordagem de SE demonstrou ter potencial para facilitar a comunicação de tomadores de decisão com a população, ao identificar sinergias e trade-offs entre os objetivos de conservação e o uso, podendo ajudar na busca de soluções para aumentar a efetividade desses espaços protegidos. 
Currently, the Conservation Science mainly debates the science-practice interface, with the aim of integrating society and nature to achieve viable solutions for current environmental problems. The creation of protected areas has been the main biodiversity conservation strategy, however, the lack of effective management results in a low level of achievement of objectives. The chances of achieving successful environmental protection can be increased when the protection goals are shared and supported by the local population. The "ecosystem services (ES)" approach can be an important strategy in extending conservation objectives including social, economic and cultural values. This dissertation has the general objective of exploring the perceptions, uses and preferences of the population in relation to the ES provided by protected areas. In chapter 1, I present a systematic review of 75 articles to analyze the state of the art of studies that investigate the relationship between the provision of ES and people in protected areas. This field of research is new and it has been expanding, especially in recent years. Among the studies that explored the perception of ES provided by protected areas, our analysis showed that the most valued ES are, in general, compatible with conservation objectives. On the order hand, the presence of communities depend on many types of provisioning ES and it is still considerable, showing a challenge to be faced. Sociocultural and economic characteristics, in addition to the geographical context, seem to be important factors related to people's preference for ES. In chapter 2, I present a case study to assess the perception of different groups of beneficiaries in relation to the ES provided by the Brasília National Park (PARNA Brasília), an important protected area of the Cerrado and adjacent to an important urban center. Fifty-eight interviews were conducted with different groups of stakeholders. The conservation objectives of PARNA Brasilia is a great value for the stakeholders (provision of habitat, leisure, and existence value). However, some trade-offs with provisioning ES could be identified, a value that most distinguished stakeholders. There was a high correlation between the importance value given to the ES and the perception of its decline. In this way, the ES approach has the potential to facilitate communication between decision-makers and the population, by identifying synergies and trade-offs between conservation objectives and uses, and it can help in the search for solutions to problems to increase the effectiveness of these protected spaces. 
Áreas Protegidas como fonte de serviços ecossistêmicos: conflitos e sinergias com as perspectivas da população

\section{Ecosystem services supply by protected áreas: conflicts and synergies with the population's perspectives}

\section{INTRODUÇÃO GERAL}

O estabelecimento de áreas protegidas é reconhecido como uma das estratégias mais eficientes na contenção da crise da biodiversidade (Bruner et al., 2001; Balmford et al. 2002). Essa estratégia se mostra bem justificada, pois análises concluíram que, na maioria das vezes, áreas protegidas bem gerenciadas reduzem as taxas de perda de habitat - principal ameaça à biodiversidade (Butchart et al. 2012) - tanto em ambientes terrestres (Geldmann et al. 2013; Joppa e Pfaff. 2010) como em ambientes marinhos (Micheli e Niccolini, 2013; Edgar et. al. 2014). Também há fortes evidências de que as áreas protegidas mantêm melhor os níveis populacionais das espécies do que outras estratégias de conservação (Geldmann et.al. 2013, Lester et.al. 2009, Karanth et.al. 2009; Taylor et.al. 2011; Sheehan et al. 2013; Sciberras et al. 2013).

Ao mesmo tempo, pela ausência de capacidade efetiva de gerenciamento, existem os chamados "parques de papel" (Dudley e Stolton, 1999), que não proporcionam conservação efetiva ( Joppa et al., 2008). As principais limitações à gestão eficaz das áreas protegidas surgem da falta de recursos financeiros (especialmente nos países em desenvolvimento) ou deficiências na gestão (por exemplo, falta de pessoal qualificado). O princípio "cercas e multas" (Mariki 2013; Mutanga et al. 2015) forneceu apenas sucesso limitado. Vários estudos mostraram que as chances de se obter uma proteção ambiental bem-sucedida podem ser aumentadas se as metas de proteção forem compartilhadas e apoiadas pela população local (Dickman 2010 ; Lindell e Perry 2012 ). Para alcançar esse apoio, é necessário reconhecer a natureza interligada dos sistemas sociais e ecológicos (sistemas socioecológicos) e considerar e incorporar ativamente as vozes, os conhecimentos e as expectativas dos habitantes locais ( Delgado-Serrano e Ramos 2015).

Nos últimos anos, uma nova abordagem vem sendo utilizada como ferramenta para fortalecer a conservação da biodiversidade e, ao mesmo tempo, entender que a população faz 
parte desse sistema: os serviços ecossistêmicos (SE). Uma das definições utilizadas para esse termo é do Millennium Ecosystem Assessment (2003) dado como "os benefícios que o ser humano obtém dos ecossistemas", no entanto, os modelos teóricos e conceituais ainda estão em processo de construção e consolidação (Wallace, 2007; Costanza, 2008; Fisher e Turner, 2008; Fisher, Turner e Morling 2009; De Groot et al., 2010). Mas, apesar disso, o ponto de concordância ocorre no fato do bem estar humano estar intimamente associado aos diferentes componentes dos ecossistemas (Haines-Young e Potschin, 2010) e na necessidade de haver demanda por um beneficiário para que um SE exista (Fisher e Turner, 2008; De Groot et al., 2010).

A abordagem dos serviços ecossistêmicos (SE) estende os objetivos de conservação além dos valores intrínsecos para cobrir os valores sociais, econômicos e culturais da natureza (Cowling et al. 2008 ; López-Hoffman et al. 2010 ). Reconhece a ampla gama de benefícios que as áreas protegidas proporcionam (Dudley et al. 2011 ) e a importância de considerar os interesses múltiplos - e muitas vezes conflitantes - dos atores sociais em sua gestão (GarcíaNieto et al. 2015).

As pesquisas que envolvem os SE abordam diferentes temas, como identificação, quantificação e valoração, mas ainda mantêm lacunas referentes às preferências e percepções socioculturais dos SE a partir da perspectiva de valores e atitudes dos seres humanos (MartínLópez et al., 2012). Tais lacunas podem ser consideradas incoerentes, dado o papel central da relação humano-natureza no conceito de SE.

Tendo em vista esse escopo, esta dissertação centra-se em explorar essas lacunas visando, particularmente, áreas protegidas. Para isso, o trabalho está dividido em dois capítulos. O Capítulo 1 trata-se de uma revisão sistemática para analisar o estado da arte dos estudos que investigam a relação entre o fornecimento de serviços ecossistêmicos e pessoas dentro de áreas protegidas. E o capítulo 2 traz uma pesquisa empírica que investiga a percepção de diferentes grupos sobre os serviços ecossistêmicos prestados pelo Parque Nacional de Brasília.

\section{BIBLIOGRAFIA}

Balmford, A., Bruner, A., Cooper, P., Costanza, R., Farber, S., Green, R. E., .. \& Munro, K. (2002). Economic reasons for conserving wild nature. science, 297(5583), 950-953.

Bruner, A. G., Gullison, R. E., Rice, R. E., \& Da Fonseca, G. A. (2001). Effectiveness of parks in protecting tropical biodiversity. Science, 291(5501), 125-128. 
Butchart, S. H., Scharlemann, J. P., Evans, M. I., Quader, S., Arico, S., Arinaitwe, J., ... \& Boucher, T. M. (2012). Protecting important sites for biodiversity contributes to meeting global conservation targets. PloS one, 7(3).

Costanza, R. 2008. Ecosystem services: Multiple classification systems are needed. Biological Conservation 141, p: $350-352$.

Cowling, R. M., Egoh, B., Knight, A. T., O'Farrell, P. J., Reyers, B., Rouget, M., ... \& WilhelmRechman, A. (2008). An operational model for mainstreaming ecosystem services for implementation. Proceedings of the National Academy of Sciences, 105(28), 9483-9488.

De Groot, R.S., et al. 2010. Challenges in integrating the concept of ecosystem services and values in landscape planning, management and decision making. Ecological Complexity 7, p: 260-272.

Delgado-Serrano, M., \& Ramos, P. (2015). Making Ostrom's framework applicable to characterise social ecological systems at the local level. International Journal of the Commons, 9(2).

Dickman, A. J. (2010). Complexities of conflict: the importance of considering social factors for effectively resolving human-wildlife conflict. Animal conservation, 13(5), 458-466.

Dudley, N., \& Stolton, S. (1999). Conversion of paper parks to effective management: developing a target.

Dudley, N., Higgins-Zogib, L. H., Hockings, M., MacKinnon, K., Sandwith, T., \& Stolton, S. (2011). National parks with benefits: how protecting the planet's biodiversity also provides ecosystem services. Solutions, 2(6), 87-95.

Edgar, G. J., Stuart-Smith, R. D., Willis, T. J., Kininmonth, S., Baker, S. C., Banks, S., ... \& Buxton, C. D. (2014). Global conservation outcomes depend on marine protected areas with five key features. Nature, 506(7487), 216-220.

Fisher, B., Turner, R.K., 2008. Ecosystem services: classification for valuation. Biological Conservation 141, p: 1167-1169.

Fisher, B., Turner, R.K., Morling, P., 2009. Defining and classifying ecosystem services for decision making. Ecological Economics 68, p: 643-653.

García-Nieto, A. P., Quintas-Soriano, C., García-Llorente, M., Palomo, I., Montes, C., \& MartínLópez, B. (2015). Collaborative mapping of ecosystem services: The role of stakeholders' profiles. Ecosystem Services, 13, 141-152.

Geldmann, J., Barnes, M., Coad, L., Craigie, I. D., Hockings, M., \& Burgess, N. D. (2013). Effectiveness of terrestrial protected areas in reducing habitat loss and population declines. Biological Conservation, 161, 230-238.

Haines-Young, R., Potschin, M. 2010. The links between biodiversity, ecosystem services and human well-being. In: Raffaelli, D. \& C. Frid (eds.): Ecosystem Ecology: a new synthesis. BES Ecological Reviews Series, CUP, Cambridge. 
Joppa, L. N., Loarie, S. R., \& Pimm, S. L. (2008). On the protection of "protected areas". Proceedings of the National Academy of Sciences, 105(18), 6673-6678.

Joppa, L., \& Pfaff, A. (2010). Reassessing the forest impacts of protection: the challenge of nonrandom location and a corrective method. Annals of the New York Academy of Sciences, 1185(1), 135-149.

Karanth, K. K., Nichols, J. D., Hines, J. E., Karanth, K. U., \& Christensen, N. L. (2009). Patterns and determinants of mammal species occurrence in India. Journal of Applied Ecology, 46(6), 1189-1200.

Lester, S. E., Halpern, B. S., Grorud-Colvert, K., Lubchenco, J., Ruttenberg, B. I., Gaines, S. D., ... \& Warner, R. R. (2009). Biological effects within no-take marine reserves: a global synthesis. Marine Ecology Progress Series, 384, 33-46.

Lindell, M. K., \& Perry, R. W. (2012). The protective action decision model: theoretical modifications and additional evidence. Risk Analysis: An International Journal, 32(4), 616-632.

López-Hoffman, L., Varady, R. G., Flessa, K. W., \& Balvanera, P. (2010). Ecosystem services across borders: a framework for transboundary conservation policy. Frontiers in Ecology and the Environment, 8(2), 84-91.

Mariki, S. B. (2013). Conservation with a human face? Comparing local participation and benefit sharing from a national park and a state forest plantation in Tanzania. Sage Open, 3(4), 2158244013512665.

Martín-López, B., et al. 2012. Uncovering ecosystem services bundles through social preferences. PLoS ONE, 7, n. 6, e38970.

Micheli, F., \& Niccolini, F. (2013). Achieving success under pressure in the conservation of intensely used coastal areas. Ecology and Society, 18(4).

Millennium Ecosystem Assessment (MEA). 2005. Ecosystems and Human Well-being: synthesis, Ecosystems. Island Press, Washington. doi:10.1196/annals.1439.003

Mutanga, C. N., Vengesayi, S., Muboko, N., \& Gandiwa, E. (2015). Towards harmonious conservation relationships: A framework for understanding protected area staff-local community relationships in developing countries. Journal for Nature Conservation, 25, 8-16.

Sciberras, M., Jenkins, S. R., Kaiser, M. J., Hawkins, S. J., \& Pullin, A. S. (2013). Evaluating the biological effectiveness of fully and partially protected marine areas. Environmental Evidence, 2(1), 4.

Sheehan, E. V., Stevens, T. F., Gall, S. C., Cousens, S. L., \& Attrill, M. J. (2013). Recovery of a temperate reef assemblage in a marine protected area following the exclusion of towed demersal fishing. PloS one, 8(12).

Taylor, M. F., Sattler, P. S., Evans, M., Fuller, R. A., Watson, J. E., \& Possingham, H. P. (2011). What works for threatened species recovery? An empirical evaluation for Australia. Biodiversity and conservation, 20(4), 767-777. 
Wallace, K.J., 2007. Classification of ecosystem services: problems and solutions. Biological Conservation 139, p: 235-246. 
Conflitos e sinergias entre áreas protegidas e provisão de serviços ecossistêmicos: uma revisão da literatura

Conflicts and sinergies between protected áreas and ecosystem services supply: a literature review

Maria Fernanda Pistori, Vânia Regina Pivello

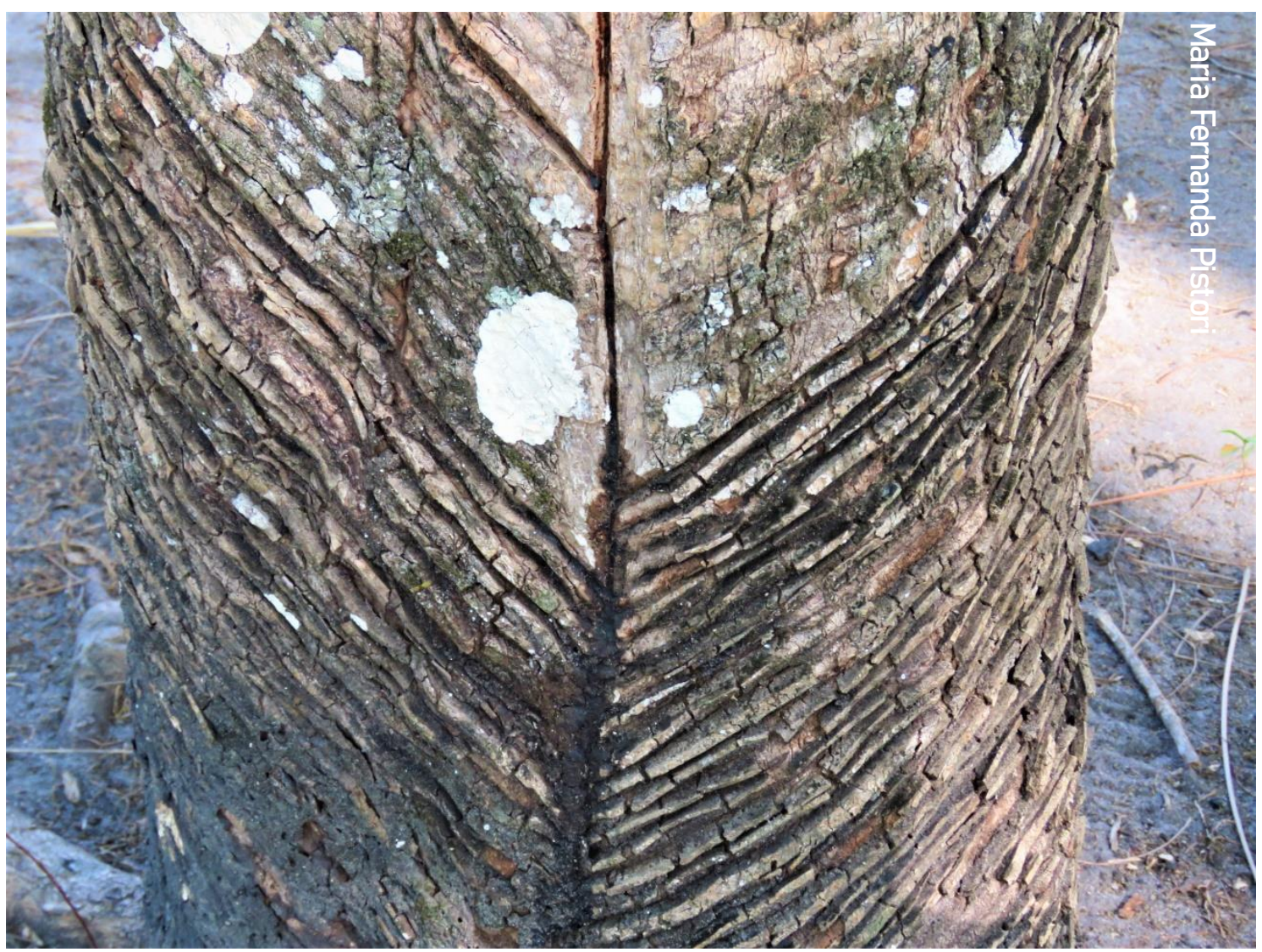




\section{Resumo}

Esta revisão sistemática de literatura explora as relações encontradas entre a relação das pessoas com os serviços ecossistêmicos (SE) fornecidos por áreas naturais protegidas. Extraímos de 75 trabalhos selecionados i) os tipos de SE mais investigados; ii) as metodologias utilizadas para explorar essa temática; iii) os SE mais identificados como fornecidos pelas áreas protegidas; iv) características importantes dos stakeholders que influenciam essa relação. Nossos resultados sugerem que SE compatíveis com os objetivos das áreas naturais estão entre os mais valorizados, mas ainda é notável o maior foco em serviços ecossistêmicos de provisão, que podem resultar em trade-offs, tanto entre diferentes SE, como entre diferentes stakeholders e, principalmente, entre a demanda da população por esses SE e os objetivos da área protegida. De maneira geral, os fatores socioeconômicos, socioculturais, contexto geográfico e gênero influenciam fortemente a percepção e o valor dado aos SE fornecidos pelas áreas protegidas. Por fim, discutimos esses aspectos e a importância de se considerar áreas protegidas como sistemas socioculturais, bem como a abordagem de serviços ecossistêmicos como uma potencial ferramenta para melhorar a gestão de áreas protegidas.

Palavras-chave: serviço ecossistêmico, parque, área natural, sistema sociocultural, bem-estar humano.

\section{Introdução}

O conceito de serviços ecossistêmicos (SE) vem atraindo cada vez mais o interesse da literatura científica, bem como de seu uso na da formulação de políticas públicas (García-Nieto et. al., 2013; Palomo et. al., 2013). A definição mais amplamente utilizada é a do Millenium Ecosystem Assessment (2005): "serviços ecossistêmicos são os benefícios que o ser humano obtém dos ecossistemas". O destaque para a abordagem de SE ocorre pelo potencial em responder à demanda por uma temática mais integrada ao gerenciamento de ecossistemas e por trazer um equilíbrio entre as necessidades humanas e a conservação da natureza, pois engloba a interação entre as esferas ecológica e social (Clemente et.al., 2019). Por exemplo, as áreas protegidas (AP) são reconhecidas por sua importante contribuição para a conservação da biodiversidade, manutenção, aprimoramento da integridade ecológica e, mais recentemente, pelo fornecimento de serviços ecossistêmicos (Millennium Ecosystem Assessment, 2003; Millennium Ecosystem Assessment, 2005 ).

No entanto, as APs gerenciadas e valorizadas conscientemente por seus serviços ecossistêmicos representam ainda uma exceção e não a regra (Dudley et.al. 2011). Neste estudo, consideramos área protegida como um espaço geográfico claramente definido, reconhecido, dedicado e gerenciado por meios legais ou outros meios eficazes, para alcançar, em longo prazo, a conservação da natureza, mantendo os serviços ecossistêmicos e valores culturais associados (IUCN, 2008). Tais áreas podem ter diferentes categorias, de acordo com seus objetivos de gerenciamento, permitindo distintas atividades dentro de seus perímetros. Para definir uma estratégia eficaz de política para a conservação da biodiversidade e provisão de serviços ecossistêmicos é necessário contabilizar os fatores que podem dificultar ou facilitar a missão das APs, tanto do ponto de vista ecológico quanto social (Jones-Walters e Čivić, 2013). 
A integração da perspectiva sociocultural na avaliação de SE ainda se dá de maneira fragmentada e com grande diversidade metodológica, como foi constatado por Sppelt e colaboradores (2011) em uma revisão que explorou as metodologias utilizadas nesse campo de pesquisa. Essa variação metodológica representa uma barreira para a incorporação explícita da abordagem de SE para formuladores de políticas, tomadores de decisão e pesquisadores, pois dificulta a avaliação da credibilidade dos resultados e reduz a comparabilidade dos estudos.

Dentro do contexto mais amplo de pesquisa em serviços ecossistêmicos, a maioria dos estudos concentra-se em avaliações biofísicas do ecossistema e na capacidade de fornecer SE (Martin-Lopez et.al. 2012). A falta de inclusão explícita da dimensão humana representa um grande gargalo (Menzel et.al. 2010). Uma lacuna paradoxal, visto que o conceito de SE tem base na perspectiva antropogênica. Incluir o fator social na avaliação de SE é essencial para melhorar a gestão, já que pode revelar preferências e trade-offs, possibilitando o gerenciamento de conflitos para o uso mais sustentável dos recursos. Além disso, os benefícios derivados dos serviços ecossistêmicos podem trazer poderosos incentivos à conservação da biodiversidade (Costanza et al. 1997 ; Balmford et al. 2002 ).

Aqui, fizemos uma extensa pesquisa da literatura científica para organizar as pesquisas que investigam a relação entre pessoas e serviços ecossistêmicos ofertados por APs ao redor do mundo, com o objetivo de entender quais SE são valorizados e quais são focos de conflitos, assim como explorar os possíveis fatores que influenciam essas escolhas. Em seguida, avaliamos o estado da arte das pesquisas nessa área de estudo. Discutimos as lacunas e a importância dessa abordagem temática dentro da Ciência da Conservação como uma ferramenta para auxiliar a gestão em relação a SE, identificando atividades que são incompatíveis com os objetivos da área, além de reforçar a importância de APs. 


\section{Material e Método}

\subsection{Busca Bibliográfica}

Uma pesquisa bibliográfica foi realizada, em dezembro de 2019, na base de dados científicos indexados no ISI Web of Science, utilizando seletores de consulta em inglês: (("ecosystem service*") AND (park* OR "protected area*" OR *reserve* OR "natural area*") AND (people) NOT (marine OR costal)). A busca foi realizada utilizando o campo tópico (topic), que encontra os termos utilizados nos títulos dos artigos, resumos, palavras-chave do autor e palavras-chave criadas (keywords plus). Não foi feito nenhum recorte temporal, incluindo todos os anos de publicações sobre o tema. Utilizamos apenas artigos científicos, não incluímos livros, capítulos de livros, dissertações e teses, resumos estendidos ou resumos de eventos científicos.

Após o resultado da busca, os critérios a serem considerados para a inclusão do artigo na análise foram: i) abordar serviços ecossistêmicos; ii) a pesquisa ter sido realizada em área protegida; iii) ter incluído nos resultados a dimensão humana (valores e/ou demandas por SE). A primeira triagem ocorreu pela leitura dos títulos, sendo excluídos os que se mostraram totalmente fora do escopo deste trabalho. Para a segunda seleção, foi realizada a leitura de todos os resumos, tendo sido mantidos apenas trabalhos que tratavam da relação entre pessoas e serviços ecossistêmicos dentro de APs. Os trabalhos que seguiam esse escopo mas tratavam de áreas marinhas ou costeiras foram excluídos. A última etapa ocorreu com a leitura, na íntegra, dos trabalhos selecionados. Para a decisão de mantê-los ou não na análise quali-quantitativa, foram analisados os resultados de cada estudo tendo como o foco nosso objetivo (Figura 1). As informações sobre os artigos selecionados encontram-se na Tabela S1 (Material Suplementar).

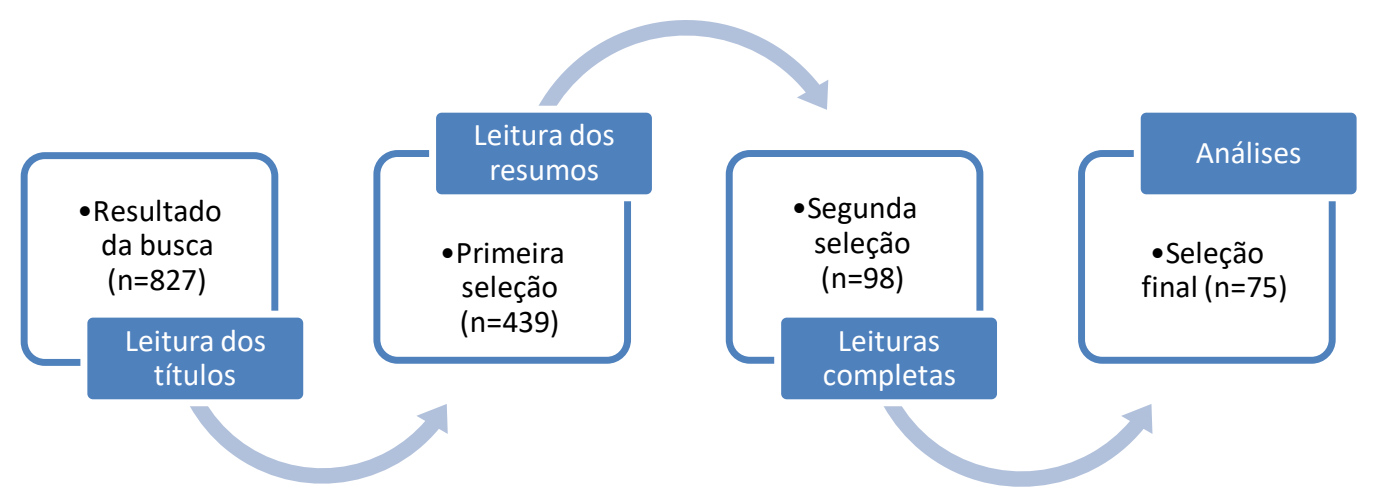

Figura 1: Fluxograma do processo de seleção de artigos incluídos nesta revisão.

\subsection{Análise de variáveis}

As informações extraídas dos artigos incluíram o país de localização da AP, a categoria da AP de acordo com a IUCN, os SE considerados no estudo, o público avaliado (de forma individual ou separadamente por grupos), o método utilizado para extrair informação do público-alvo e o componente do processo de entrega do serviço ecossistêmico investigado (Tabela 1). Este último pode ser classificado dentro de 4 componentes-foco na pesquisa: processos ecossistêmicos, capacidade do ecossistema, fluxo de serviços ecossistêmicos e valores socioculturais (Figura 2). 0 processo ecossistêmico refere-se pesquisas que investigam interações entre os elementos bióticos e abióticos (Lyouns et.al. 2005). Pesquisas com foco na 
capacidade do ecossistema avaliam o potencial do ecossistema em fornecer serviços ecossistêmicos com base em propriedades biofísicas, condições sociais e funções ecológicas (Egoh et al. 2008, Daily et al. 2009, Chan et al. 2006, e van Oudenhoven et al. 2012). O fluxo de serviços ecossistêmicos constitui pesquisas que buscam investigar o SE realmente recebido pelas pessoas, que pode ser medido diretamente, como a quantidade de um serviço entregue, ou indiretamente, como o número de beneficiários atendidos (Villamagna et al. 2013). As pesquisas que focam nos valores socioculturais avaliam a importância que as pessoas, como indivíduos ou grupo, atribuem ao (pacote de) SE (Scholte et al. 2015). As pesquisas podem englobar um ou mais desses componentes.

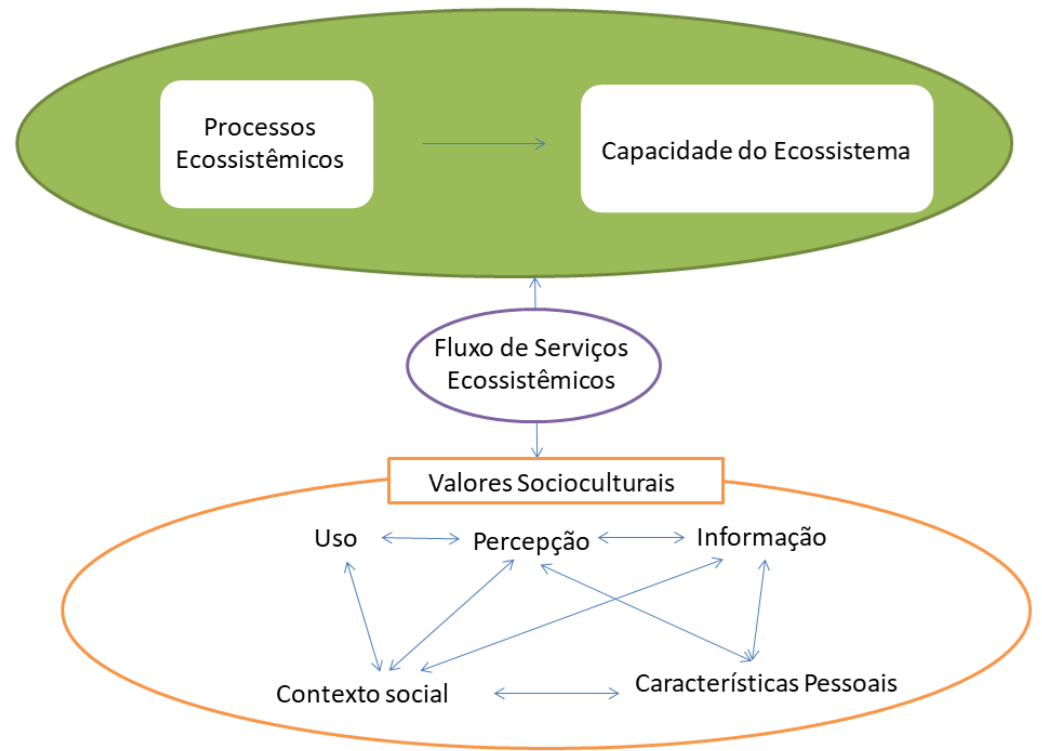

Figura 2: Principais componentes do processo de entrega do serviço ecossistêmico analisados em pesquisas na temática. A caixa verde representa componentes do ecossistema. Processos ecossistêmicos influenciam na capacidade de um ecossistema de fornecer serviços ecossistêmicos. A entrega desses serviços ecossistêmicos gerados é determinada pelo fluxo dos serviços ecossistêmicos, que influem e são influenciados pelos valores socioculturais. Os valores socioculturais são determinados por uma gama de fatores que interagem como o uso, a percepção a informação sobre os serviços, assim como o contexto social e características pessoais.

Os trabalhos também foram categorizados por grupo de $\mathrm{SE}$, podendo conter um ou mais grupos, seguindo a classificação feita pelo MEA (2005): cultural, que são benefícios não materiais que as pessoas obtêm do ecossistema (ex.: recreação, espiritual, desenvolvimento de pesquisas, atividades educativas); regulação, quando refletem em benefícios obtidos pelo controle dos processos naturais que mantêm o ecossistema (ex: regulação do clima, da qualidade do ar); provisão, são benefícios materiais obtidos diretamente do ecossistema (ex: água, madeira, plantas medicinais); suporte, que são serviços que contribuem para a produção de outros serviços ecossistêmicos (ex: ciclagem de nutrientes, habitat, formação do solo). Para a variável "Grupo de SE", as pesquisas que deixavam em aberto os SE a serem mencionados foram categorizadas como englobando todos os tipos de SE, visto que havia probabilidade de surgir nos resultados serviços ecossistêmicos das diferentes categorias.

Tabela 1: Classificação das variáveis analisadas nos trabalhos revisados. ( $\mathrm{AP}=$ área protegida; IUCN= International Union for Conservation of Nature; $\mathrm{SE}=$ serviço ecossistêmico) 


\begin{tabular}{|c|c|}
\hline Variáveis & Categorias \\
\hline País & País em que a AP está localizada \\
\hline Área Protegida & Classificação de acordo com a IUCN (2008) \\
\hline \multirow{4}{*}{$\begin{array}{c}\text { Categoria de SE } \\
\text { (classificação baseada no MEA, 2005): }\end{array}$} & Cultural \\
\hline & Regulação \\
\hline & Provisão \\
\hline & Suporte \\
\hline \multirow[t]{2}{*}{ Público } & $\begin{array}{l}\text { Individual: sem separação por grupos de interesse, pesquisas com o } \\
\text { público em geral. }\end{array}$ \\
\hline & Grupos: separado por grupos de interessados. \\
\hline \multirow[t]{9}{*}{ Método } & $\begin{array}{l}\text { Questionário de interceptação (questionários, entrevistas } \\
\text { semiestruturadas, entrevistas estruturadas e em profundidade). }\end{array}$ \\
\hline & Questionário online \\
\hline & Observação \\
\hline & Dados socioeconômicos e de infraestrutura \\
\hline & Dados Geográficos \\
\hline & Mapeamento participativo \\
\hline & Diário de Recursos \\
\hline & Grupos Focais \\
\hline & BigData Fotos (rede sociais) \\
\hline \multirow[t]{4}{*}{$\begin{array}{l}\text { Componentes do processo de entrega } \\
\text { do serviço ecossistêmico }\end{array}$} & $\begin{array}{l}\text { Processos ecossistêmicos: interações entre os elementos bióticos e } \\
\text { abióticos. }^{\text {a }}\end{array}$ \\
\hline & $\begin{array}{l}\text { Capacidade do ecossistema: o potencial do ecossistema em fornecer } \\
\text { serviços ecossistêmicos baseado em propriedades biofísicas, } \\
\text { condições sociais e funções ecológicas. }{ }^{\text {b }}\end{array}$ \\
\hline & $\begin{array}{l}\text { Fluxo de SE: o serviço realmente recebido pelas pessoas, que pode } \\
\text { ser medido diretamente como a quantidade de um serviço entregue } \\
\text { ou indiretamente como o número de beneficiários atendidos. }{ }^{c}\end{array}$ \\
\hline & $\begin{array}{l}\text { Valores Socioculturais: importância que as pessoas, como indivíduos } \\
\text { ou grupo, atribuem ao (pacote de) SE. d }\end{array}$ \\
\hline
\end{tabular}

Lyons et.al. (2005)

${ }^{\mathrm{b}}$ Egoh et al. (2008), Daily et al. (2009), Chan et al. (2006), e van Oudenhoven et al. (2012).

c Villamagna et.al. (2013)

${ }^{\mathrm{d}}$ Scholte et. al. (2015)

Para capturar aspectos de multidisciplinaridade em cada estudo, utilizamos os campos disciplinares dos periódicos, conforme relatados pelo ISI Web of Science como proxy para o campo acadêmico de cada estudo. Usamos a ferramenta de visualização de código aberto, RAWGraphs, para visualizar os metadados relevantes e ilustrar a diversidade de campos envolvidos nesses estudos (Mauri et. al., 2017).

\section{Resultados}

\subsection{Características Gerais}

Após triagem, selecionamos 75 artigos para incluir na análise (Material Suplementar S1). Nossos resultados mostram que a linha de pesquisa na área de serviços ecossistêmicos com inclusão explícita do componente humano - que busca analisar a relação entre as pessoas e os SE fornecidos por APs - é bastante recente, tendo iniciado em 2007, mas com um aumento mais expressivo de publicações apenas a partir de 2017 (Figura 3A). Apesar disso, a 
discussão em torno da temática surgiu na década de 1980. A distribuição do número de estudos realizados em APs por país revela que a China recebe grande destaque, com 11 estudos que investigaram essa temática em suas APs, seguido pelos Estados Unidos, Madagascar e Brasil, todos com apenas cinco artigos encontrados (Figura 3B).
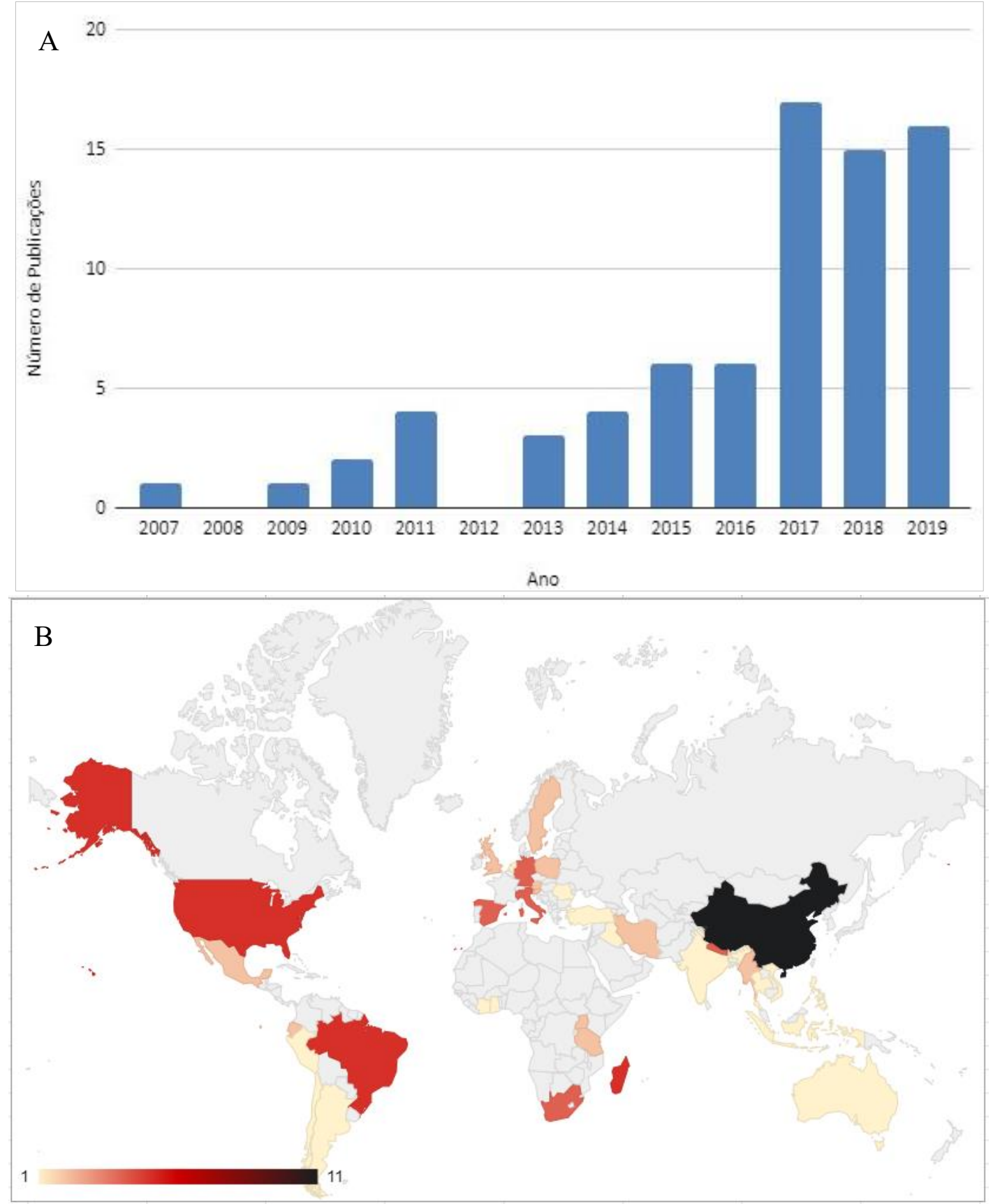

Figura 3: Panorama geral de distribuição de publicações que exploram a relação das pessoas e os serviços ecossistêmicos fornecidos por áreas protegidas. A: Número de publicações por ano. B: Distribuição geográfica de estudos em áreas protegidas, por país. O código de cores reflete a quantidade de estudos por localidade, quanto mais forte a tonalidade, maior a quantidade de estudos no país.

Os metadados indicam que não somente o número de publicações aumentou no período analisado, como também a variedade de campos acadêmicos incluídos nas pesquisas (Figura 4). Há uma tendência crescente de mais colaborações e representação mais ampla entre as diferentes disciplinas, aumentando a multidisciplinaridade dentro desse campo de 
pesquisa. Inicialmente, as pesquisas concentravam-se mais nas áreas de Ecologia e Meio Ambiente (E\&E) e Ciência da Conservação (Bio\&C), mas, a partir de 2011, passaram a ser acrescentados outros campos de pesquisa, ligados aos seguintes temas: Ciência e Tecnologia (Sci\&Tec), Ciência da Computação (Comp), Administração Pública (PA), Estudos de Desenvolvimento (Dev), Silvicultura (For), Estudos Urbanos (Urban), Geografia (Geo), Geografia física (PhyGeo), Negócios e Economia (Bus\&Econ), Agricultura (Agri), Recursos Hídricos (Water), Saúde Pública, Ambiental e Ocupacional (Health), Biofísica (Biophy), Engenharia (Eng), Botânica (Plant). E \& E continua tendo muito maior destaque dentre as disciplinas contempladas. Em 2019 houve publicações classificadas em nove campos de pesquisas diferentes (Material Suplementar S2).

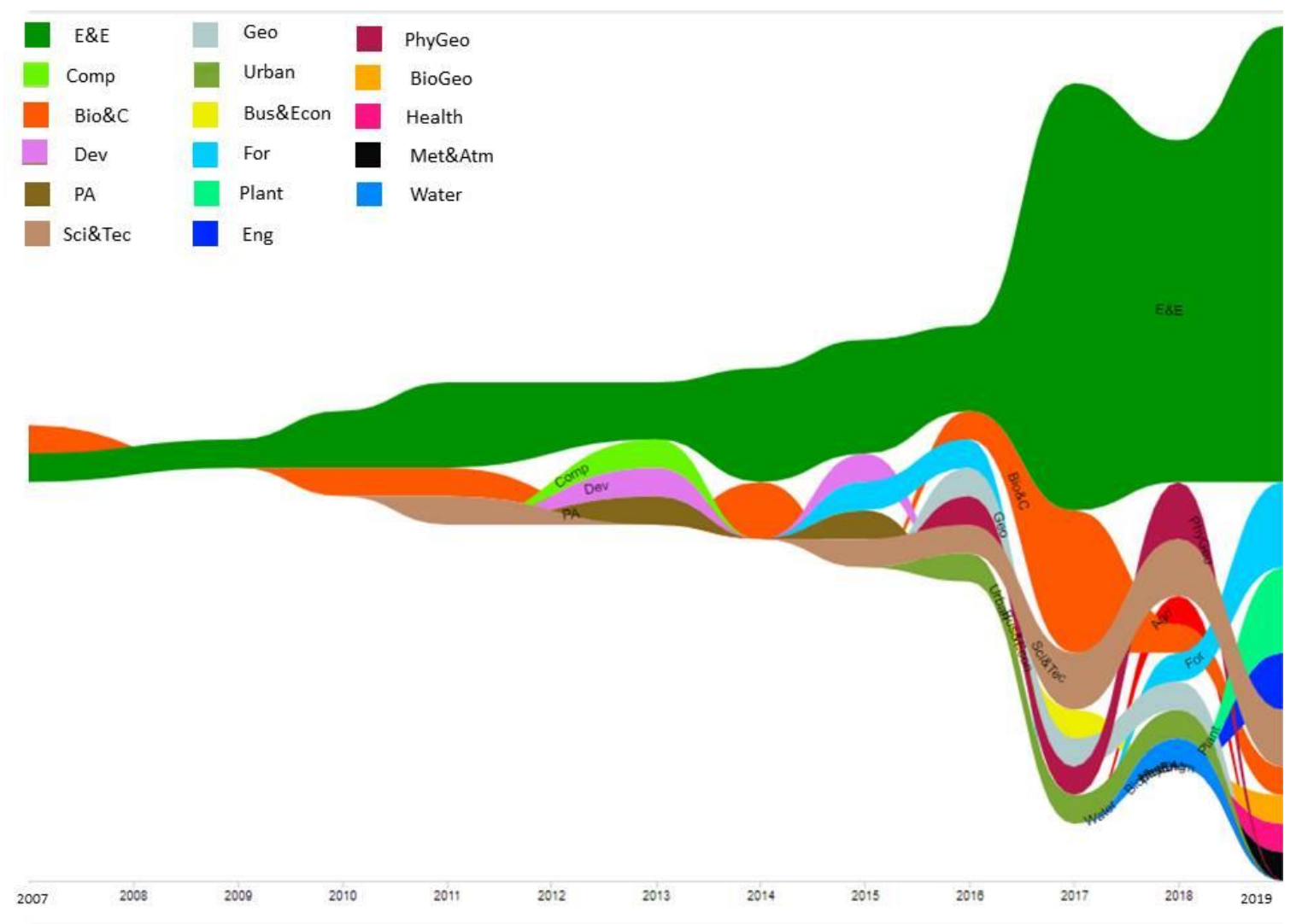

Figura 4: Evolução dos principais campos acadêmicos classificados nas publicações em cada ano (2007 a 2019). Cada faixa com cores distintas corresponde a um campo acadêmico e a largura da faixa indica o número de publicações dentro do campo acadêmico; quanto mais larga, mais publicações. O gráfico foi obtido utilizando o RAWGraphs.

Dentre as $\mathrm{AP}$, foram predominantemente consideradas as relações entre $\mathrm{SE}$ e a categoria II da IUCN (Parques Nacionais) (27), sendo que mais de uma categoria de SE pode ter sido explorada em cada um dos estudos. A categoria IV (Reserva Natural) foi objeto de investigação de 11 estudos, enquanto a categoria V (Paisagem Protegida) foi explorada em 3 estudos. Os estudos classificados como múltiplos abrangeram diferentes categorias de APs (17) e os Parques Urbanos, assim denominados nas pesquisas incluídas e que não possuem classificação reconhecimento formal internacional, mas são APs em grandes centros populacionais, que foram investigados em 11 artigos, tendo despertado maior interesse 
recentemente. A numeração das categorias em ordem crescente indica diminuição do nível de restrição da área protegida.

A análise sobre os grupos de serviços ecossistêmicos revelou que os SE culturais são o mais investigados, independentemente da categoria de proteção (Figura 5). Os Parques urbanos também são bastante investigados quanto ao fornecimento de SE de regulação, com mais $25 \%$ dos estudos tendo esse SE como foco. Os SE de Provisão são abordados de forma expressiva nas categorias mais restritivas, como a categoria II. E por fim, os SE de suporte aparecem, de forma geral, em menor proporção para todos os grupos, com exceção da categoria IV.

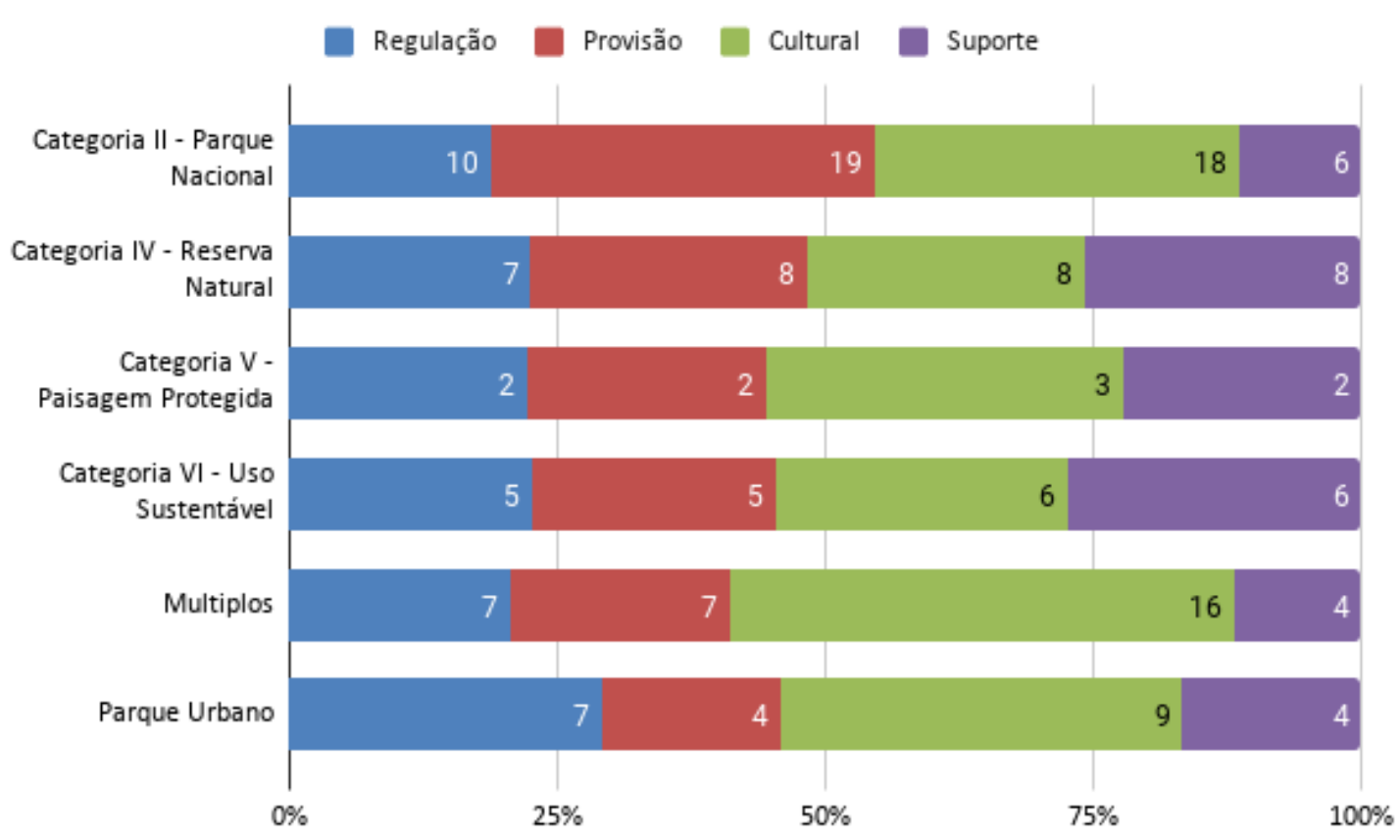

Figura 5:Categorias de serviços ecossistêmicos, com base no MEA (2005), investigados nas diferentes categorias de classificação pela IUCN

\subsection{Stakeholders}

A grande maioria dos trabalhos, $65,3 \%$, não divide a análise em categorização do público. As pesquisas com separação por grupo constataram que as preferências e usos dos SE diferem entre grupos ou até mesmo conflitam. Outro fator que se mostrou importante para as análises de grupos foi a influência da proximidade da residência da área protegida (Muller et.al. 2019; Specht et.al. 2019; Goker et.al. 2019; Ward et.al. 2019; He et.al. 2018; Acquah et.al. 2017; Eufracio-Torres et.al. 2016; Hartter et.al. 2011). Martinez-Harms e colaboradores (2018) mostraram que, no Chile, fatores como localização e renda influenciam no acesso aos SE culturais ofertados pela AP. A renda foi fator de influência (Martinez-Harms et.al. 2018) principalmente em relação aos serviços de provisão (Specht et.al. 2019), tanto na dependência desses recursos (Gross-Camp et.al. 2015) como também na aceitação, por parte da população, 
de atividades ilegais para a obtenção de SE de Provisão, quando realizadas por moradores de baixa renda, como a extração de madeira (Bragagnolo et.al. 2017).

\subsection{Diversidade de métodos}

De maneira geral, os métodos para extrair informações sobre a relação entre as pessoas e os SE fornecidos por APs são bastante comuns entre os trabalhos. O método mais comumente utilizado é o questionário de interceptação $(78,6 \%)$, que aqui inclui tanto questionários como entrevista semiestruturada e entrevista em profundidade. Os questionários são entrevistas já estruturadas que consistem na escolha de alternativas ou valores de uma escala e permitem análises quantitativas, enquanto que as entrevistas semiestruturas contêm perguntas abertas e fechadas e as entrevistas em profundidade utilizam técnicas para incentivar entrevistados a falarem livremente sobre o tema.

Em muitos casos, o questionário de interceptação foi combinado com outras informações, como, por exemplo, dados socioeconômicos e ambientais. A metodologia de observação também foi utilizada em cinco pesquisas, assim como a estratégia da utilização de grupos focais. Esta constitui em selecionar apenas alguns membros para representar os grupos sociais para uma discussão conjunta sobre o tema proposto.

Gross-Camp et.al. 2015, utilizaram uma metodologia diferente dos outros trabalhos, o diário de recursos. Tal técnica foi empregada para coletar informações acerca de serviços de provisão, onde era necessário o envolvimento participativo dos stakeholders para o preenchimento das informações sobre coleta de recursos. E, mais recentemente, têm sido empregados questionários online e Big data Fotos extraídas de redes sociais. Tais técnicas buscam expandir a escala de estudo, visto que os outros métodos são custosos e envolvem grande aporte de recursos. Os estudos com dados de Big data Fotos de redes sociais utilizam informações de geolocalização das etiquetas fotográficas das redes de compartilhamento, tanto para verificar os locais de maior visitação dentro das APs como para avaliar o conteúdo da imagem como um proxy para a valorização dos recursos naturais.

\subsection{Componentes da entrega de serviços ecossistêmicos investigados}

Naturalmente, os componentes de pesquisa para o processo da entrega de serviços ecossistêmicos que mais foram investigados nos artigos selecionados são os valores socioculturais e o fluxo de serviços ecossistêmicos providos pelas APs para a população, já que esses estão diretamente relacionados com o componente humano e social. Alguns estudos passam por mais de um componente: dos 75 artigos inclusos na pesquisa, 20 utilizaram mais de um componente $(26,6 \%)$, buscando uma análise mais integrada.

\subsection{Valores Socioculturais e suas influências}

Dentre as pesquisas que exploraram valores socioculturais atribuídos aos serviços ecossistêmicos, destacamos como os SE fornecidos por AP mais citados: a provisão de água (10), seguida por lazer e recreação (9), beleza cênica (9) e fornecimento de habitat (8). Vale ressaltar que o grupo de SE mais explorado na literatura pesquisada refere-se aos SE culturais, 
o que pode enviesar os dados aqui levantados, já que alguns dos trabalhos tiveram como objetivo explorar apenas essa categoria (Figura 4). Foram constatados 14 tipos diferentes de SE Culturais (cultural - inclui o conjunto de SE da categoria, lazer e recreação, beleza cênica, turismo, esporte, identidade, experiência, espiritual, saúde mental, saúde, patrimônio cultural, educacional, sociocultural), 13 tipos de SE de Provisão (provisão - inclui o conjunto de SE da categoria, água, coleta de plantas, lenha, alimento, plantas medicinais, biomassa, madeira, recursos para artesanato, caça, pesca, pastagem, cultivo), 6 de Regulação (regulação - inclui o conjunto de SE da categoria, qualidade do ar, clima, chuva, regulação da quantidade de água, prevenção de enchentes) e 4 de Suporte (suporte - inclui o conjunto de SE da categoria, habitat, formação de solo e fotossíntese) (Figura 6).

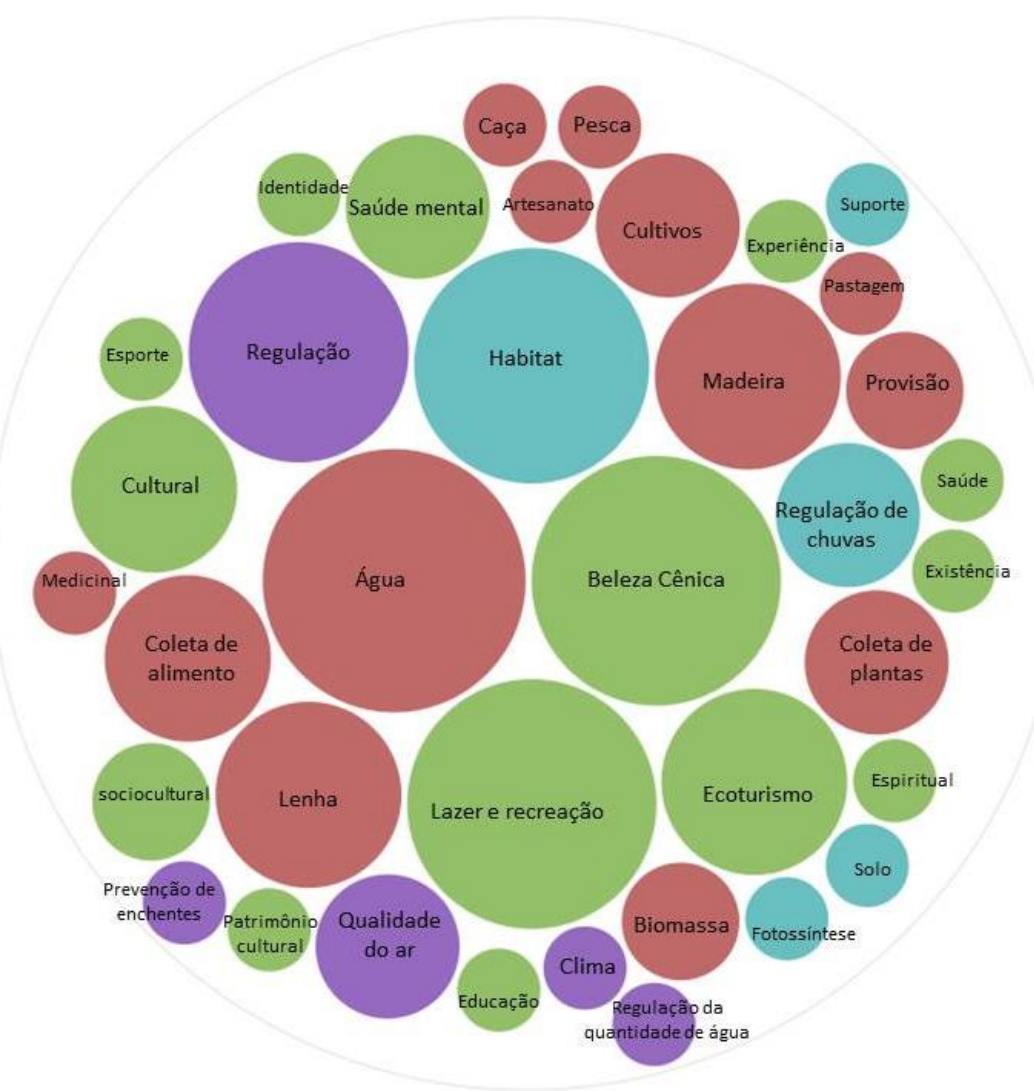

Figura 6: Serviços Ecossistêmicos levantados pelas pesquisas de valores socioculturais como os de maior importância. Em verde encontramos o grupo de serviços ecossistêmicos culturais, em roxo os serviços de regulação, em vermelho os serviços de provisão e em azul de suporte. O tamanho da circunferência é proporcional ao número de trabalhos que levantaram o SE como importante. O gráfico foi obtido utilizando o RAWGraphs.

De maneira geral, os trabalhos que investigaram influências na percepção e valor atribuído aos SE fornecidos pelas APs verificaram que fatores socioeconômicos, socioculturais, contexto geográfico e gênero são variáveis importantes que influem nas opiniões das pessoas.

Ao examinar o fluxo de serviços que eram fornecidos pelas áreas de estudo e sua oferta para a população, trabalhos relataram a influência do local de moradia no acesso aos SE, mostrando um fluxo desigual entre a população (Martinez-Harms et.al. 2018, Paul et.al. 2017). Villamagna et. al. (2017) encontraram diferença de acesso aos SE entre raças, o que Booth et. al. (2010) também já haviam observado, ao reportar que os maiores beneficiários dos SE de recreação de diferentes APs no Reino Unido são homens brancos e mais velhos. 
Entre as pesquisas que investigaram outras relações entre a população e serviços ecossistêmicos, destaca-se a dependência de muitas famílias aos serviços de provisão (Specht et.al. 2019; Walde et.al. 2019; Ward et.al. 2018; Akyol et.al. 2018; Bragagnolo et.al. 2017; FritzVietta et.al. 2016; Sharma et.al. 2015; Gross-Camp et.al. 2015; Golden et.al. 2014; Carter et.al. 2014; Kari \& Korhonen-Kurki 2013; Salum 2009). O uso de SE de provisão pode depender das condições socioeconômicas (Gross-Camp et.al. 2015), como também de questões socioculturais (Walde et.al. 2019). Assim, a criação de APs, ao restringir alguns tipo de atividades, pode trazer um impacto negativo do ponto de vista da necessidade de recursos naturais para algumas populações que dependem dos mesmos e muitas vezes possuem a sua cultura atrelada a essas atividades, como demonstrado por Akyol et.al. (2018). Latham e colaboradores (2017) constataram que o acesso aos SE de provisão podem variar de acordo com o status de proteção da AP, quanto mais restritivo, menor o acesso. Dessa forma, os pesquisadores pontuaram que, quando se tem uma paisagem com áreas com diferentes status de proteção, a busca pelos SE de provisão se concentra na área protegida com o menor status de proteção. Outro fator que pode interferir no acesso ao recurso pela população local é a mudança de gestão da AP, como Gross-Camp et.al. (2015) constataram, relatando que a privatização do Parque Nacional de Nyungwe representou uma perda substancial para a comunidade local em termos de provisão de recursos e acesso.

E, por fim, outra relação encontrada foi que diferentes grupos de stakeholders, como as comunidades locais, não locais e pesquisadores, podem diferir na sua percepção do valor de serviços ecossistêmicos (Egerer et.al. 2019; Vieira et.al. 2018; Martinez-Cruz et.al. 2017; Martin-Lopez et.al. 2011).

\section{Discussão}

\section{1 Áreas Protegidas e Parques - Sistemas socioculturais}

Dentre os grupos de SE mais investigados em todas as categorias de APs encontram-se os SE Culturais. Esse grupo está diretamente relacionado com o componente humano, além disso, a relação entre sociedade e APs se dá de forma explícita muitas vezes através desse tipo de $\mathrm{SE}$, já que as atividades dentro desses espaços protegidos possuem restrições e as APs são buscadas pela população para essa finalidade, como para atividades turísticas. Os SE de Provisão também são bastante investigados, principalmente nas categorias mais restritiva e, em menor proporção, em Parques Urbanos. Nesse grupo de SE se concentram maiores tradeoffs, ou seja, quando a provisão de um SE é reduzida como consequência do aumento do uso de outro $\mathrm{SE}$, ou quando mais de um SE específico é capturado por uma parte interessada à custa de outras (Rodriguez et. al., 2006). Os trade-offs ocorrem entre as partes interessadas, bem como entre os $\mathrm{SE}$, e podem ser entendidos de diferentes maneiras, influenciados por normas sociais e pela experiência de vida (McShane et. al., 2011). No caso de APs, os serviços de provisão normalmente concentram esses trade-offs, porque é onde há incompatibilidades entre atividades individuais (ex: coleta de madeira) e os objetivos da área - conservação da biodiversidade e atividades de recreação e educação/pesquisa. Para os SE de Regulação, os Parques Urbanos são relativamente mais explorados. Esse esforço pode estar relacionado à demanda que se tem sobre esse grupo de SE em ambientes urbanos, já que é nesses ambientes que efeitos como poluição e ilhas de calor são percebidos mais intensamente e, dessa forma, há um aumento de demanda pelos serviços ofertados. 
Os resultados em relação às preferencias de SE mostram um cenário interessante. Dentre os SE mais valorizados incluem-se, com destaque, SE compatíveis com os objetivos da criação de APs: provisão de habitat, turismo, beleza cênica e lazer/recreação. Isto é um indicativo importante para o apoio à estratégia de criação de APs para a conservação, visto que as pessoas valorizam e consideram importante o estabelecimento desses espaços para tais finalidades.

Por outro lado, cabe destacar que os SE de Provisão aparecem também de forma notória. A provisão de água é o primeiro destaque, mostrando a importância percebida da área protegida para o suprimento de um requisito básico de bem- estar. Apesar do viés de muitas das pesquisas aqui incluídas terem restringido seu escopo a apenas essa classe de $\mathrm{SE}$, o fato é que se constatou que, em muitas APs, a população possui demandas de SE de provisão que, muitas vezes supridas de modo ilegal. Essas atividades podem ser fonte de trade-off entre SE (como caça e fornecimento de habitat) e também entre os SE de provisão e os objetivos da conservação. Bragagnolo et. al. (2017) concluíram que não somente as atividades ilegais relacionadas ao fornecimento de SE de Provisão (caça, extração de madeira) ocorriam, como também eram aceitas pela população quando os beneficiários eram moradores de baixa renda. No entanto, constatou-se que essa aceitação estava relacionada com o conhecimento sobre o regulamento da área protegida, ou seja, quando se tinha clareza sobre os objetivos da área protegida e as atividades permitidas, a aceitação das atividades ilegais relacionadas com os SE de provisão diminuía. Com isso, trazemos nossa primeira recomendação: o regulamento, finalidade e objetivos da AP precisam ser claramente explicitados e comunicados à população, assim como sua delimitação geográfica, promovendo maior conscientização.

Ainda com relação aos SE de Provisão, Chen et.al. (2017) demonstraram que oferecer alternativa de fonte de energia diminui a dependência de lenha retirada da área protegida, assim como Salum (2009) mostrou que o envolvimento da comunidade local com o turismo diminuiu a demanda por SE de provisão provenientes do Parque Nacional da Baía Jozani, na Tanzânia. Nossa segunda recomendação é oferecer alternativas de fontes de renda para diminuir a demanda da população local em relação aos serviços de provisão.

Essas relações descritas nos trazem reflexões sobre a importância da incorporação de uma abordagem socioecológica na gestão de APs, que reconheça a complexidade das interações, permitindo uma gestão mais integrada. Tratar as APs como isoladas e desconexas do contexto humano pode diminuir sua efetividade, visto que o impacto social que algumas populações locais experimentam devido ao estabelecimento de APs reduz seu apoio a elas (Palomo et.al. 2014).

Uma das principais recomendações do MEA (2005) para APs é desenvolver, através de meios legais, políticos e outros meios eficazes, um apoio social mais forte com base nos benefícios e valores dos serviços que as APs fornecem. Por isso, destaca-se a importância de se aumentar os esforços de pesquisa nessa temática. As pesquisas mostraram que as relações existentes entre os stakeholders e os SE é fortemente dependente do contexto local, sendo fundamental o esforço em escala local. Nossa terceira recomendação é promover o envolvimento das partes interessadas em processos participativos reais, para possibilitar a identificação de trade-offs e atividades incompatíveis, além da identificação das demanda da 
população local, buscando soluções win-win entre conservação da biodiversidade e bem-estar humano. A abordagem de SE indica ser uma promissora linguagem comum para auxiliar nesse caminho.

\subsection{0 caminho até aqui}

A pesquisa resultou em uma seleção interessante e em caminhos para se obter avanços nessa área, no entanto, é importante ressaltar que esta revisão sistemática possui algumas limitações que podem ser exploradas em estudos futuros: i) seleção de palavras-chave: o termo "serviços ecossistêmicos" ganhou amplo apoio principalmente após o MEA (2005), sendo que, anteriormente, outros termos possam ter sido utilizados. Além disso, a relação humana com os SE pode ser explorada por inúmeros outros termos, como "beneficiários", "demanda"; ii) não inclusão de grey literature: essa decisão foi consciente, para permitir a reprodutibilidade e garantir a qualidade dos estudos inclusos.

A quantidade de pesquisas encontradas e a distribuição ao redor do mundo é um cenário que confirma o que outros autores já haviam relatado: a falta de estudos dentro da temática de SE que envolvam explicitamente o componente humano (ex.: Menzel et.al. 2010; Anton et.al. 2010; Vihervaara et.al. 2010; Martín-López et. al. 2012; Asah et. al. 2014). O gap de investigações sobre o que é importante para as pessoas nas avaliações de SE pode prejudicar a relevância social e política do conceito e, portanto, sua aplicabilidade no direcionamento de mudança social (Anton et. al., 2010 ; Menzel e Teng, 2010). Além disso, a pesquisa nesse contexto pode revelar os trade-offs existentes, abrindo possibilidade de gerenciar melhor os recursos naturais e conflitos ao redor de APs. Assim, a abordagem de SE revela-se como um importante aliado na conservação da biodiversidade.

Os artigos pesquisados seguem diferentes classificações acerca do conceito de serviços ecossistêmicos ou não explicitam qual foi utilizada. Tal fator merece destaque, visto que a falta de padronização nos estudos reflete um dos pontos de dificuldade que tomadores de decisão encontram para transpor os estudos em políticas públicas. Em 2002, DeGroot e colaboradores já apontava para a falta de coesão entre as publicações dentro do tema de bens e serviços ecossistêmicos, mas, apesar de grandes avanços terem sido feitos nesse sentido, ainda falta uma maior integração no uso da tipologia.

As metodologias utilizadas nos trabalhos analisados seguem, em sua maioria, o que Scholte et.al. (2015) havia levantado em sua revisão sobre métodos utilizados para a integração de perspectivas socioculturais na avaliação de serviços ecossistêmicos. A novidade aqui ocorre nos trabalhos mais recentes que utilizam BigData Fotos extraídos de redes sociais. O volume e a distribuição espacial de fotografias com etiquetas geográficas carregadas nas plataformas globais de mídia social online, como Instagram ou Flickr, podem fornecer uma fonte fértil de dados para novas metodologias de mapeamento ( Cao e O'Halloran, 2014 ; Hollenstein e Purves, 2010; Li et al., 2013 ; Sun et al., 2013 ). Os dados de informações geográficas e o conteúdo de fotografias são usados como proxy para preferencias observadas, principalmente para SE culturais. Tal método permite que uma grande quantidade de informações seja extraída, permitindo também que a escala do estudo seja maior e menos custosa. No entanto, deve-se ressaltar que existem limitações: o proxy enviesa para que apenas atividades legais possam ser explorada, já que dificilmente uma atividade ilegal será 
exposta nas redes sociais. Outro ponto de grande relevância é que o público se restringe apenas às pessoas que possuem acesso às redes sociais. No entanto, as populações mais pobres, que mais dependem do fornecimento de SE, não possuem acesso.

\subsection{Caminho para o futuro}

O futuro parece próspero para essa temática, tendo um expressivo aumento na temática para pesquisas e os caminhos sendo trilhados buscam abranger mais disciplinas. É necessário ainda um esforço para uma maior padronização acerca dos modelos conceituais em serviços ecossistêmicos que serão utilizados nas investigações.

A ponte entre o levantamento de dados e a aplicação desses conhecimentos em busca de uma melhor gestão das APs e de seus serviços ecossistêmicos ainda está em seus primeiros passos. Será necessário um esforço ainda maior para avaliar o sucesso das ações que incorporam essa abordagem na gestão e políticas públicas. $O$ uso da temática de serviços ecossistêmicos na conservação é mais uma ferramenta disponível na busca da efetividade dos objetivos, visto que certamente irá haver o enfrentamento de decisões nas quais os cenários não serão de win-win entre biodiversidade e bem-estar humano (Palomo et.al. 2014).

\section{Conclusões}

Existem desafios significativos na pesquisa que investiga a relação entre pessoas e serviços ecossistêmicos prestados por áreas protegidas e parques no mundo. Esta revisão sistemática da literatura demonstra que esse campo de pesquisa é recente e está em expansão e buscando cada vez mais a transdisciplinaridade, além de novas metodologias que vêm surgindo para contribuir nas avaliações.

No geral, vimos que características socioculturais e econômicas, além do contexto geográfico, parecem ser importantes fatores relacionados à preferência das pessoas pelos serviços ecossistêmicos. SE compatíveis com os objetivos das áreas naturais estão entre os mais valorizados, mostrando que a população valoriza e entende a importância da criação desses espaços, enfatizando a importância dessa estratégia de conservação. Mas ainda é notável a presença da dependência de comunidades em relação a muitos tipos de serviços ecossistêmicos de provisão, destacando ainda um desafio a ser enfrentado.

A abordagem socioecológica na gestão de áreas protegidas, utilizando a temática de serviços ecossistêmicos se mostra um caminho fértil para melhorar a efetividade e apoio social.

\section{Agradecimentos}

Agradeço o apoio dos pesquisadores Dr. Alexandre Toshiro Igari e Dr. Leandro Tambosi pelas contribuições para o projeto.

\section{Fontes de Financiamento}

Este trabalho foi financiado pelo Conselho Nacional de Desenvolvimento Científico e Tecnológico (CNPq) [168722/2018-6]; Instituto de Pesquisas Tecnológicas (IPT) - Programa Novos Talentos Edital 01/2018; e Coordenação de Aperfeiçoamento de Pessoal de Nível Superior - Brasil (CAPES) - [88887.506471/2020-00]. 


\section{Referências}

Acquah, E., Rollins, R., Dearden, P., \& Murray, G. (2017). Concerns and benefits of parkadjacent communities in Northern Ghana: the case of Mole National Park. International Journal of Sustainable Development \& World Ecology, 24(4), 316-327.

Akyol, A., Türkoğlu, T., Bekiroğlu, S., \& Tolunay, A. (2018). Resident perceptions of livelihood impacts arising from the Kızıldağ National Park, Turkey. Environment, Development and Sustainability, 20(3), 1037-1052.

Anton, C., Young, J., Harrison, P. A., Musche, M., Bela, G., Feld, C. K., ... \& Skourtos, M. (2010). Research needs for incorporating the ecosystem service approach into EU biodiversity conservation policy. Biodiversity and Conservation, 19(10), 2979-2994.

Asah, S. T., Guerry, A. D., Blahna, D. J., \& Lawler, J. J. (2014). Perception, acquisition and use of ecosystem services: human behavior, and ecosystem management and policy implications. Ecosystem Services, 10, 180-186.

Balmford, A., Bruner, A., Cooper, P., Costanza, R., Farber, S., Green, R. E., ... \& Munro, K. (2002). Economic reasons for conserving wild nature. Science, 297(5583), 950-953.

Booth, J. E., Gaston, K. J., \& Armsworth, P. R. (2010). Who benefits from recreational use of protected areas?. Ecology and Society, 15(3).

Bragagnolo, C., Correia, R., Malhado, A. C., De Marins, M., \& Ladle, R. J. (2017). Understanding non-compliance: Local people's perceptions of natural resource exploitation inside two national parks in northeast Brazil. Journal for Nature Conservation, 40, 64-76.

Cao, Y., \& O'Halloran, K. (2015). Learning human photo shooting patterns from large-scale community photo collections. Multimedia Tools and Applications, 74(24), 11499-11516.

Carter, N. H., Viña, A., Hull, V., McConnell, W. J., Axinn, W., Ghimire, D., \& Liu, J. (2014). Coupled human and natural systems approach to wildlife research and conservation. Ecology and Society, 19(3).

Chan, K. M., Satterfield, T., \& Goldstein, J. (2012). Rethinking ecosystem services to better address and navigate cultural values. Ecological Economics, 74, 8-18.

Chan, K. M., Shaw, M. R., Cameron, D. R., Underwood, E. C., \& Daily, G. C. (2006). Conservation Planning for Ecosystem Services. PLoS Biol, 4(11), e379.

Clemente, P., Calvache, M., Antunes, P., Santos, R., Cerdeira, J. O., \& Martins, M. J. (2019). Combining social media photographs and species distribution models to map cultural ecosystem services: The case of a Natural Park in Portugal. Ecological Indicators, 96, 59-68.

Costanza, R., d'Arge, R., De Groot, R., Farber, S., Grasso, M., Hannon, B., ... \& Raskin, R. G. (1997). The value of the world's ecosystem services and natural capital. Nature, 387(6630), 253-260. 
Daily, G. C., Polasky, S., Goldstein, J., Kareiva, P. M., Mooney, H. A., Pejchar, L., ... \& Shallenberger, R. (2009). Ecosystem services in decision making: time to deliver. Frontiers in Ecology and the Environment, 7(1), 21-28.

De Groot, R. S., Wilson, M. A., \& Boumans, R. M. (2002). A typology for the classification, description and valuation of ecosystem functions, goods and services. Ecological Economics, 41(3), 393-408.

Dudley, N., Higgins-Zogib, L. H., Hockings, M., MacKinnon, K., Sandwith, T., \& Stolton, S. (2011). National parks with benefits: how protecting the planet's biodiversity also provides ecosystem services. Solutions, 2(6), 87-95.

Egerer, M., Ordóñez, C., Lin, B. B., \& Kendal, D. (2019). Multicultural gardeners and park users benefit from and attach diverse values to urban nature spaces. Urban Forestry \& Urban Greening, 46, 126445.

Egoh, B., Reyers, B., Rouget, M., Richardson, D. M., Le Maitre, D. C., \& van Jaarsveld, A. S. (2008). Mapping ecosystem services for planning and management. Agriculture, Ecosystems \& Environment, 127(1-2), 135-140.

Eufracio-Torres, A. E., Wehncke, E. V., Lopez-Medellin, X., \& Maldonado-Almanza, B. (2016). Fifty years of environmental changes of the Amacuzac riparian ecosystem: a social perceptions and historical ecology approach. Ethnobiology and Conservation, 5.

Fritz-Vietta, N. V. (2016). What can forest values tell us about human well-being? Insights from two biosphere reserves in Madagascar. Landscape and Urban Planning, 147, 28-37.

García-Nieto, A. P., García-Llorente, M., Iniesta-Arandia, I., \& Martín-López, B. (2013). Mapping forest ecosystem services: from providing units to beneficiaries. Ecosystem Services, 4, 126138.

Göker, P., Hergül, C. E. N. G. I. Z., \& Öc-kahveci, H. (2019). A research on the function and usability of historical urban parks: case study of Shah Goli Park, Tabriz, Iran. Applied Ecology and Environmental Research, 17(2), 3147-3163.

Golden, C. D., Bonds, M. H., Brashares, J. S., Rodolph Rasolofoniaina, B. J., \& Kremen, C. (2014). Economic valuation of subsistence harvest of wildlife in Madagascar. Conservation Biology, 28(1), 234-243.

Gross-Camp, N. D., Martin, A., McGuire, S., \& Kebede, B. (2015). The privatization of the Nyungwe National Park Buffer Zone and implications for adjacent communities. Society \& Natural Resources, 28(3), 296-311.

Hartter, J., Solomon, J., Ryan, S. J., Jacobson, S. K., \& Goldman, A. B. E. (2014). Contrasting perceptions of ecosystem services of an African forest park. Environmental Conservation, 41(4), 330-340. 
He, S., Gallagher, L., Su, Y., Wang, L., \& Cheng, H. (2018). Identification and assessment of ecosystem services for protected area planning: A case in rural communities of Wuyishan national park pilot. Ecosystem Services, 31, 169-180.

Hollenstein, L., \& Purves, R. (2010). Exploring place through user-generated content: Using Flickr tags to describe city cores. Journal of Spatial Information Science, 2010(1), 21-48.

IUCN, (2008). Dudley, N. (Ed.). Guidelines for applying protected area management categories. Jones-Walters, L., \& Čivić, K. (2013). European protected areas: Past, present and future. Journal for Nature Conservation, 21(2), 122-124.

Kari, S., \& Korhonen-Kurki, K. (2013). Framing local outcomes of biodiversity conservation through ecosystem services: a case study from Ranomafana, Madagascar. Ecosystem Services, 3, e32-e39.

Latham, J. E., Sallu, S. M., Loveridge, R., \& Marshall, A. R. (2017). Examining the impact of forest protection status on firewood sufficiency in rural Africa. Environmental Conservation, 44(3), 221-233.

Li, L., Goodchild, M. F., \& Xu, B. (2013). Spatial, temporal, and socioeconomic patterns in the use of Twitter and Flickr. Cartography and Geographic Information Science, 40(2), 61-77.

Lyons, K. G., Brigham, C. A., Traut, B. H., \& Schwartz, M. W. (2005). Rare species and ecosystem functioning. Conservation Biology, 19(4), 1019-1024.

Martinez-Cruz, A. L., \& Sainz-Santamaria, J. (2015). Recreational value of two peri-urban forests in Mexico City. El Trimestre Economico, 117, 1-26.

Martinez-Harms, M. J., Bryan, B. A., Wood, S. A., Fisher, D. M., Law, E., Rhodes, J. R., ... \& Wilson, K. A. (2018). Inequality in access to cultural ecosystem services from protected areas in the Chilean biodiversity hotspot. Science of the Total Environment, 636, 1128-1138.

Martín-López, B., García-Llorente, M., Palomo, I., \& Montes, C. (2011). The conservation against development paradigm in protected areas: Valuation of ecosystem services in the Doñana social-ecological system (southwestern Spain). Ecological Economics, 70(8), 14811491.

Martín-López, B., Iniesta-Arandia, I., García-Llorente, M., Palomo, I., Casado-Arzuaga, I., Del Amo, D. G., ... \& González, J. A. (2012). Uncovering ecosystem service bundles through social preferences. PLoS One, 7(6).

Mauri, M., Elli, T., Caviglia, G., Uboldi, G., \& Azzi, M. (2017, September). RAWGraphs: a visualisation platform to create open outputs. In Proceedings of the 12th biannual conference on Italian SIGCHI chapter (pp. 1-5).

McShane, T. O., Hirsch, P. D., Trung, T. C., Songorwa, A. N., Kinzig, A., Monteferri, B., ... \& Welch-Devine, M. (2011). Hard choices: making trade-offs between biodiversity conservation and human well-being. Biological Conservation, 144(3), 966-972. 
MEA (Millennium Ecosystem Assessment), (2003). Ecosystems and human well-being: a framework for assessment, Island Press, Washington DC.

MEA (Millennium Ecosystem Assessment), (2005). Ecosystems and human well-being (Vol. 5). Washington, DC:: Island press.

Menzel, S., \& Teng, J. (2010). Ecosystem services as a stakeholder-driven concept for conservation science. Conservation Biology, 24(3), 907-909.

Müller, S. M., Peisker, J., Bieling, C., Linnemann, K., Reidl, K., \& Schmieder, K. (2019). The importance of cultural ecosystem services and biodiversity for landscape visitors in the biosphere reserve Swabian Alb (Germany). Sustainability, 11(9), 2650.

Palomo, I., Martín-López, B., Potschin, M., Haines-Young, R., \& Montes, C. (2013). National Parks, buffer zones and surrounding lands: Mapping ecosystem service flows. Ecosystem Services, 4, 104-116.

Palomo, I., Montes, C., Martin-Lopez, B., González, J. A., Garcia-Llorente, M., Alcorlo, P., \& Mora, M. R. G. (2014). Incorporating the social-ecological approach in protected areas in the Anthropocene. BioScience, 64(3), 181-191.

Paul, S., \& Nagendra, H. (2017). Factors influencing perceptions and use of urban nature: Surveys of park visitors in Delhi. Land, 6(2), 27.

Rodríguez, J. P., Beard Jr, T. D., Bennett, E. M., Cumming, G. S., Cork, S. J., Agard, J., ... \& Peterson, G. D. (2006). Trade-offs across space, time, and ecosystem services. Ecology and Society, 11(1).

Salum, L. A. (2009). Ecotourism and biodiversity conservation in Jozani-Chwaka Bay National Park, Zanzibar. African Journal of Ecology, 47, 166-170.

Scholte, S. S., Van Teeffelen, A. J., \& Verburg, P. H. (2015). Integrating socio-cultural perspectives into ecosystem service valuation: a review of concepts and methods. Ecological Economics, 114, 67-78.

Seppelt, R., Dormann, C. F., Eppink, F. V., Lautenbach, S., \& Schmidt, S. (2011). A quantitative review of ecosystem service studies: approaches, shortcomings and the road ahead. Journal of Applied Ecology, 48(3), 630-636.

Sharma, B., Rasul, G., \& Chettri, N. (2015). The economic value of wetland ecosystem services: evidence from the Koshi Tappu Wildlife Reserve, Nepal. Ecosystem Services, 12, 84-93.

Specht, M. J., Santos, B. A., Marshall, N., Melo, F. P. L., Leal, I. R., Tabarelli, M., \& Baldauf, C. (2019). Socioeconomic differences among resident, users and neighbour populations of a protected area in the Brazilian dry forest. Journal of Environmental Management, 232, 607614.

Sun, Y., Fan, H., Helbich, M., \& Zipf, A. (2013). Analyzing human activities through volunteered geographic information: Using Flickr to analyze spatial and temporal pattern of tourist 
accommodation. In Progress in location-based services (pp. 57-69). Springer, Berlin, Heidelberg.

Van Oudenhoven, A. P., Petz, K., Alkemade, R., Hein, L., \& de Groot, R. S. (2012). Framework for systematic indicator selection to assess effects of land management on ecosystem services. Ecological Indicators, 21, 110-122.

Vieira, F. A., Bragagnolo, C., Correia, R. A., Malhado, A. C., \& Ladle, R. J. (2018). A salience index for integrating multiple user perspectives in cultural ecosystem service assessments. Ecosystem Services, 32, 182-192.

Vihervaara, P., Rönkä, M., \& Walls, M. (2010). Trends in ecosystem service research: early steps and current drivers. Ambio, 39(4), 314-324.

Villamagna, A. M., Angermeier, P. L., \& Bennett, E. M. (2013). Capacity, pressure, demand, and flow: a conceptual framework for analyzing ecosystem service provision and delivery. Ecological Complexity, 15, 114-121.

Walde, J., Huy, D., Tappeiner, U., \& Tappeiner, G. (2019). A protected area between subsistence and development. International Journal of the Commons, 13(1).

Ward, C., Stringer, L. C., \& Holmes, G. (2018). Protected area co-management and perceived livelihood impacts. Journal of Environmental Management, 228, 1-12. 


\begin{tabular}{|c|c|c|c|}
\hline AUTOR & TITULO & REVISTA & ANO \\
\hline Jiang, YQ; Huang, GL; Fisher, B & $\begin{array}{l}\text { Air quality, human behavior and urban park visit: A case study in } \\
\text { Beijing }\end{array}$ & $\begin{array}{l}\text { JOURNAL OF CLEANER } \\
\text { PRODUCTION }\end{array}$ & 2019 \\
\hline $\begin{array}{l}\text { Egerer, M; Ordonez, C; Lin, BB; } \\
\text { Kendal, D }\end{array}$ & $\begin{array}{l}\text { Multicultural gardeners and park users benefit from and attach } \\
\text { diverse values to urban nature spaces }\end{array}$ & $\begin{array}{l}\text { URBAN FORESTRY \& URBAN } \\
\text { GREENING }\end{array}$ & 2019 \\
\hline $\begin{array}{l}\text { Yang, FP; Ignatieva, M; Larsson, } \\
\text { A; Zhang, SX; Ni, N }\end{array}$ & $\begin{array}{l}\text { Public perceptions and preferences regarding lawns and their } \\
\text { alternatives in China: A case study of Xi'an }\end{array}$ & $\begin{array}{l}\text { URBAN FORESTRY \& URBAN } \\
\text { GREENING }\end{array}$ & 2019 \\
\hline $\begin{array}{l}\text { Rossi, SD; Barros, A; Walden- } \\
\text { Schreiner, C; Pickering, C }\end{array}$ & $\begin{array}{l}\text { Using social media images to assess ecosystem services in a remote } \\
\text { protected area in the Argentinean Andes }\end{array}$ & AMBIO & \\
\hline $\begin{array}{l}\text { Collins, CMT; Cook-Monie, I; } \\
\text { Raum, S }\end{array}$ & $\begin{array}{l}\text { What do people know? Ecosystem services, public perception and } \\
\text { sustainable management of urban park trees in London, U.K }\end{array}$ & $\begin{array}{l}\text { URBAN FORESTRY \& URBAN } \\
\text { GREENING }\end{array}$ & 2019 \\
\hline Heng, SL; Chow, WTL & $\begin{array}{l}\text { How "hot' is too hot? Evaluating acceptable outdoor thermal } \\
\text { comfort ranges in an equatorial urban park }\end{array}$ & $\begin{array}{l}\text { INTERNATIONAL JOURNAL OF } \\
\text { BIOMETEOROLOGY }\end{array}$ & 2019 \\
\hline $\begin{array}{l}\text { Muller, SM; Peisker, J; Bieling, C; } \\
\text { Linnemann, K; Reidl, K; } \\
\text { Schmieder, K }\end{array}$ & $\begin{array}{l}\text { The Importance of Cultural Ecosystem Services and Biodiversity for } \\
\text { Landscape Visitors in the Biosphere Reserve Swabian Alb (Germany) }\end{array}$ & SUSTAINABILITY & 2019 \\
\hline $\begin{array}{l}\text { Taff, BD; Benfield, J; Miller, ZD; } \\
\text { D'Antonio, A; Schwartz, F }\end{array}$ & The Role of Tourism Impacts on Cultural Ecosystem Services & ENVIRONMENTS & 2019 \\
\hline $\begin{array}{l}\text { Jiricka-Purrer, A; Tadini, V; Salak, } \\
\text { B; Taczanowska, K; Tucki, A; } \\
\text { Senes, G }\end{array}$ & $\begin{array}{l}\text { Do Protected Areas Contribute to Health and Well-Being? A Cross- } \\
\text { Cultural Comparison }\end{array}$ & $\begin{array}{l}\text { INTERNATIONAL JOURNAL OF } \\
\text { ENVIRONMENTAL RESEARCH } \\
\text { AND PUBLIC HEALTH } \\
\end{array}$ & 2019 \\
\hline $\begin{array}{l}\text { Specht, MJ; Santos, BA; Marshall, } \\
\text { N; Melo, FPL; Leal, IR; Tabarelli, } \\
\text { M; Baldauf, C }\end{array}$ & $\begin{array}{l}\text { Socioeconomic differences among resident, users and neighbour } \\
\text { populations of a protected area in the Brazilian dry forest }\end{array}$ & $\begin{array}{l}\text { JOURNAL OF ENVIRONMENTAL } \\
\text { MANAGEMENT }\end{array}$ & 2019 \\
\hline $\begin{array}{l}\text { Rocchi, L; Cortina, C; Paolotti, L; } \\
\text { Massei, G; Fagioli, FF; } \\
\text { Antegiovanni, P; Boggia, A }\end{array}$ & $\begin{array}{l}\text { Provision of ecosystem services from the management of Natura } \\
2000 \text { sites in Umbria (Italy): Comparing the costs and benefits, using } \\
\text { choice experiment }\end{array}$ & LAND USE POLICY & 2019 \\
\hline $\begin{array}{l}\text { Mancini, F; Coghill, GM; Lusseau, } \\
\text { D }\end{array}$ & $\begin{array}{l}\text { Quantifying wildlife watchers' preferences to investigate the } \\
\text { overlap between recreational and conservation value of natural } \\
\text { areas }\end{array}$ & JOURNAL OF APPLIED ECOLOGY & 2019 \\
\hline $\begin{array}{l}\text { Zhou, CW; Yan, LB; Yu, LF; Wei, } \\
\text { HX; Guan, HM; Shang, CF; Chen, } \\
\text { FY; Bao, JZ }\end{array}$ & $\begin{array}{l}\text { Effect of Short-term Forest Bathing in Urban Parks on Perceived } \\
\text { Anxiety of Young-adults: A Pilot Study in Guiyang, Southwest China }\end{array}$ & $\begin{array}{l}\text { CHINESE GEOGRAPHICAL } \\
\text { SCIENCE }\end{array}$ & 2019 \\
\hline $\begin{array}{l}\text { Bogdan, SM; Stupariu, I; Andra- } \\
\text { Toparceanu, A; Nastase, II }\end{array}$ & $\begin{array}{l}\text { MAPPING SOCIAL VALUES FOR CULTURAL ECOSYSTEM SERVICES IN } \\
\text { A MOUNTAIN LANDSCAPE IN THE ROMANIAN CARPATHIANS }\end{array}$ & $\begin{array}{l}\text { CARPATHIAN JOURNAL OF } \\
\text { EARTH AND ENVIRONMENTAL } \\
\text { SCIENCES }\end{array}$ & 2019 \\
\hline $\begin{array}{l}\text { Walde, JF; Huy, DT; Tappeiner, U; } \\
\text { Tappeiner, G }\end{array}$ & A protected area between subsistence and development & $\begin{array}{l}\text { INTERNATIONAL JOURNAL OF } \\
\text { THE COMMONS }\end{array}$ & 2019 \\
\hline Goker, P; Hergul, OCC; Kahveci, H & $\begin{array}{l}\text { A RESEARCH ON THE FUNCTION AND USABILITY OF HISTORICAL } \\
\text { URBAN PARKS: CASE STUDY OF SHAH GOLI PARK, TABRIZ, IRAN }\end{array}$ & $\begin{array}{l}\text { APPLIED ECOLOGY AND } \\
\text { ENVIRONMENTAL RESEARCH }\end{array}$ & 2019 \\
\hline
\end{tabular}




\begin{tabular}{|c|c|c|c|}
\hline Ward, C; Stringer, LC; Holmes, G & Protected area co-management and perceived livelihood impacts & $\begin{array}{l}\text { JOURNAL OF ENVIRONMENTAL } \\
\text { MANAGEMENT }\end{array}$ & 2018 \\
\hline $\begin{array}{l}\text { Gao, H; Xiao, Y; Van Koppen, CSA; } \\
\text { Ouyang, ZY }\end{array}$ & $\begin{array}{l}\text { Local perceptions of ecosystem services and protection of culturally } \\
\text { protected forests in southeast China }\end{array}$ & $\begin{array}{l}\text { ECOSYSTEM HEALTH AND } \\
\text { SUSTAINABILITY }\end{array}$ & 2018 \\
\hline $\begin{array}{l}\text { de Santana, AC; de Santana, AL; } \\
\text { de Oliveira, GMTD; de Santana, } \\
\text { AL; Quaresma, JL }\end{array}$ & $\begin{array}{l}\text { The importance of ecosystem services for economic development } \\
\text { and social welfare in the population's perception: the case of the } \\
\text { Carajas National Forest }\end{array}$ & NATIVA & 2018 \\
\hline $\begin{array}{l}\text { Martinez-Harms, MJ; Bryan, BA; } \\
\text { Wood, SA; Fisher, DM; Law, E; } \\
\text { Rhodes, JR; Dobbs, C; Biggs, D; } \\
\text { Wilson, KA }\end{array}$ & $\begin{array}{l}\text { Inequality in access to cultural ecosystem services from protected } \\
\text { areas in the Chilean biodiversity hotspot }\end{array}$ & $\begin{array}{l}\text { SCIENCE OF THE TOTAL } \\
\text { ENVIRONMENT }\end{array}$ & 2018 \\
\hline $\begin{array}{l}\text { Merriman, JC; Gurung, H; } \\
\text { Adhikari, S; Butchart, SHM; } \\
\text { Khatri, TB; Pandit, RS; Ram, AK; } \\
\text { Thomas, DHL; Thapa, I }\end{array}$ & $\begin{array}{l}\text { Rapid ecosystem service assessment of the impact of Koshi Tappu } \\
\text { Wildlife Reserve on wetland benefits to local communities }\end{array}$ & $\begin{array}{l}\text { WETLANDS ECOLOGY AND } \\
\text { MANAGEMENT }\end{array}$ & 2018 \\
\hline $\begin{array}{l}\text { Blancas, ANI; La Torre-Cuadros, } \\
\text { MD; Carrera, GAM }\end{array}$ & $\begin{array}{l}\text { Using Foresight to Gain a Local Perspective on the Future of } \\
\text { Ecosystem Services in a Mountain Protected Area in Peru }\end{array}$ & $\begin{array}{l}\text { MOUNTAIN RESEARCH AND } \\
\text { DEVELOPMENT }\end{array}$ & 2018 \\
\hline $\begin{array}{l}\text { Vieira, FAS; Bragagnolo, C; } \\
\text { Correia, RA; Malhado, ACM; } \\
\text { Ladle, RJ }\end{array}$ & $\begin{array}{l}\text { A salience index for integrating multiple user perspectives in } \\
\text { cultural ecosystem service assessments }\end{array}$ & ECOSYSTEM SERVICES & 2018 \\
\hline $\begin{array}{l}\text { Donahue, ML; Keeler, BL; Wood, } \\
\text { SA; Fisher, DM; Hamstead, ZA; } \\
\text { McPhearson, T }\end{array}$ & $\begin{array}{l}\text { Using social media to understand drivers of urban park visitation in } \\
\text { the Twin Cities, MN }\end{array}$ & $\begin{array}{l}\text { LANDSCAPE AND URBAN } \\
\text { PLANNING }\end{array}$ & 2018 \\
\hline $\begin{array}{l}\text { Garcia-Llorente, M; Harrison, PA; } \\
\text { Berry, P; Palomo, I; Gomez- } \\
\text { Baggethun, E; Iniesta-Arandia, I; } \\
\text { Montes, C; del Amo, DG; Martin- } \\
\text { Lopez, B }\end{array}$ & $\begin{array}{l}\text { What can conservation strategies learn from the ecosystem } \\
\text { services approach? Insights from ecosystem assessments in two } \\
\text { Spanish protected areas }\end{array}$ & $\begin{array}{l}\text { BIODIVERSITY AND } \\
\text { CONSERVATION }\end{array}$ & 2018 \\
\hline $\begin{array}{l}\text { Fischer, LK; Honold, J; Botzat, A; } \\
\text { Brinkmeyer, D; Cvejic, R; } \\
\text { Delshammar, T; Elands, B; Haase, } \\
\text { D; Kabisch, N; Karle, SJ; } \\
\text { Lafortezza, R; Nastran, M; } \\
\text { Nielsen, AB; van der Jagt, AP; } \\
\text { Vierikko, K; Kowarik, I }\end{array}$ & $\begin{array}{l}\text { Recreational ecosystem services in European cities: Sociocultural } \\
\text { and geographical contexts matter for park use }\end{array}$ & ECOSYSTEM SERVICES & 2018 \\
\hline $\begin{array}{l}\text { Akyol, A; Turkoglu, T; Bekiroglu, } \\
\text { S; Tolunay, A }\end{array}$ & $\begin{array}{l}\text { Resident perceptions of livelihood impacts arising from the } \\
\text { KAizAildag National Park, Turkey }\end{array}$ & $\begin{array}{l}\text { ENVIRONMENT DEVELOPMENT } \\
\text { AND SUSTAINABILITY }\end{array}$ & 2018 \\
\hline Zandi, S; Limaei, SM; Amiri, N & $\begin{array}{l}\text { An economic evaluation of a forest park using the individual travel } \\
\text { cost method (a case study of Ghaleh Rudkhan forest park in } \\
\text { northern Iran) }\end{array}$ & $\begin{array}{l}\text { ENVIRONMENTAL \& SOCIO- } \\
\text { ECONOMIC STUDIES }\end{array}$ & 2018 \\
\hline $\begin{array}{l}\text { He, SY; Gallagher, L; Su, Y; Wang, } \\
\text { L; Cheng, HG }\end{array}$ & $\begin{array}{l}\text { Identification and assessment of ecosystem services for protected } \\
\text { area planning: A case in rural communities of Wuyishan national }\end{array}$ & ECOSYSTEM SERVICES & 2018 \\
\hline
\end{tabular}




\begin{tabular}{|c|c|c|c|}
\hline & park pilot & & \\
\hline $\begin{array}{l}\text { Gungor, BS; Chen, JQ; Wu, SR; } \\
\text { Zhou, PL; Shirkey, G }\end{array}$ & $\begin{array}{l}\text { Does Plant Knowledge within Urban Forests and Parks Directly } \\
\text { Influence Visitor Pro-Environmental Behaviors }\end{array}$ & FORESTS & 2018 \\
\hline $\begin{array}{l}\text { Fazaa, NA; Dunn, JC; } \\
\text { Whittingham, MJ }\end{array}$ & $\begin{array}{l}\text { Evaluation of the Ecosystem Services of the Central Marsh in } \\
\text { Southern Iraq }\end{array}$ & BAGHDAD SCIENCE JOURNAL & 2018 \\
\hline $\begin{array}{l}\text { Cundill, G; Bezerra, JC; De Vos, A; } \\
\text { Ntingana, N }\end{array}$ & $\begin{array}{l}\text { Beyond benefit sharing: Place attachment and the importance of } \\
\text { access to protected areas for surrounding communities }\end{array}$ & ECOSYSTEM SERVICES & 2017 \\
\hline Cumming, GS; Maciejewski, K & $\begin{array}{l}\text { Reconciling community ecology and ecosystem services: Cultural } \\
\text { services and benefits from birds in South African National Parks }\end{array}$ & ECOSYSTEM SERVICES & 2017 \\
\hline $\begin{array}{l}\text { Smit, IPJ; Roux, DJ; Swemmer, LK; } \\
\text { Boshoff, N; Novellie, P }\end{array}$ & $\begin{array}{l}\text { Protected areas as outdoor classrooms and global laboratories: } \\
\text { Intellectual ecosystem services flowing to-and-from a National Park }\end{array}$ & ECOSYSTEM SERVICES & 2017 \\
\hline $\begin{array}{l}\text { Bragagnolo, C; Correia, R; } \\
\text { Malhado, ACM; De Marins, M; } \\
\text { Ladle, RJ }\end{array}$ & $\begin{array}{l}\text { Understanding non-compliance: Local people's perceptions of } \\
\text { natural resource exploitation inside two national parks in northeast } \\
\text { Brazil }\end{array}$ & $\begin{array}{l}\text { JOURNAL FOR NATURE } \\
\text { CONSERVATION }\end{array}$ & 2017 \\
\hline Chen, XD; Lupi, F; Liu, JG & $\begin{array}{l}\text { Accounting for ecosystem services in compensating for the costs of } \\
\text { effective conservation in protected areas }\end{array}$ & BIOLOGICAL CONSERVATION & 2017 \\
\hline $\begin{array}{l}\text { Martinez-Cruz, AL; Sainz- } \\
\text { Santamaria, J }\end{array}$ & Value of Two Peri-urban Recreational Sites in Mexico City & TRIMESTRE ECONOMICO & 2017 \\
\hline $\begin{array}{l}\text { Latham, JE; Sallu, SM; Loveridge, } \\
\text { R; Marshall, AR }\end{array}$ & $\begin{array}{l}\text { Examining the impact of forest protection status on firewood } \\
\text { sufficiency in rural Africa }\end{array}$ & $\begin{array}{l}\text { ENVIRONMENTAL } \\
\text { CONSERVATION }\end{array}$ & 2017 \\
\hline $\begin{array}{l}\text { Torres-Miralles, M; } \\
\text { Grammatikopoulou, I; Rescia, AJ }\end{array}$ & $\begin{array}{l}\text { Employing contingent and inferred valuation methods to evaluate } \\
\text { the conservation of olive groves and associated ecosystem services } \\
\text { in Andalusia (Spain) }\end{array}$ & ECOSYSTEM SERVICES & 2017 \\
\hline $\begin{array}{l}\text { Schmidt, K; Walz, A; Martin- } \\
\text { Lopez, B; Sachse, R }\end{array}$ & $\begin{array}{l}\text { Testing socio-cultural valuation methods of ecosystem services to } \\
\text { explain land use preferences }\end{array}$ & ECOSYSTEM SERVICES & 2017 \\
\hline $\begin{array}{l}\text { Ament, JM; Moore, CA; Herbst, } \\
\text { M; Cumming, GS }\end{array}$ & $\begin{array}{l}\text { Cultural Ecosystem Services in Protected Areas: Understanding } \\
\text { Bundles, Trade-Offs, and Synergies }\end{array}$ & CONSERVATION LETTERS & 2017 \\
\hline Paul, S; Nagendra, $\mathrm{H}$ & $\begin{array}{l}\text { Factors Influencing Perceptions and Use of Urban Nature: Surveys } \\
\text { of Park Visitors in Delhi }\end{array}$ & LAND & 2017 \\
\hline $\begin{array}{l}\text { Delgado-Aguilar, MJ; Konold, W; } \\
\text { Schmitt, CB }\end{array}$ & $\begin{array}{l}\text { Community mapping of ecosystem services in tropical rainforest of } \\
\text { Ecuador }\end{array}$ & ECOLOGICAL INDICATORS & 2017 \\
\hline Allendorf, TD; Yang, JM & $\begin{array}{l}\text { The role of gender in local residents' relationships with } \\
\text { Gaoligongshan Nature Reserve, Yunnan, China }\end{array}$ & $\begin{array}{l}\text { ENVIRONMENT DEVELOPMENT } \\
\text { AND SUSTAINABILITY }\end{array}$ & 2017 \\
\hline $\begin{array}{l}\text { Villamagna, AM; Mogollon, B; } \\
\text { Angermeier, PL }\end{array}$ & $\begin{array}{l}\text { Inequity in ecosystem service delivery: socioeconomic gaps in the } \\
\text { public-private conservation network }\end{array}$ & ECOLOGY AND SOCIETY & 2017 \\
\hline $\begin{array}{l}\text { Palliwoda, J; Kowarik, I; von der } \\
\text { Lippe, M }\end{array}$ & $\begin{array}{l}\text { Human-biodiversity interactions in urban parks: The species level } \\
\text { matters }\end{array}$ & $\begin{array}{l}\text { LANDSCAPE AND URBAN } \\
\text { PLANNING }\end{array}$ & 2017 \\
\hline $\begin{array}{l}\text { Acquah, E; Rollins, R; Dearden, P; } \\
\text { Murray, G }\end{array}$ & $\begin{array}{l}\text { Concerns and benefits of park-adjacent communities in Northern } \\
\text { Ghana: the case of Mole National Park }\end{array}$ & $\begin{array}{l}\text { INTERNATIONAL JOURNAL OF } \\
\text { SUSTAINABLE DEVELOPMENT } \\
\text { AND WORLD ECOLOGY }\end{array}$ & 2017 \\
\hline Uzun, FV; Gilbertson, KL & Tettegouche State Park Summer Visitors' Perceptions on Ecosystem & EUROPEAN JOURNAL OF & 2017 \\
\hline
\end{tabular}




\begin{tabular}{|c|c|c|c|}
\hline & Services of the Park and Management Practices They Support & SUSTAINABLE DEVELOPMENT & \\
\hline $\begin{array}{l}\text { Chaudhary, S; Chettri, N; Uddin, } \\
\text { K; Khatri, TB; Dhakal, M; } \\
\text { Bajracharya, B; Ning, W }\end{array}$ & $\begin{array}{l}\text { Implications of land cover change on ecosystems services and } \\
\text { people's dependency: A case study from the Koshi Tappu Wildlife } \\
\text { Reserve, Nepal }\end{array}$ & ECOLOGICAL COMPLEXITY & 2016 \\
\hline Jin, X; Ma, JZ; Cai, TJ; Sun, XX & $\begin{array}{l}\text { Non-use value assessment for wetland ecosystem service of } \\
\text { Hongxing National Nature Reserve in northeast China }\end{array}$ & $\begin{array}{l}\text { JOURNAL OF FORESTRY } \\
\text { RESEARCH }\end{array}$ & 2016 \\
\hline $\begin{array}{l}\text { Eufracio-Torres, AE; Wehncke, } \\
\text { EV; Lopez-Medellin, X; } \\
\text { Maldonado-Almanza, B }\end{array}$ & $\begin{array}{l}\text { Fifty years of environmental changes of the Amacuzac riparian } \\
\text { ecosystem: a social perceptions and historical ecology approach }\end{array}$ & $\begin{array}{l}\text { ETHNOBIOLOGY AND } \\
\text { CONSERVATION }\end{array}$ & 2016 \\
\hline $\begin{array}{l}\text { Briceno, J; Iniguez-Gallardo, V; } \\
\text { Ravera, F }\end{array}$ & $\begin{array}{l}\text { Factors influencing the perception of ecosystem services in } \\
\text { Ecuadorian tropical dry forests }\end{array}$ & ECOSISTEMAS & 2016 \\
\hline Fritz-Vietta, NVM & $\begin{array}{l}\text { What can forest values tell us about human well-being? Insights } \\
\text { from two biosphere reserves in Madagascar }\end{array}$ & $\begin{array}{l}\text { LANDSCAPE AND URBAN } \\
\text { PLANNING }\end{array}$ & 2016 \\
\hline $\begin{array}{l}\text { Franca, JUB; Ferreira, APNL; Ruiz, } \\
\text { MS; Quaresma, CC; Kniess, CT; } \\
\text { Ramos, HR; Ferreira, ML }\end{array}$ & $\begin{array}{l}\text { ECOLOGICAL KNOWLEDGE ABOUT CONSERVATION UNITS IN THE } \\
\text { EAST ZONE OF SAO PAULO, SP: IMPLICATIONS FOR SUSTAINABILITY } \\
\text { IN URBAN AREA }\end{array}$ & HOLOS & 2016 \\
\hline $\begin{array}{l}\text { Yang, H; Harrison, R; Yi, ZF; } \\
\text { Goodale, E; Zhao, MX; Xu, JC }\end{array}$ & $\begin{array}{l}\text { Changing Perceptions of Forest Value and Attitudes toward } \\
\text { Management of a Recently Established Nature Reserve: A Case } \\
\text { Study in Southwest China }\end{array}$ & FORESTS & 2015 \\
\hline $\begin{array}{l}\text { Willemen, L; Cottam, AJ; Drakou, } \\
\text { EG; Burgess, ND }\end{array}$ & $\begin{array}{l}\text { Using Social Media to Measure the Contribution of Red List Species } \\
\text { to the Nature-Based Tourism Potential of African Protected Areas }\end{array}$ & PLOS ONE & 2015 \\
\hline $\begin{array}{l}\text { Amin, A; Zaehringer, JG; } \\
\text { Schwilch, G; Kone, I }\end{array}$ & $\begin{array}{l}\text { People, protected areas and ecosystem services: a qualitative and } \\
\text { quantitative analysis of local people's perception and preferences } \\
\text { in Cote d'Ivoire }\end{array}$ & NATURAL RESOURCES FORUM & 2015 \\
\hline Sharma, B; Rasul, G; Chettri, N & $\begin{array}{l}\text { The economic value of wetland ecosystem services: Evidence from } \\
\text { the Koshi Tappu Wildlife Reserve, Nepal }\end{array}$ & ECOSYSTEM SERVICES & 2015 \\
\hline Bertram, C; Rehdanz, K & $\begin{array}{l}\text { Preferences for cultural urban ecosystem services: Comparing } \\
\text { attitudes, perception, and use }\end{array}$ & ECOSYSTEM SERVICES & 2015 \\
\hline $\begin{array}{l}\text { Gross-Camp, ND; Martin, A; } \\
\text { McGuire, S; Kebede, B }\end{array}$ & $\begin{array}{l}\text { The Privatization of the Nyungwe National Park Buffer Zone and } \\
\text { Implications for Adjacent Communities }\end{array}$ & SOCIETY \& NATURAL RESOURCES & 2015 \\
\hline $\begin{array}{l}\text { Hartter, J; Solomon, J; Ryan, SJ; } \\
\text { Jacobson, SK; Goldman, A }\end{array}$ & $\begin{array}{l}\text { Contrasting perceptions of ecosystem services of an African forest } \\
\text { park }\end{array}$ & $\begin{array}{l}\text { ENVIRONMENTAL } \\
\text { CONSERVATION }\end{array}$ & 2014 \\
\hline $\begin{array}{l}\text { Niedzialkowski, K; Blicharska, M; } \\
\text { Mikusinski, G; Jedrzejewska, B }\end{array}$ & $\begin{array}{l}\text { Why is it difficult to enlarge a protected area? Ecosystem services } \\
\text { perspective on the conflict around the extension of the Bialowieza } \\
\text { National Park in Poland }\end{array}$ & LAND USE POLICY & 2014 \\
\hline $\begin{array}{l}\text { Golden, CD; Bonds, MH; } \\
\text { Brashares, JS; Rasolofoniaina, } \\
\text { BJR; Kremen, C }\end{array}$ & $\begin{array}{l}\text { Economic Valuation of Subsistence Harvest of Wildlife in } \\
\text { Madagascar }\end{array}$ & CONSERVATION BIOLOGY & 2014 \\
\hline $\begin{array}{l}\text { Carter, NH; Vina, A; Hull, V; } \\
\text { McConnell, WJ; Axinn, W; } \\
\text { Ghimire, D; Liu, JG }\end{array}$ & $\begin{array}{l}\text { Coupled human and natural systems approach to wildlife research } \\
\text { and conservation }\end{array}$ & ECOLOGY AND SOCIETY & 2014 \\
\hline
\end{tabular}




\begin{tabular}{|c|c|c|c|}
\hline Allendorf, TD; Allendorf, K & Gender and Attitudes toward Protected Areas in Myanmar & SOCIETY \& NATURAL RESOURCES & 2013 \\
\hline Kari, S; Korhonen-Kurki, K & $\begin{array}{l}\text { Framing local outcomes of biodiversity conservation through } \\
\text { ecosystem services: A case study from Ranomafana, Madagascar }\end{array}$ & ECOSYSTEM SERVICES & 2013 \\
\hline Modica, G; Zoccali, P; Di Fazio, S & $\begin{array}{l}\text { The e-Participation in Tranquillity Areas Identification as a Key } \\
\text { Factor for Sustainable Landscape Planning }\end{array}$ & $\begin{array}{l}\text { COMPUTATIONAL SCIENCE AND } \\
\text { ITS APPLICATIONS (ICCSA 2013), } \\
\text { PT III }\end{array}$ & 2013 \\
\hline $\begin{array}{l}\text { Zhu, L; Chen, Y; Gong, HL; Jiang, } \\
\text { WG; Zhao, WJ; Xiao, YF }\end{array}$ & $\begin{array}{l}\text { Economic value evaluation of wetland service in Yeyahu Wetland } \\
\text { Nature Reserve, Beijing }\end{array}$ & $\begin{array}{l}\text { CHINESE GEOGRAPHICAL } \\
\text { SCIENCE }\end{array}$ & 2011 \\
\hline Siikamaki, J & Contributions of the US state park system to nature recreation & $\begin{array}{l}\text { PROCEEDINGS OF THE NATIONAL } \\
\text { ACADEMY OF SCIENCES OF THE } \\
\text { UNITED STATES OF AMERICA }\end{array}$ & 2011 \\
\hline $\begin{array}{l}\text { Garcia-Llorente, M; Martin- } \\
\text { Lopez, B; Montes, C }\end{array}$ & $\begin{array}{l}\text { Exploring the motivations of protesters in contingent valuation: } \\
\text { Insights for conservation policies }\end{array}$ & $\begin{array}{l}\text { ENVIRONMENTAL SCIENCE \& } \\
\text { POLICY }\end{array}$ & 2011 \\
\hline Hartter, J; Goldman, A & $\begin{array}{l}\text { Local responses to a forest park in western Uganda: alternate } \\
\text { narratives on fortress conservation }\end{array}$ & ORYX & 2011 \\
\hline $\begin{array}{l}\text { Sodhi, NS; Lee, TM; Sekercioglu, } \\
\text { CH; Webb, EL; Prawiradilaga, DM; } \\
\text { Lohman, DJ; Pierce, NE; Diesmos, } \\
\text { AC; Rao, M; Ehrlich, PR }\end{array}$ & $\begin{array}{l}\text { Local people value environmental services provided by forested } \\
\text { parks }\end{array}$ & $\begin{array}{l}\text { BIODIVERSITY AND } \\
\text { CONSERVATION }\end{array}$ & 2010 \\
\hline $\begin{array}{l}\text { Booth, JE; Gaston, KJ; } \\
\text { Armsworth, PR }\end{array}$ & Who Benefits from Recreational Use of Protected Areas? & ECOLOGY AND SOCIETY & 2010 \\
\hline Salum, LA & $\begin{array}{l}\text { Ecotourism and biodiversity conservation in Jozani-Chwaka Bay } \\
\text { National Park, Zanzibar }\end{array}$ & AFRICAN JOURNAL OF ECOLOGY & 2009 \\
\hline $\begin{array}{l}\text { Martin-Lopez, B; Montes, C; } \\
\text { Benayas, J }\end{array}$ & $\begin{array}{l}\text { Influence of user characteristics on valuation of ecosystem services } \\
\text { in Do(n)over-tildeana Natural Protected Area (south-west Spain) }\end{array}$ & $\begin{array}{l}\text { ENVIRONMENTAL } \\
\text { CONSERVATION }\end{array}$ & 2007 \\
\hline
\end{tabular}


Tabela 1.S2 Capítulo 1: Campos de pesquisas dos periódicos dos artigos inclusos na revisão de acordo com os dados do ISI Web of Science, por ano de publicação.

\begin{tabular}{|c|c|c|c|}
\hline & Academic fields & Year & Number of Publication \\
\hline Sci\&Tec & Science \& Technology - Other Topics & 2019 & 2 \\
\hline Plant & Plant Sciences & 2019 & 3 \\
\hline Eng & Engineering & 2019 & 2 \\
\hline Biophy & Biophysics & 2019 & 1 \\
\hline E\&E & Environmental Sciences \& Ecology & 2019 & 16 \\
\hline Bio\&C & Biodiversity \& Conservation & 2019 & 1 \\
\hline Health & Public, Environmental \& Occupational Health & 2019 & 1 \\
\hline For & Forestry & 2019 & 3 \\
\hline Met\&Atm & Meteorology \& Atmospheric Sciences & 2019 & 1 \\
\hline Sci\&Tec & Science \& Technology - Other Topics & 2018 & 2 \\
\hline E\&E & Environmental Sciences \& Ecology & 2018 & 12 \\
\hline Bio\&C & Biodiversity \& Conservation & 2018 & 1 \\
\hline For & Forestry & 2018 & 1 \\
\hline Water & Water Resources & 2018 & 1 \\
\hline PhyGeo & Physical Geography & 2018 & 2 \\
\hline Geo & Geography & 2018 & 1 \\
\hline Urban & Urban Studies & 2018 & 1 \\
\hline Agri & Agriculture & 2018 & 1 \\
\hline Sci\&Tec & Science \& Technology - Other Topics & 2017 & 2 \\
\hline E\&E & Environmental Sciences \& Ecology & 2017 & 15 \\
\hline Bio\&C & Biodiversity \& Conservation & 2017 & 5 \\
\hline PhyGeo & Physical Geography & 2017 & 1 \\
\hline Geo & Geography & 2017 & 1 \\
\hline Urban & Urban Studies & 2017 & 1 \\
\hline Bus\&Econ & Business \& Economics & 2017 & 1 \\
\hline Sci\&Tec & Science \& Technology - Other Topics & 2016 & 1 \\
\hline E\&E & Environmental Sciences \& Ecology & 2016 & 3 \\
\hline Bio\&C & Biodiversity \& Conservation & 2016 & 1 \\
\hline For & Forestry & 2016 & 1 \\
\hline PhyGeo & Physical Geography & 2016 & 1 \\
\hline Geo & Geography & 2016 & 1 \\
\hline Urban & Urban Studies & 2016 & 1 \\
\hline Sci\&Tec & Science \& Technology - Other Topics & 2015 & 1 \\
\hline E\&E & Environmental Sciences \& Ecology & 2015 & 4 \\
\hline
\end{tabular}




\begin{tabular}{llll}
\hline For & Forestry & 2015 & 1 \\
Dev & Development Studies & 2015 & 1 \\
\hline PA & Public Administration & 2015 & 1 \\
E\&E & Environmental Sciences \& Ecology & 2014 & 4 \\
Bio\&C & Biodiversity \& Conservation & 2014 & 2 \\
E\&E & Environmental Sciences \& Ecology & 2013 & 2 \\
Dev & Development Studies & 2013 & 1 \\
PA & Public Administration & 2013 & 1 \\
Comp & Computer Science & 2013 & 1 \\
\hline Sci\&Tec & Science \& Technology - Other Topics & 2011 & 1 \\
E\&E & Environmental Sciences \& Ecology & 2011 & 3 \\
\hline Bio\&C & Biodiversity \& Conservation & 2011 & 1 \\
E\&E & Environmental Sciences \& Ecology & 2010 & 2 \\
\hline Bio\&C & Biodiversity \& Conservation & 2010 & 1 \\
\hline E\&E & Environmental Sciences \& Ecology & 2009 & 1 \\
\hline E\&E & Environmental Sciences \& Ecology & 2007 & 1 \\
\hline Bio\&C & Biodiversity \& Conservation & 2007 & 1 \\
\hline
\end{tabular}


Aspectos socioculturais e a percepção sobre os serviços ecossistêmicos: um estudo do Parque Nacional de Brasília

Sociocultural aspects and the perception about the ecosystem services: a case study of Brasilia National Park

Maria Fernanda Pistori, Caroline Almeida Souza e Alexandre Toshiro Igari, Vânia Regina Pivello

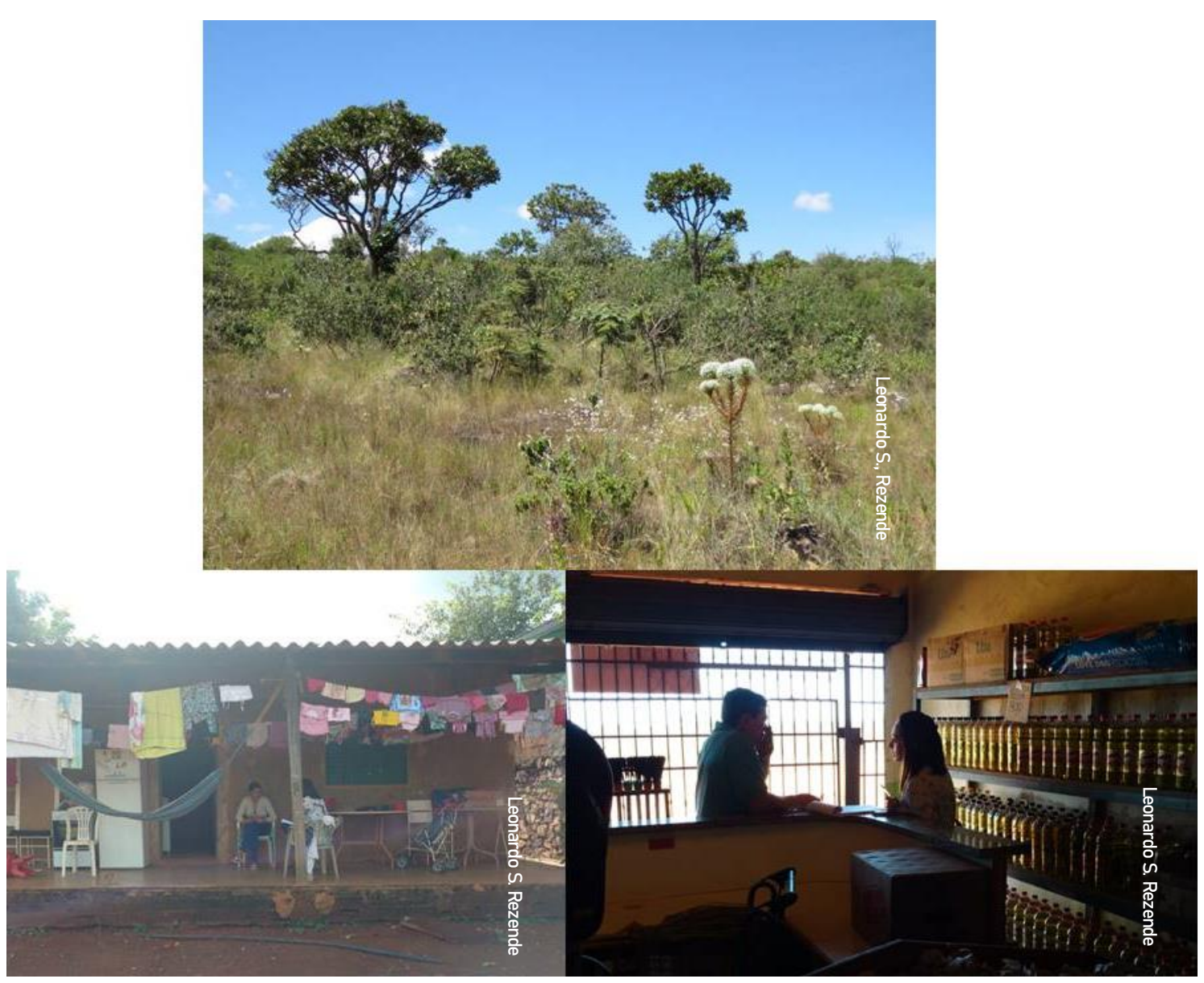




\section{Resumo}

A criação e estabelecimento de áreas protegidas é uma das principais estratégias para a conservação da biodiversidade. No entanto, cada vez mais se torna necessária a integração de uma perspectiva mais ampla desses sistemas socioecológicos, englobando os diferentes interesses sociais nos serviços ecossistêmicos (SE), preservando a integridade e saúde dos sistemas naturais. A abordagem de SE pode contribuir para esse cenário ao reconhecer a ampla gama de benefícios que as áreas protegidas proporcionam e a relação com o bemestar humano. Dentro desse contexto, esta pesquisa teve como objetivo avaliar a percepção de diferentes grupos de beneficiários em relação aos SE fornecidos pelo Parque Nacional de Brasília (PARNA Brasília), assim como verificar quais SE são percebidos como em declínio. Para isso, foram mapeado diferentes grupos de interesses (urbano frequente, urbano não frequente, rural, turistas e gestores) e foram realizadas 58 entrevistas. Uma parte expressiva da população tem/teve contato com a natureza exclusivamente através de áreas protegidas e grande parte demanda pela criação de mais espaços para a conservação da biodiversidade. O PARNA Brasília é valorizado em grande parte pelos seus objetivos de criação (provisão de habitat, lazer e valor de existência). No entanto, puderam ser identificados alguns trade-offs com serviços ecossistêmicos de provisão, valor que mais diferenciou os grupos de interesse. Houve uma alta correlação entre o valor de importância conferido ao SE e sua percepção de declínio. A abordagem de SE pode ser promissora para facilitar a comunicação de tomadores de decisão com a população.

Palavras-chaves: sistemas sociológicos, serviços ambientais, unidades de conservação, stakeholders.

\section{Introdução}

A atual crise de biodiversidade seria muito mais grave se o estabelecimento de áreas protegidas no último século não tivesse ocorrido. Mas o objetivo de criação pode ir além dos objetivos da conservação de ecossistemas e suas espécies constituintes (Dudley, 2008) ou proteção de espécies específicas ameaçadas (Liu et al., 2001), podendo também incluir o fornecimento de serviços ecossistêmicos (Campos e Nepstad, 2006). As estratégias de conservação precisam integrar uma perspectiva mais ampla dos sistemas socioecológicos e englobar os diferentes interesses sociais nos serviços ecossistêmicos, preservando a integridade e a saúde dos sistemas naturais (Ban et al. 2013 , Palomo et al. 2014, Cumming et al. 2015 ). O conceito de serviços ecossistêmicos (SE), ou seja, os benefícios que as pessoas obtêm dos ecossistemas, surgiu do crescente reconhecimento da importância da inclusão de valores humanos nas avaliações dos ecossistemas (de Groot et al., 2002, Millenium Ecosystem Assessment, 2003, Meyerson et al., 2005 , Folke, 2006 ).

A abordagem de SE reconhece a ampla gama de benefícios que as áreas protegidas proporcionam (Dudley et al. 2011 ) e a importância de reconhecer os múltiplos - e muitas vezes conflitantes - interesses dos atores sociais em sua gestão (García-Nieto et al. 2015 ). Trabalhos com ênfase nas preferências de determinados SE pela população local podem ser considerados mais uma ferramenta a auxiliar no direcionamento da tomada de decisão e na elaboração de políticas públicas que visem à conservação do meio ambiente e ao desenvolvimento econômico e social de uma região (Martín-López et al., 2012). 
Curiosamente, muitos estudos lidam com o gerenciamento ideal de áreas protegidas (APs) com base na opinião de especialistas, além de numerosos estudos com base na percepção de turistas, mas poucos estudos trazem a preferência da população que vive na zona tampão (ou zona de amortecimento) das áreas protegidas (Walde et.al. 2019). A população local é particularmente afetada e, portanto, indispensável no estabelecimento de diretrizes de manejo e gestão. A abordagem de serviços ecossistêmicos, incluindo diferentes atores sociais (stakeholders), pode revelar conflitos sociais existentes e potenciais entre gerenciamento e uso, especialmente quando políticas de conservação são aplicadas sem a devida consideração dos interesses e necessidades das comunidades locais (Kovács et al. 2015).

No Brasil, a quantidade de estudos na área também ainda é pequena, apesar da significante contribuição para o sistema de áreas protegidas no mundo, sendo $18,7 \%$ do seu território continental protegido e $26,5 \%$ das áreas marinhas, considerando os diferentes níveis de proteção e tipos de UC (CNUC, 2019). Desse total de 18,7\%, 8,21\% são representados pelo bioma Cerrado, o qual recebe poucas ações concretas e estudos visando a sua conservação, mesmo sendo um hotspot de biodiversidade. Dentro desse contexto, uma das recomendações do Millenium Ecosystem Assessment (2005) é desenvolver um apoio social mais forte com base nos benefícios e valores que as áreas protegidas fornecem.

Buscando contribuir para esse cenário, o presente trabalho teve como objetivo avaliar a percepção de diferentes stakeholders em relação ao Parque Nacional de Brasília, sob a forma de estudo de caso. Além de ser uma importante área natural protegida para a região, possui característica singular, estando parcialmente adjacente a um grande e importante centro urbano e parcialmente localizada em zona rural. Martín-Lopez et. al.(2012) concluíram que diferentes partes interessadas possuem valores e percepções diferentes em relação aos serviços ecossistêmicos, assim como existe um importante gradiente rural-urbano nas preferências em relação aos serviços ecossistêmicos, com base em diferentes características sociais. Desse modo, avaliaremos se o mesmo ocorre para o Parque em questão, além de trazer subsídios para aperfeiçoar sua gestão.

\section{Objetivos}

Este capítulo teve como objetivo principal identificar a percepção dos stakeholders sobre serviços ecossistêmicos prestados pelo Parque Nacional de Brasília e a percepção sobre tendência de fornecimento dos mesmos, com o foco em quais SE estão em declínio na região. Para isso, os objetivos específicos estabelecidos foram: (i) Identificar as preferências socioculturais dos diferentes stakeholders por serviços ecossistêmicos e seus graus de importância; (ii) Diagnosticar as diferenças de percepções entre os diferentes grupos de stakeholders e verificar se há um gradiente rural-urbano; (iii) Identificar quais SE são percebidos como em declínio na região. Por fim, discutimos como avaliações socioculturais podem ser úteis para melhorar o manejo de APs. 
4. Material e Método

\section{1. Área de Estudo}

Nosso estudo investigou o Parque Nacional de Brasília (PARNA Brasília), uma Unidade de Conservação de Proteção Integral, de acordo com o Sistema Nacional de Unidades de Conservação (SNUC) - Lei 9985/2000. Conforme a legislação vigente, os parques nacionais têm como objetivo a preservação de ecossistemas naturais de grande relevância ecológica e beleza cênica, possibilitando a realização de pesquisas científicas e o desenvolvimento de atividades de educação e interpretação ambiental, de recreação e de turismo ecológico.

O PARNA Brasília está localizado no bioma Cerrado, no estado de Goiás e Distrito Federal, a cerca de $10 \mathrm{~km}$ do centro da cidade de Brasília, capital do Brasil. A entrada principal do PARNA Brasília articula-se de forma direta com toda a estrutura urbana localizada no sul e sudeste do entorno imediato. Ao norte, nordeste, noroeste e oeste, o PARNA Brasília possui em seu entorno uma área pouco habitada, com predomínio de propriedades rurais, onde estão localizadas a Área de Preservação Ambiental (APA) do Rio Descoberto e a APA de Cafuringa (Figura 1).

O Cerrado é considerado a savana mais rica do mundo em espécies de plantas (Forzza et al. 2012), com alto grau de endemismo. Apesar de sua relevância, esse bioma vem sofrendo uma severa perda e fragmentação de áreas nativas, cujos remanescentes somam apenas $52 \%$ da área original do bioma (INPE 2018). Hoje é considerado um dos hotspots de biodiversidade, ou seja, região com altíssimo valor biológico, mas muito ameaçado (Myers et al. 2000). Sabe-se que a degradação de recursos naturais provoca a diminuição da biodiversidade, bem como compromete sua capacidade de geração de SE (Constanza et al., 2014). No caso do PARNA Brasília, os reflexos já podem ser sentidos pela população da região, um exemplo disso foi a recente crise hídrica do distrito federal, uma das mais severas da história (Distrito Federal, 2017). 


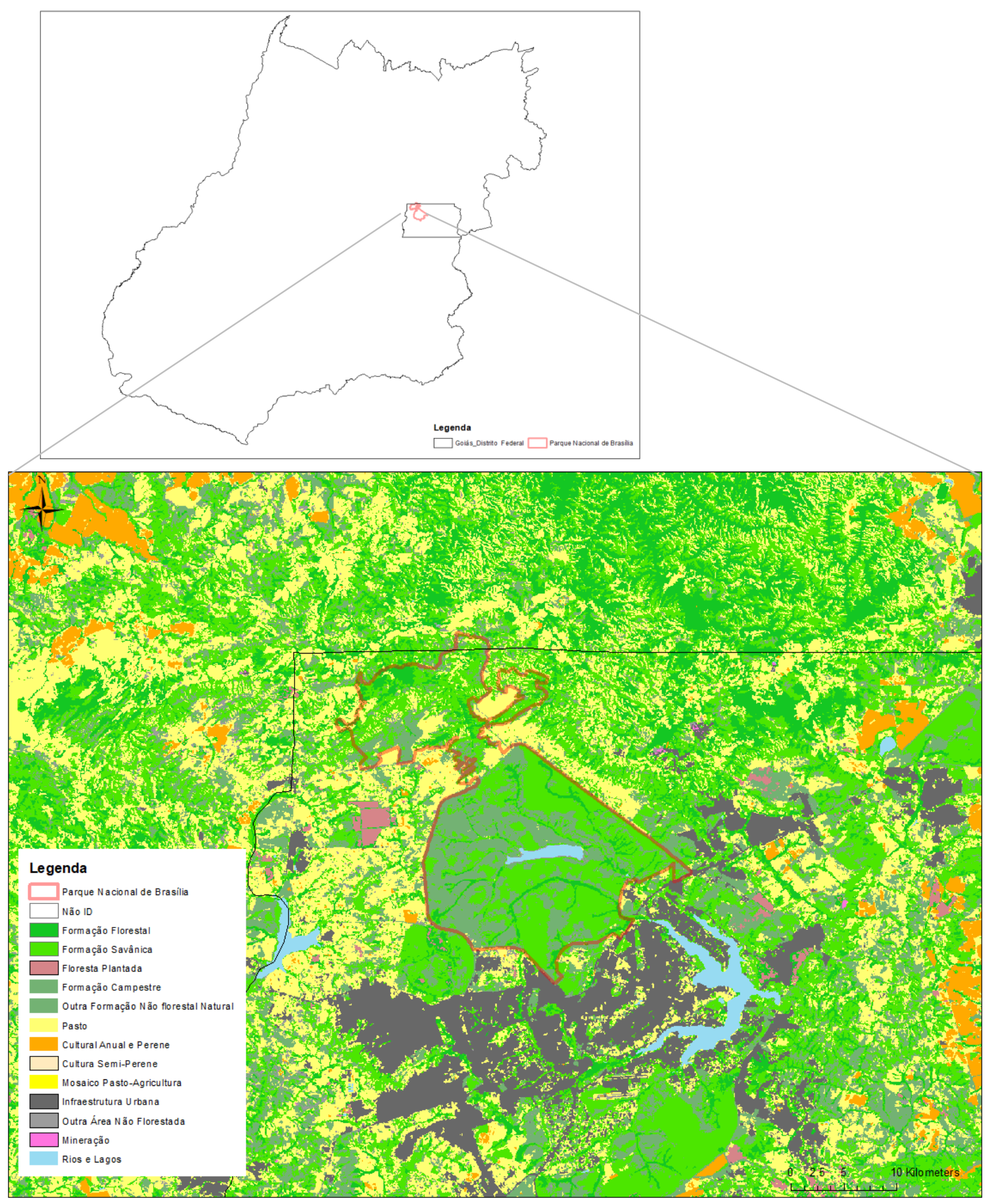

Figura 3: Mapa de Localização e Uso e Ocupação da terra do Parque Nacional de Brasília e seu entorno. 


\subsection{ENTREVISTAS}

\subsubsection{Seleção dos Entrevistados}

A primeira etapa da pesquisa envolveu uma reunião com os gestores do PARNA Brasília para identificar os principais grupos e características dos moradores do entorno (zona tampão). Os entrevistados foram separados em grupos, de acordo com as características de localização da moradia e/ou atuação: urbano, rural, turistas e gestores. As entrevistas foram realizadas dentro do Parque, na casa dos moradores do entorno e em praças públicas no entorno do Parque, buscando cobrir as diferentes regiões do entorno imediato, considerada a zona de amortecimento do PARNA Brasília.

\subsubsection{Percepção dos Entrevistados}

A coleta de dados para analisar a percepção dos stakeholders sobre os SE foi realizada por meio de entrevistas, as quais envolveram perguntas estruturadas e semiestruturadas (Lüdke \& André, 1986). Os entrevistados foram convidados a contribuir após explicação clara sobre os objetivos da pesquisa e esclarecimento de dúvidas, ou seja, elas tiveram caráter voluntário e os direitos de privacidade foram assegurados. As entrevistas foram gravadas e também anotadas em papel, sempre com a permissão declarada do entrevistado. A amostra foi restrita a pessoas com mais de 18 anos de idade.

A elaboração do roteiro de entrevista baseou-se nos objetivos propostos e em pesquisas que buscaram identificar a percepção e os valores dos SE pelas pessoas, destacando os trabalhos de García-Llorente et.al. 2018, Scholte et.al. (2015) e Martín-López et.al. (2012). Foram elaborados dois roteiros (Material Suplementar S1), tendo sido o primeiro (roteiro I) aplicado à população urbana, rural e turistas, enquanto que o segundo (roteiro II) foi aplicado apenas aos gestores, visto que eles possuem visão técnico-administrativa sobre o Parque.

O roteiro I (Material Suplementar S1 - Roteiro I) está dividido em três seções: i) características gerais; ii) contato com a unidade de conservação; iii) serviços ecossistêmicos (Tabela 1). No momento das entrevistas, os termos que eram desconhecidos pelos participantes foram devidamente explicados, para evitar constrangimentos. A definição de SE explicada foi baseada no Millennium Ecosystem Assessment (2005) - "os benefícios que os ecossistemas fornecem aos seres humanos para melhorar sua qualidade de vida" - pois ela é didática e de fácil compreensão, diminuindo, assim, confusões em virtude dos diferentes níveis de escolaridade entre os entrevistados.

Para capturar a percepção e importância dos SE fornecidos pelo PARNA Brasília na seção do questionário sobre SE houve duas etapas, a fim de capturar múltiplas dimensões de valores socioculturais. Na primeira etapa, a pergunta foi realizada de forma aberta, ou seja, os entrevistados falaram livremente sobre os benefícios do PARNA Brasília, que foram posteriormente classificados em serviços ecossistêmicos. Na segunda etapa da seção, os entrevistados foram convidados a dar uma nota de importância para os serviços ecossistêmicos determinados previamente, baseado na escala likert (0-3), onde a nota zero era para SE que eram considerados como não importantes, 1 para pouco importantes, 2 para 
importantes, 3 para os que eram muito importantes, além disso os participantes poderiam responder que não percebiam o SE como sendo fornecido pelo Parque.

Tabela 1: Três principais componentes de dados presentes no questionário aplicado aos moradores e turistas sobre os Serviços Ecossistêmicos fornecidos pelo Parque Nacional de Brasília (Material Suplementar S1 - Roteiro II).

\begin{tabular}{|c|c|c|}
\hline Componente dos dados & Variáveis & Método \\
\hline \multirow[t]{3}{*}{ Características Gerais } & $\begin{array}{l}\text { Sexo; Escolaridade; Grupo } \\
\text { (Rural, Urbano, Turista) }\end{array}$ & Escolha de item \\
\hline & Idade & Aberto \\
\hline & $\begin{array}{l}\text { Contato com áreas naturais } \\
\text { durante a vida }\end{array}$ & Aberto (palavras próprias) \\
\hline \multirow{6}{*}{$\begin{array}{llll}\text { Contato } & \text { com } & \text { a } & \text { Área } \\
\text { Protegida } & & & \\
\end{array}$} & Conhece a AP & Escolha de item \\
\hline & Frequência & Escolha de item \\
\hline & Motivação da visita & Aberto (palavras próprias) \\
\hline & Renda dependente da AP & $\begin{array}{ll}\text { Binário (sim/não) } & \text { e } \\
\text { complementação aberta } & \end{array}$ \\
\hline & $\begin{array}{l}\text { Substituição da AP por outro } \\
\text { Uso }\end{array}$ & $\begin{array}{ll}\text { Binário } \quad \text { (sim/não) } & \text { e } \\
\text { complementação aberta }\end{array}$ \\
\hline & Mais áreas protegidas & $\begin{array}{l}\text { Binário } \quad \text { (sim/não) } \\
\text { complementação aberta }\end{array}$ \\
\hline \multirow[t]{2}{*}{ Serviços Ecossistêmicos } & $\begin{array}{l}\text { Identificação e Importância } \\
\text { de benefícios fornecidos pela } \\
\text { AP }\end{array}$ & $\begin{array}{l}\text { 19 etapa: Aberto (palavras } \\
\text { próprias) } \\
\text { 2a etapa: Escolha baseada na } \\
\text { Escala Likert }\end{array}$ \\
\hline & 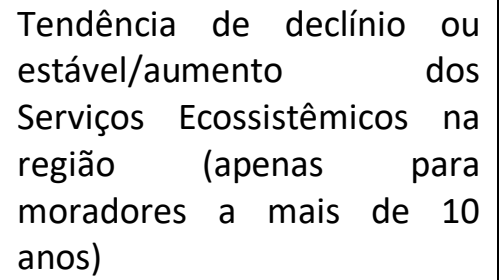 & $\begin{array}{l}\text { Escolha de Item } \\
\text { (Concordo/Discordo/Não sei) }\end{array}$ \\
\hline
\end{tabular}

O roteiro II, aplicado apenas para gestores, possui três etapas: i) dados gerais do entrevistado; ii) visão geral de problemas; iii) serviços ecossistêmicos (Tabela 2).

Tabela 2: Três principais componentes de dados presentes no questionário aplicado gestores sobre os Serviços Ecossistêmicos fornecidos pelo Parque Nacional de Brasília (Material Suplementar S1 - Roteiro II).

\begin{tabular}{|l|l|l|}
\hline Componente dos dados & Variáveis & Método \\
\hline Características Gerais & Sexo & Escolha de item \\
\cline { 2 - 3 } & Idade & Aberto \\
\cline { 2 - 3 } & $\begin{array}{l}\text { Formação e área de atuação } \\
\text { na gestão }\end{array}$ & Aberto (palavras próprias) \\
\hline Visão geral dos problemas & $\begin{array}{l}\text { Principais problemas } \\
\text { enfrentados pelo PARNA }\end{array}$ & Aberto (palavras próprias) \\
& Brasília & \\
\cline { 2 - 3 } & $\begin{array}{l}\text { Abordagem de serviços } \\
\text { ecossistêmicos como } \\
\text { ferramenta para auxiliar na }\end{array}$ & \\
\hline
\end{tabular}




\begin{tabular}{|l|l|l|}
\hline & resolução de conflitos & \\
\hline Serviços Ecossistêmicos & $\begin{array}{l}\text { Identificação e Importância } \\
\text { de benefícios fornecidos pela } \\
\text { AP }\end{array}$ & $\begin{array}{l}\text { Escolha baseada na Escala } \\
\text { Likert. }\end{array}$ \\
\hline
\end{tabular}

\subsection{Análise de dados}

\subsubsection{Caracterização geral dos entrevistados e percepção dos serviços ecossistêmicos}

Inicialmente, fizemos uma caracterização das variáveis socioculturais dos diferentes atores que participaram desta pesquisa. As variáveis analisadas foram: gênero, idade, escolaridade, contato com áreas naturais, frequência de visitação e percepção ou não da necessidade de mais áreas protegidas para preservar o bioma cerrado. A caracterização foi feita de forma descritiva.

Para a análise dos serviços ecossistêmicos verificamos os valores de importância que Ihes foram atribuídos, buscando ver de forma geral os que mais se destacavam em termos de importância, e os que eram considerados menos importantes ou que não eram percebidos como um benefício trazido pelo Parque Nacional de Brasília. Também avaliamos a frequência média de notas dadas em relação à importância dos serviços ecossistêmicos de cada grupo (cultural, provisão, regulação e suporte).

\subsubsection{Diagnóstico das diferenças de percepções entre grupos de stakeholders}

Para avaliar se havia diferença de percepção entre os grupos (Urbano não frequente, Urbano frequente, Rural, Turistas e Gestores) com relação às diferentes categorias de serviços ecossistêmicos (provisão, regulação, cultural e suporte), foi feita a média de nota de cada entrevistado para cada categoria de SE. Após esse passo, foi feita a significância das diferenças entre medianas com comparações par a par por meio de testes de aleatorização com reamostragem (10000 vezes), no software $R$. Comparamos a significância da diferença de importância dentro dos grupos de stakeholders (comparando a importância das diferentes categorias de SE dentro de cada grupo de stakeholders) e entre os grupos de stakeholders (comparando a importância dada para cada categoria de SE entre os grupos de stakeholders).

\subsubsection{Investigação de outras características demográficas}

Outras características demográficas podem influenciar na percepção da importância dos diferentes SE, como gênero (Allendorf e Yang, 2017), idade (Paul \& Nagendra, 2017) e nível educacional (Sodhi et.al., 2010). Para explorar se houve diferença no valor de importância percebido pelos entrevistados a depender dessas características demográficas, utilizamos novamente a significância das diferenças entre as medianas com comparação par a par por meio de teste de aleatorização com reamostragem, como citado anteriormente. 
Exploramos as variáveis: gênero, feminino $(n=27)$ e masculino $(n=31)$; escolaridade, os grupos testados foram os entrevistados que tinham estudos até o Ensino Fundamental (EF), $n=7$, Ensino Médio (EM), n=19, Ensino Superior (S), n=21, e Pós-graduação (PG), n=11; e por idade, que foi tratada como uma variável contínua.

Outra variável que foi explorada foi a resposta em relação ao contato da natureza ao longo da vida. Os grupos foram separados em que os que tiveram respostas positivas $(n=50)$, que incluiu tanto os entrevistados que tiveram contato exclusivamente através de áreas protegidas e os que não tiveram, e os que tiveram respostas negativas $(n=4)$.

\subsubsection{Identificação dos SE percebidos em declínio na região}

As perguntas sobre a percepção de declínio dos serviços ecossistêmicos foi aplicada apenas para moradores locais (urbanos e rurais), com residência na região de no mínimo 10 anos, já que é necessária uma comparação em uma escala de tempo maior $(n=42)$. Os serviços ecossistêmicos analisados foram: qualidade da água, quantidade de água, controle de pragas e doenças, controle da erosão, regulação da qualidade do ar, provisão de habitat, polinização, ciclagem de nutrientes, áreas de lazer/recreação e conforto espiritual. Os resultados foram correlacionados com as notas de importância dada aos respectivos serviços através do teste de correlação de Spearman no software $R$.

\section{Resultados}

\subsection{Características Gerais dos Entrevistados}

Após análise exploratória, os grupos foram separados com base nas classes identificadas anteriormente e na frequência de visitação, para uma divisão mais adequada das relações com o PARNA Brasília: rural ( $n=10)$, urbano não frequente $(n=22)$, urbano frequente $(n=15)$, turistas $(n=7)$ e gestores $(n=4)$. A população rural se caracterizava por não ser frequente (escolha do item: anual, poucas vezes ou nunca), assim como turistas; os frequentes foram considerados aqueles que frequentam o Parque mensalmente ou semanalmente.

Os entrevistados $(n=58)$, de maneira geral, possuem alta escolaridade, o que reflete os dados dos IBGE (2010) para a cidade de Brasília A quantidade de homens e mulheres entrevistados foi balanceada, apenas com o grupo de turistas tendo um predomínio maior do gênero masculino (71,4\%) (Figura 2). A média de idade para todos os grupos foi em torno de 40 anos. 

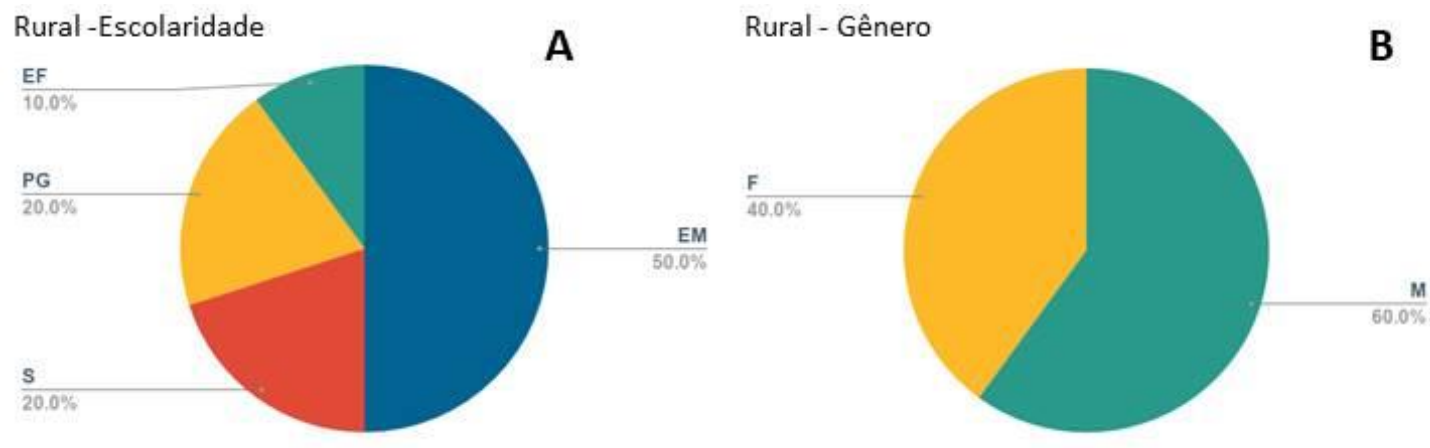

Urbano Não Frequente-Escolaridade

Urbano Não Frequente-Gênero
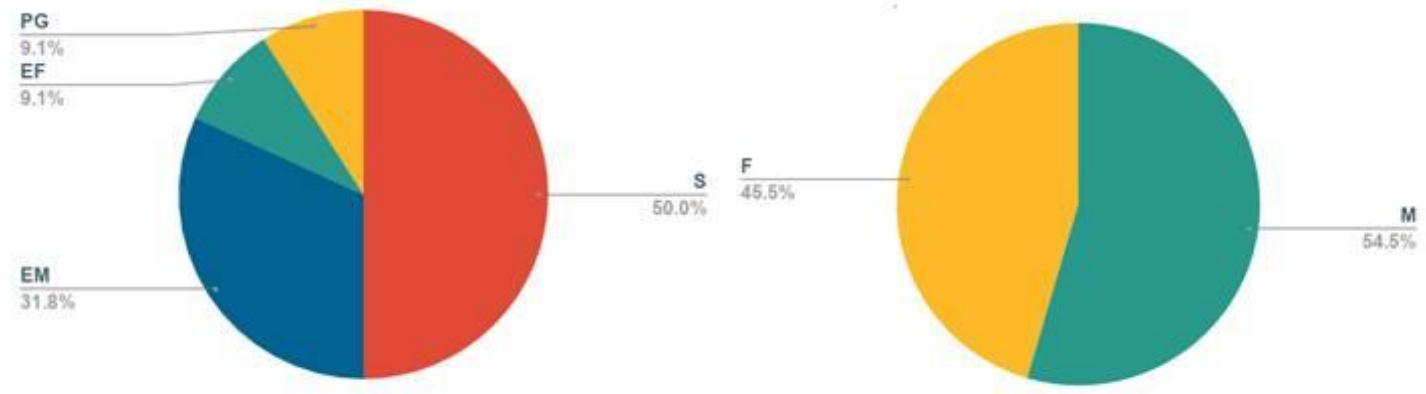

Urbano Frequente -Escolaridade

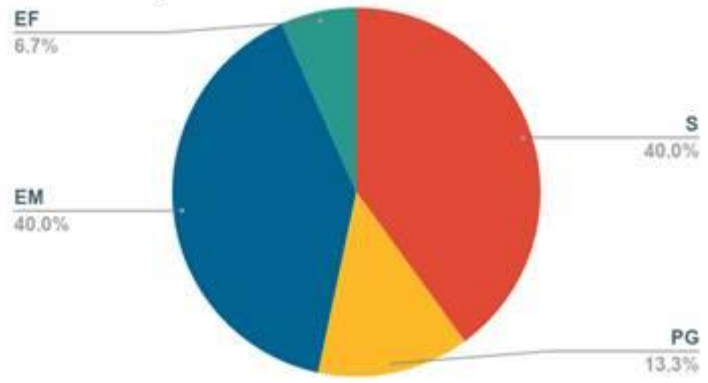

Urbano Frequente -Gênero

Turistas -Escolaridade

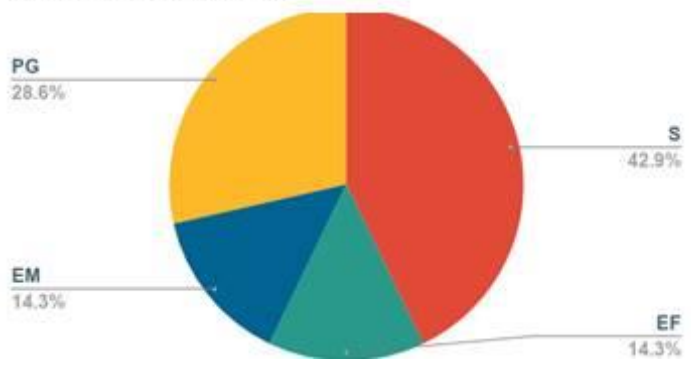

Turistas -Gênero

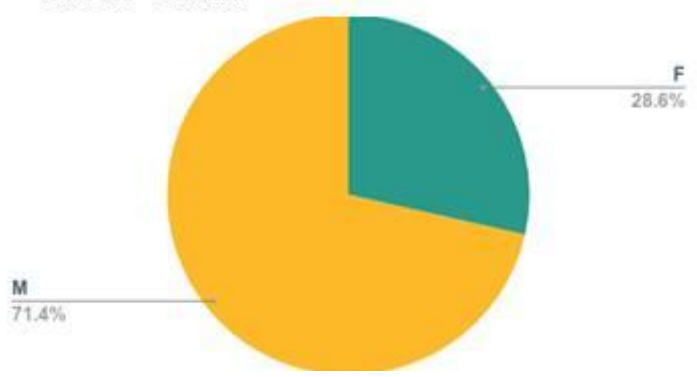

Gestores -Escolaridade

Rural -Gênero
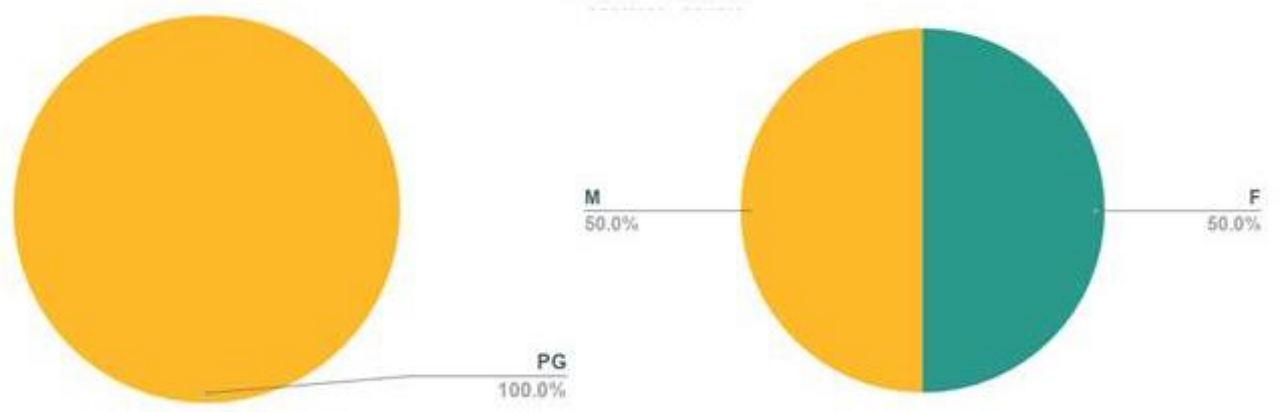

Figura 4: Características sociais dos stakeholders entrevistados (População Rural, População Urbana Não Frequente, População Urbana Frequente, Turistas e Gestores. A) Escolaridade EF= Ensino Fundamental Incompleto e Completo, 
EM = Ensino Médio Incompleto e Completo, S= Superior Incompleto e Completo e PG= Pós Graduação; B) Gênero $\mathrm{F}=$ Feminino e $\mathrm{M}=$ Masculino

Em relação ao contato com a natureza durante a vida (Figura 3), todos os entrevistados da zona rural tiveram respostas positivas. Os entrevistados da área urbana (frequente e não frequente) e turistas também tiveram a maioria das respostas positivas, com destaque de $33,3 \%$ de todos os entrevistados que declaram que esse contato com a natureza ocorreu exclusivamente através de áreas protegidas. O grupo apenas com respostas positivas (sim) foram aqueles que declaram que seu contato com a natureza incluía também outras áreas naturais, como áreas rurais e outros espaços.

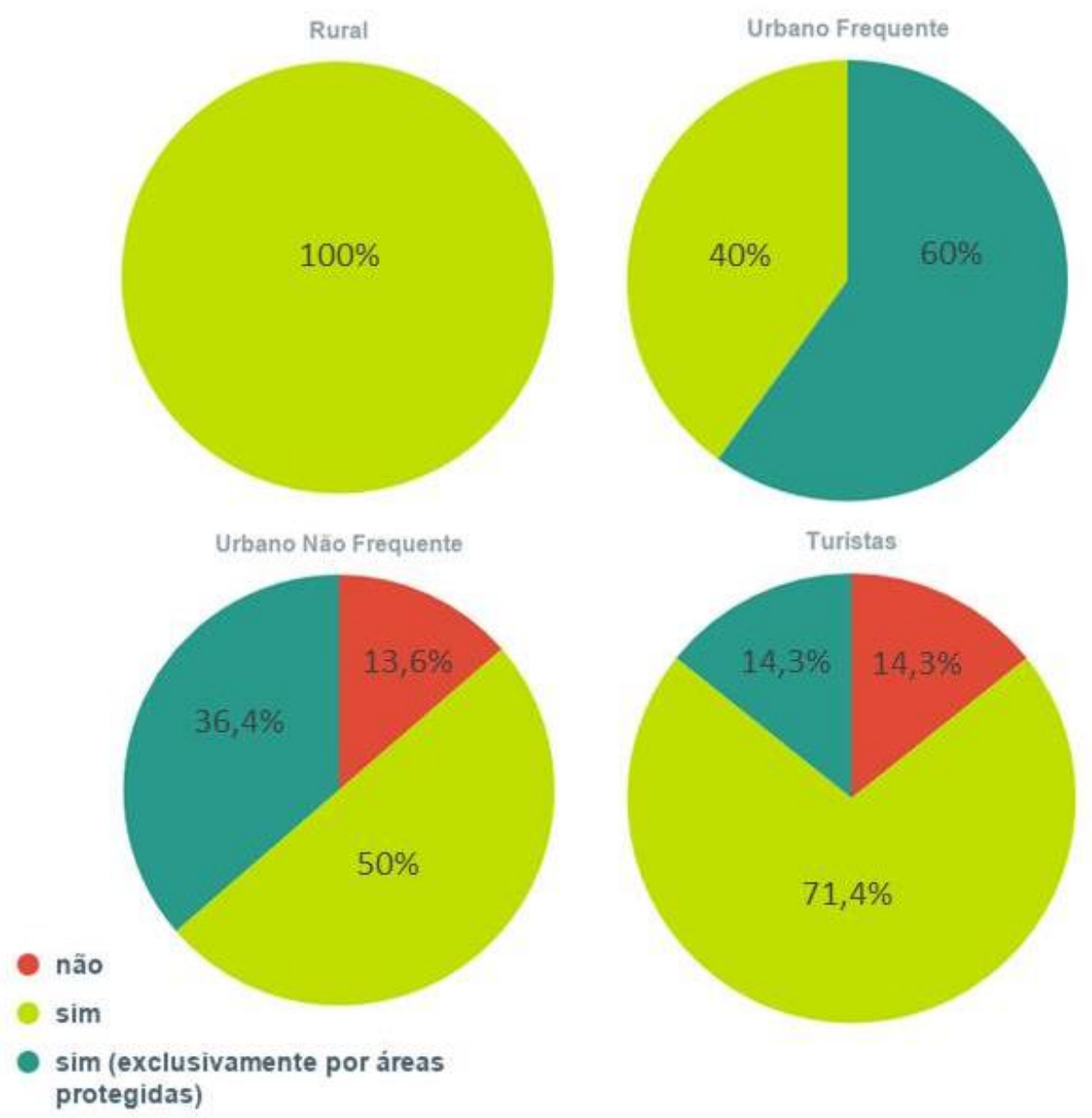

Figura 5: Respostas à pergunta sobre contato com a natureza ao longo da vida por grupo de stakeholders (Rural, Urbano Não Frequente, Urbano Frequente e Turistas). As categorias foram divididas em não, sim (exclusivamente por áreas protegidas) para quando o entrevistado só tem esse contrato através desses espaços ou sim (englobando tanto áreas protegidas como outros espaços naturais).

Em relação ao desejo de substituir o PARNA Brasília por outro uso e ocupação da terra, dois moradores da zona rural responderam que gostariam de substituir e não possuíam o desejo de mais áreas protegidas para a proteção do Cerrado. Quando questionados sobre as motivações, os entrevistados revelaram conflitos fundiários e de uso, principalmente ocasionados pelo não asfaltamento das estradas devido ao impacto no PARNA (questão levantada por todos os moradores da zona rural). 


\subsection{Importância percebida dos SE}

As respostas da primeira etapa da investigação sobre a importância dos SE para as pessoas (pergunta aberta) foram classificadas em serviços ecossistêmicos (Figura 4). Cabe destacar que, nesta etapa, os gestores não participaram, visto que eles possuem um papel diferente na interação com a AP. Em relação à variedade dos SE identificados, não houve grande variação entre os grupos; os moradores urbanos frequentes foram os que identificaram a maior variedade de SE (14, sendo 7 SE Culturais, 1 SE de Provisão, 4 SE de Regulação e 2 SE de Suporte), seguidos dos moradores rurais (12, sendo 7 SE culturais, 1 SE de Provisão, 3 de Regulação e 1 de Suporte), dos turistas (12, sendo 7 culturais, 1 de Provisão, 3 de Regulação e 1 de Suporte) e então dos moradores urbanos não frequentes (10, sendo 5 cultural, 1 de Provisão, 3 de Regulação e 1 de Suporte). Em destaque, apareceram os serviços ecossistêmicos de contato com a natureza, recreação, saúde mental e provisão de habitat.

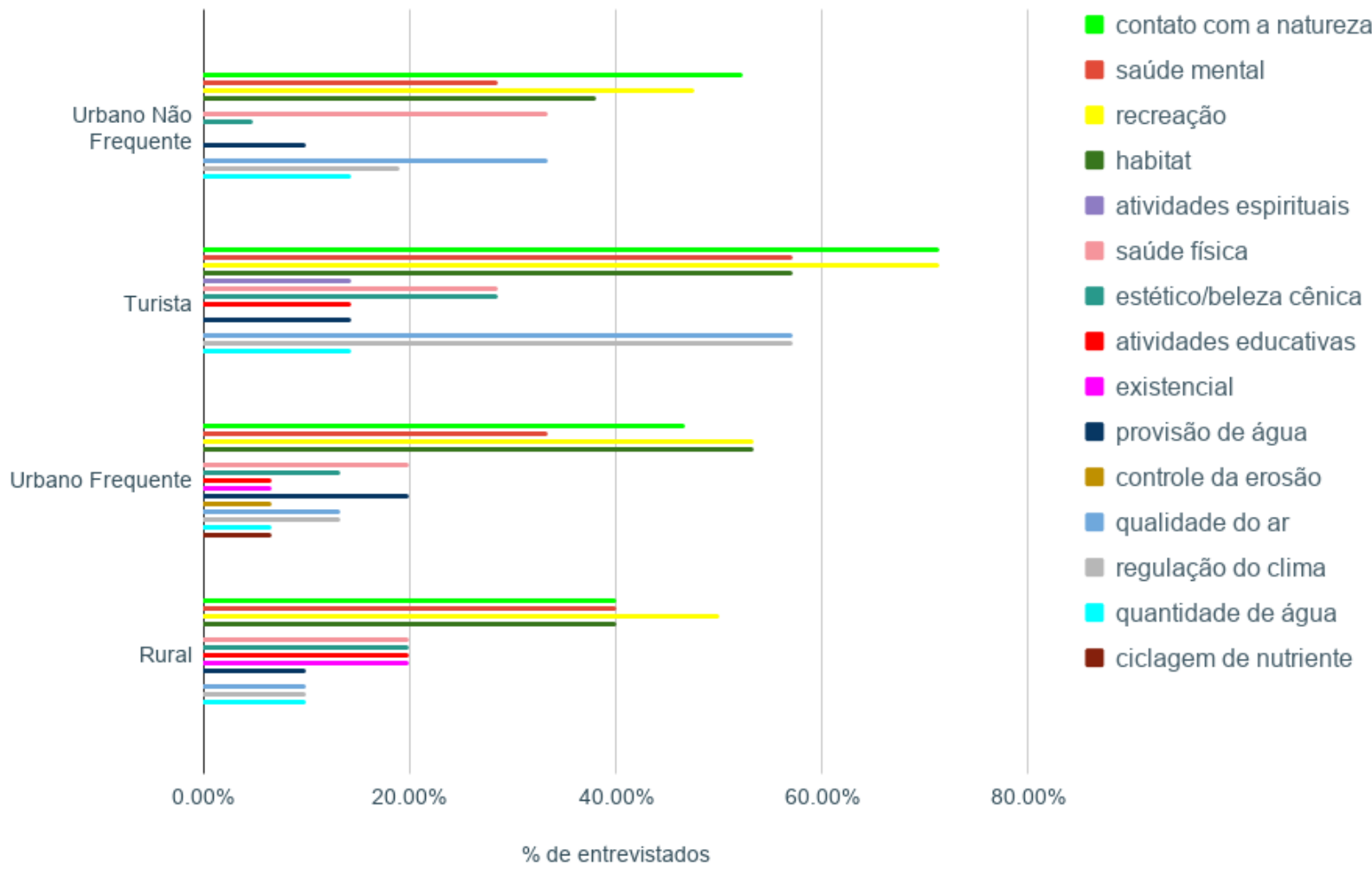

Figura 6: Percepção dos serviços ecossistêmicos providos do PARNA Brasília por grupo de stakeholders. Cada cor representa um serviço ecossistêmico citado durante a entrevista. $O$ tamanho da barra representa a porcentagem de entrevistados que citaram o mesmo serviço ecossistêmico.

Na segunda etapa da seção de investigação sobre os SE (escala likert) todos os grupos participaram (urbanos frequentes, urbanos não frequentes, população rural, turistas e gestores) (Material Suplementar S2 - Tabela 1). A escala likert permitia a escolha da opção: não percebo, não é importante (nota 0), pouco importante (nota 1), importante (nota 2) ou muito 
importante (nota 3). O resultado (Figura 5) sugere que, de maneira geral, os serviços ecossistêmicos mais importantes concentram-se nos serviços de suporte, principalmente o fornecimento de habitat, seguido pelos serviços culturais - destaque para lazer/recreação e existência, e de regulação, onde há maior variação de respostas, mas há destaque para os SE regulação da qualidade do ar, clima e quantidade de água. E, por último, em grau de importância, encontram-se os serviços de provisão, onde a maioria os classificou como não importantes. Nesse último caso, cabe destacar que o fornecimento de água e coleta de plantas medicinais e frutas aparecem com maior grau de importância. 


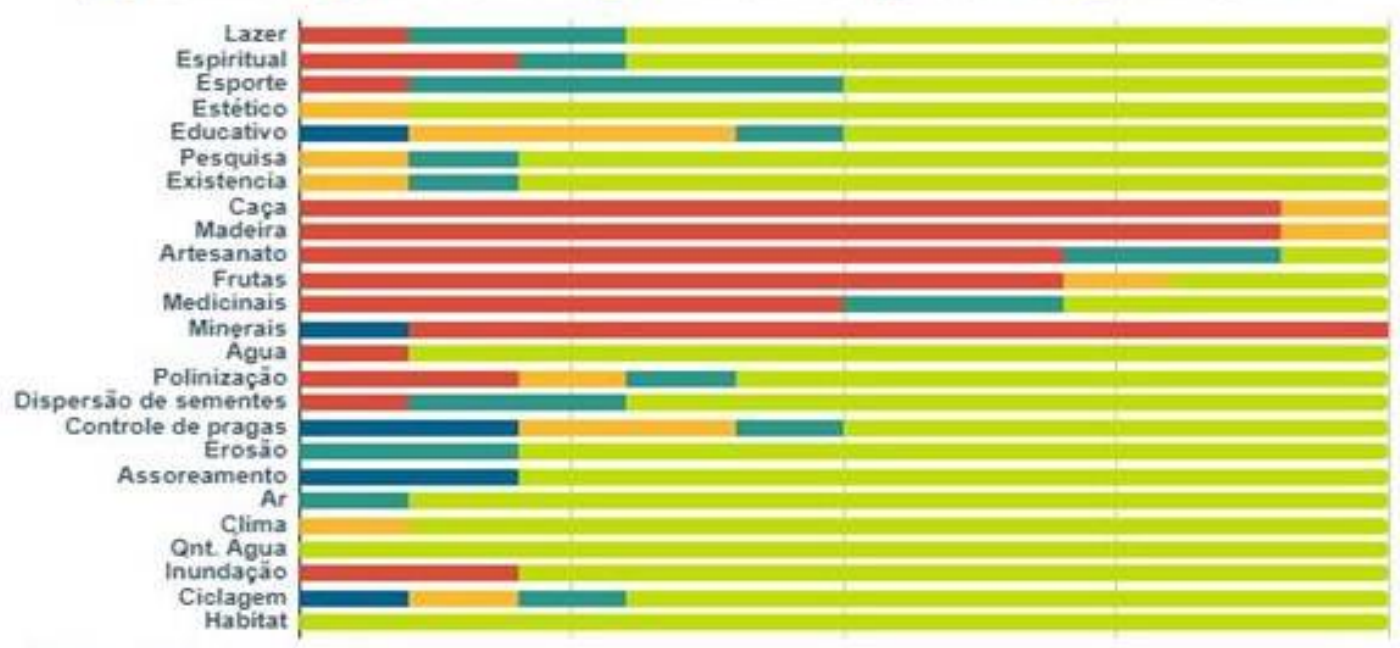

Urbano Năo Frequente

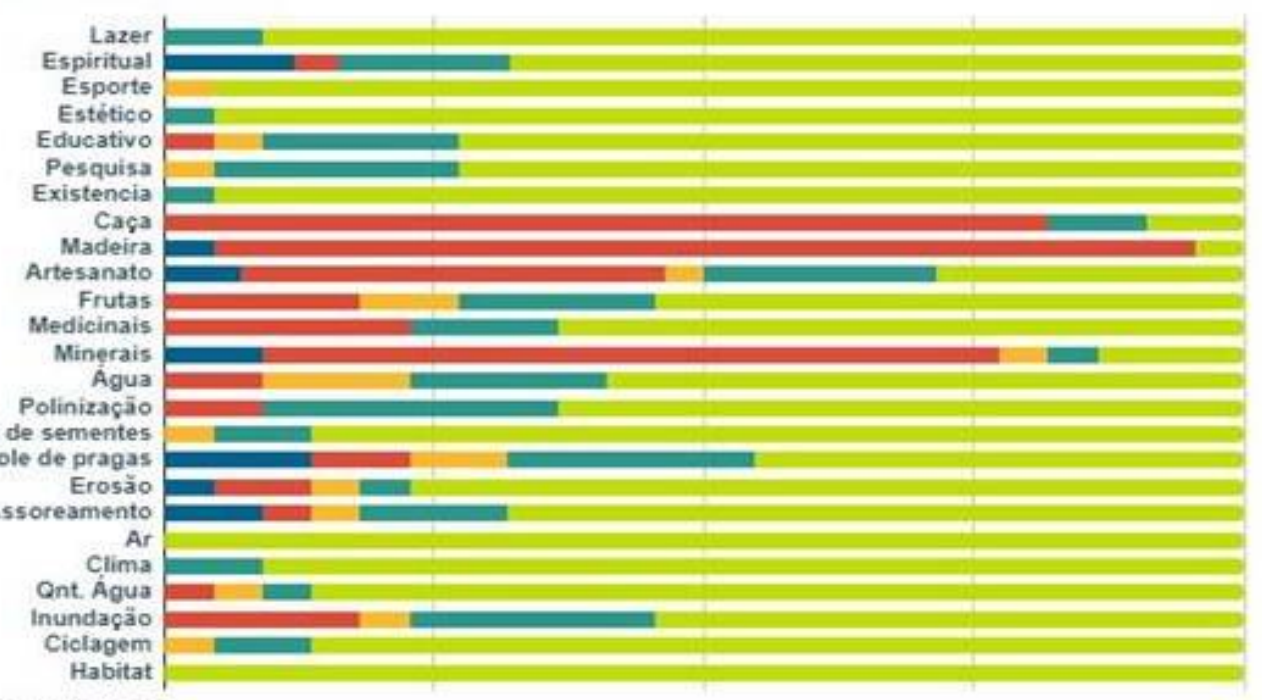

Urbano Frequente

ispersào de sementes Controle de pragas

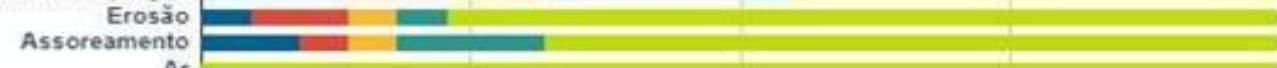
(1) Conas

Undą̧äo Habitat =

Uhano Frequente

Espiritual $=$

Esporte

Estético

Edueativo

Pesquisa 1 an

Existencia $=$

Caca $=$

Madeira $=$

Frutas

Medicinais

Minerais

Polinizaģä̊ Dispersão de seminiząäo Controle de pragas nan wan

Erosä० =a

Assoreamento

Ar

Qnt. Agua

Inundaçäo

Ciclagem $=$

Habitat $0 \%$

$25 \%$

$50 \%$

$75 \%$ 


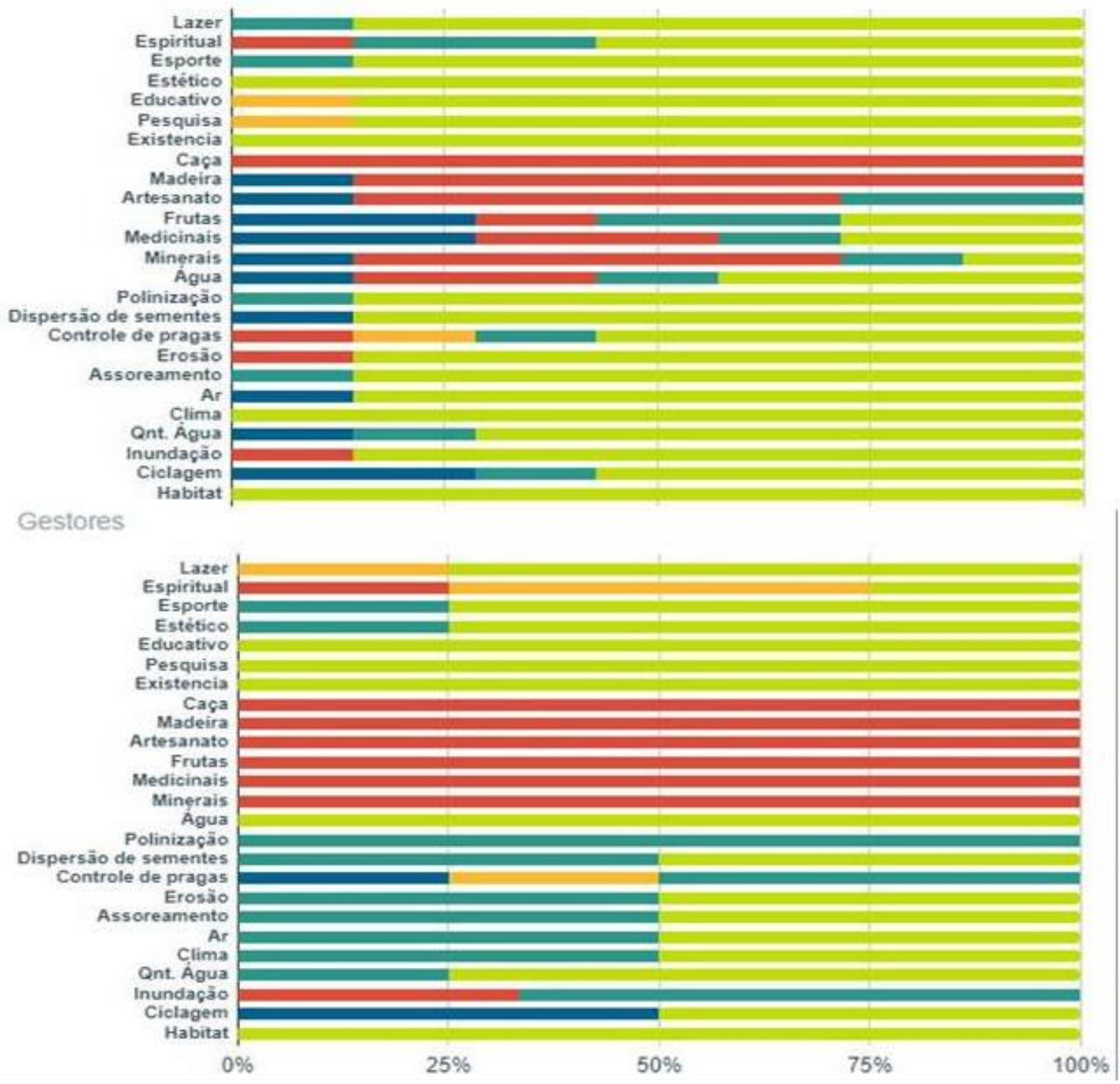

Figura 7: Avalição da percepção dos stakeholders (gestores, moradores urbanos frequentes e não frequentes, moradores da zona rural e turistas) sobre a importância dos serviços ecossistêmicos fornecidos pelo Parque Nacional de Brasília.

Os serviços ecossistêmicos que tiveram um expressivo número de entrevistados que não percebiam ou tinham desconhecimento sobre o tema foram: controle de pragas $(15,5 \%)$, ciclagem de nutrientes $(13,7 \%)$ e assoreamento $(12 \%)$.

\subsection{Diferença de percepção dos stakeholders}

Os grupos não divergem na percepção de importância para a categoria de SE Culturais e de Suporte, ambos com alto valor de importância para todos os stakeholders (Figura 6). A principal diferença concentra-se nos SE de Provisão, com diferença significativa entre o grupo urbano não frequente e os gestores $(p=0,04)$, e entre o grupo urbano não frequente e urbano frequente $(p=0,001)$, onde o grupo urbano não frequente atribui maior valor de importância a 
essa categoria de SE. Para os SE de Regulação, houve diferença significativa entre a importância dada pelos turistas, que foi maior quando comparados aos gestores $(p=0,02)$ - os gestores incluíam na sua percepção a questão da escala - apesar de acharem que o PARNA Brasília é importante para o fornecimento de SE de Regulação, ele não é suficiente para suprir a demanda (ou seja, é necessária uma maior área natural para atender à demanda), como por exemplo, no caso da regulação do clima, onde a alteração climática se dá de forma global.

A comparação da importância entre as categorias de SE dentro de cada grupo de stakeholders (Figura 6) mostra que apesar dos urbanos não frequentes atribuírem uma nota maior aos SE de provisão comparados às outras categorias, esse valor é significativamente menor que o valor dado a todos as outras categorias de SE (cultural - $\mathrm{p}=0,0002$, regulação $p=0,0003$ e suporte - $p=0,0002$ ), os SE de regulação também possuem um valor de importância significativamente menor que os de suporte $(p=0,02)$. Para os rurais, os SE de provisão são significativamente menos importantes que todos os outros SE (culturais $p=0,001$, regulação - $p=0,001$ e suporte - $p=0,005)$. Os turistas também diferem significativamente dando menor valor aos serviços de provisão quando comparados aos de regulação $(p=0,03)$. Assim como os urbanos frequentes, que também atribuem menor valor de importância aos SE de provisão comparados aos culturais $(p=0,0002)$, de regulação $(p=0,0002)$ e de suporte $(p=0,001)$. Para esse grupo, $o$ valor dado aos SE de suporte são significativamente maiores que aos SE Culturais $(p=0,013)$ e SE de regulação $(p=0,002)$. Os gestores não apresentaram diferença significativa entre diferentes categorias de $\mathrm{SE}$, mesmo nos casos em que a diferença pode ser vista no gráfico, dado o número baixo de entrevistados (Material Suplementar S2 - Tabela 2). 

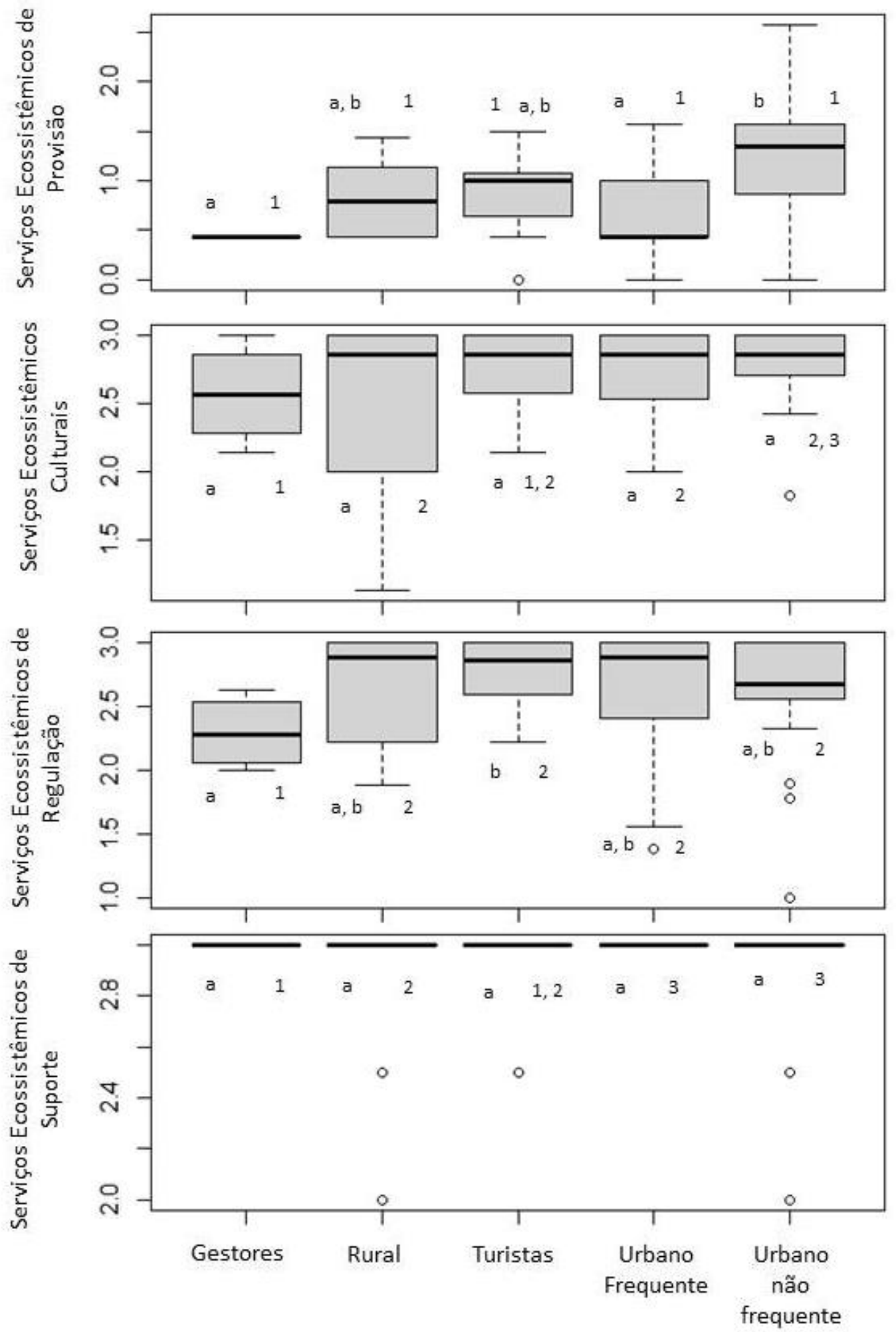

Figura 8: Boxplots com avaliações dos serviços ecossistêmicos de provisão, cultural, regulação e suporte (eixo vertical) pelos grupos sociais de gestores $(n=4)$, rural $(n=10)$, turistas $(n=7)$, urbano frequente $(n=15)$ e urbano não frequente $(n=22)$ no eixo horizontal. A linha central dos retângulos representa a mediana das avaliações sobre o valor de importância dos serviços ecossistêmicos e as extremidades inferior e superior os limites do segundo e terceiro quartis dos dados respectivamente. As letras representam significância das diferenças entre as medianas dentro de cada serviço ecossistêmico (comparação no plano horizontal) e os números representam significância das diferenças entre as medianas em por grupo social (comparação no plano vertical). A significância da diferença entre as medianas foi estimada por comparações pareadas com reamostragem em 10.000 aleatorizações cada. 


\subsection{Influência das características demográficas}

A comparação entre os gêneros feminino $(n=27)$ e masculino $(n=31)$ não revelou diferença significativa para a nota de valor de importância dada para nenhuma categoria de SE - cultural, provisão, regulação e suporte (Figura 7) (Material Suplementar S2 - Tabela 3).
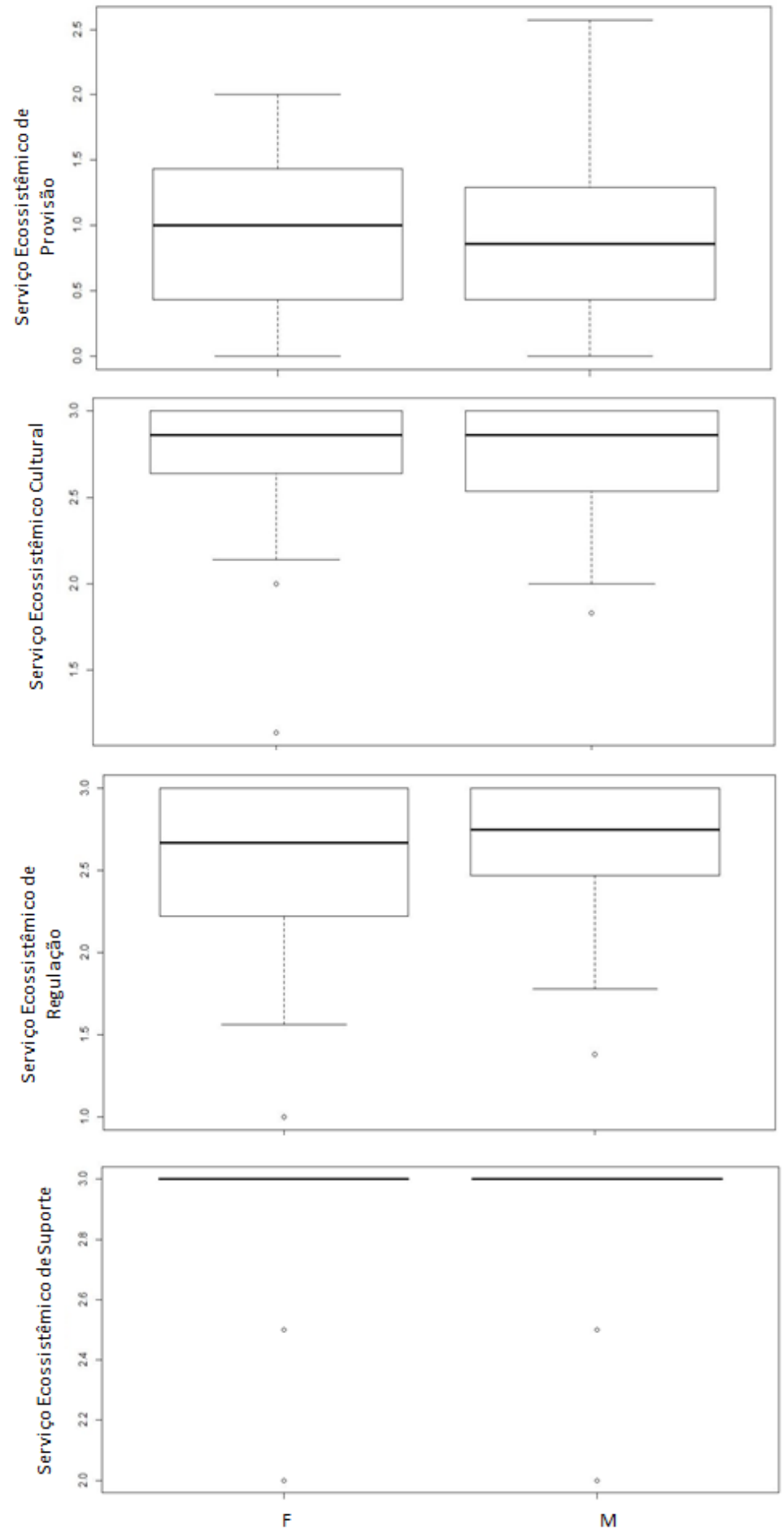

Figura 7: Boxplots com avaliações dos serviços ecossistêmicos de provisão, cultural, regulação e suporte (eixo vertical) pela característica demográfica de gênero feminino (F) e masculino (M) no eixo horizontal. A linha central dos retângulos representa a mediana das avaliações e as extremidades inferior e superior os limites do segundo e terceiro quartis dos dados respectivamente. A significância da diferença entre as medianas foi estimada por comparações pareadas com reamostragem em 10.000 aleatorizações cada. 
Para a análise da escolaridade, houve diferença significativamente maior para o valor de importância dado aos SE de Provisão pelos entrevistados com escolaridade EM em comparação aos EF $(p=0,02)$, e entre os EM e os $S(p=0,02)$ (Figura 8). Para os outros grupos não houve diferença significativa (Material Suplementar S2 - Tabela 4).
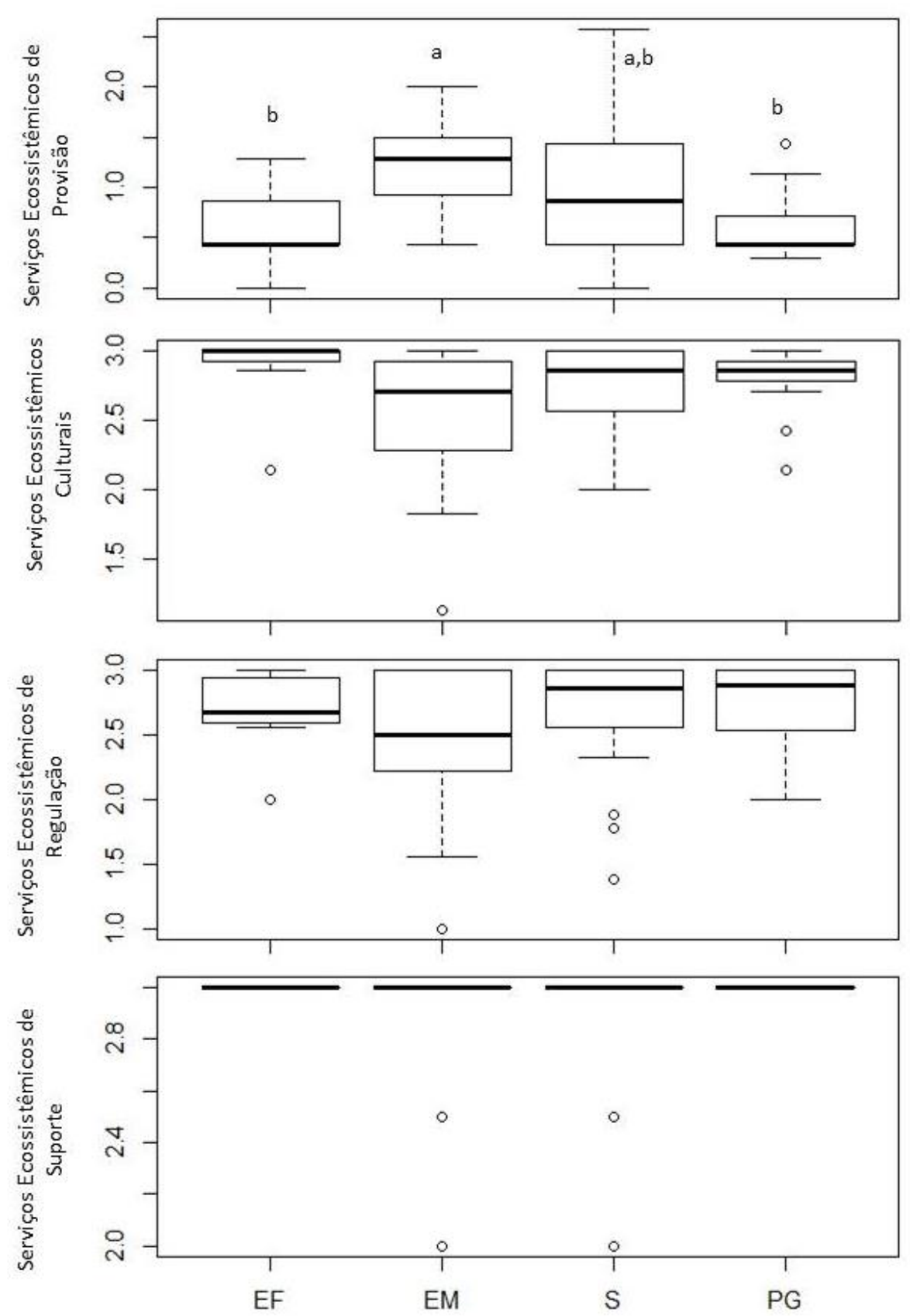

Figura 9: Boxplots com avaliações dos serviços ecossistêmicos de provisão, cultural, regulação e suporte (eixo vertical) pela característica demográfica de escolaridade ensino fundamental (EF), ensino médio (EM), ensino superior (S) e pós-graduação (PG) no eixo horizontal. A linha central dos retângulos representa a mediana das avaliações e as extremidades inferior e superior os limites do segundo e terceiro quartis dos dados respectivamente. A significância da diferença entre as medianas foi estimada por comparações pareadas com reamostragem em 10.000 aleatorizações cada. As letras representam significância das diferenças entre as medianas dentro de cada serviço ecossistêmico (comparação no plano horizontal). 
E por fim, analisamos a variável idade (Material Suplementar S2 - Tabela 5). 0 resultado da regressão linear sugere que a idade é um fator significativo $(p=0,02)$ para os valores de importância declarados pelos entrevistados em relação ao SE de Regulação quanto maior a idade, maior o valor dado a esse grupo de SE (Figura 9). No entanto, a idade é uma característica que explica muito pouco a variabilidade desses dados $R^{2}=0,09$.

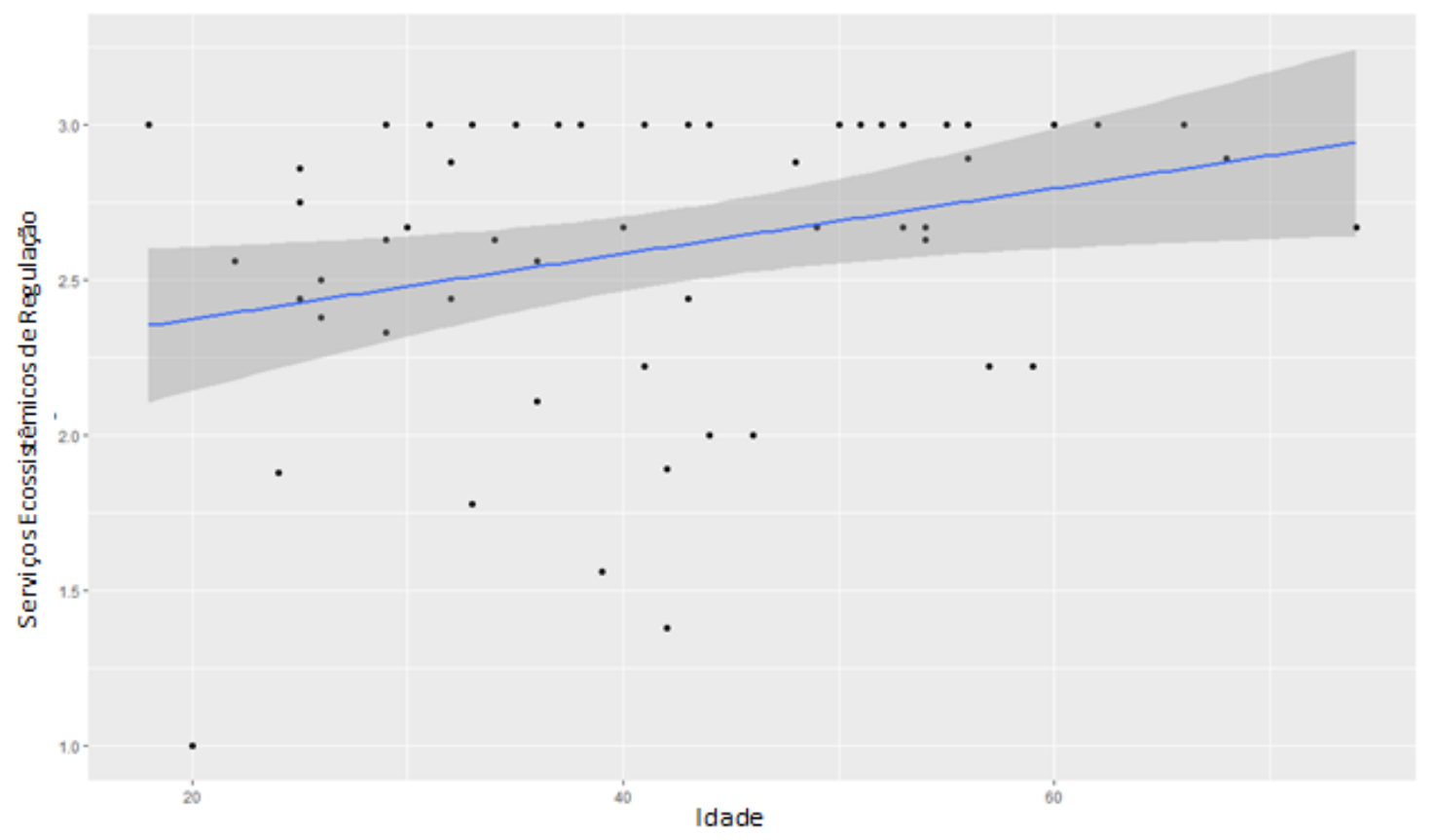

Figura 10: Regressão Linear das notas de importância média dada aos serviços ecossistêmicos de regulação com a idade como variável preditora. Os pontos representam cada entrevistado e a linha em azul representa a linha de tendência.

Analisamos também a variável "contato com a natureza ao longo da vida" para analisar se esse fator poderia ter influência nos valores dos stakeholders (Material Suplementar S2 Tabela 6). Houve diferença significativa para a categoria de SE de Provisão $(p=0,02)$, com os entrevistados que não tiveram esse contato (grupo "não"), atribuindo maior valor à esse tipo de SE em comparação aos que tiveram, sendo ela dada exclusivamente por áreas protegidas ou não (grupo "sim") (Figura 10). 

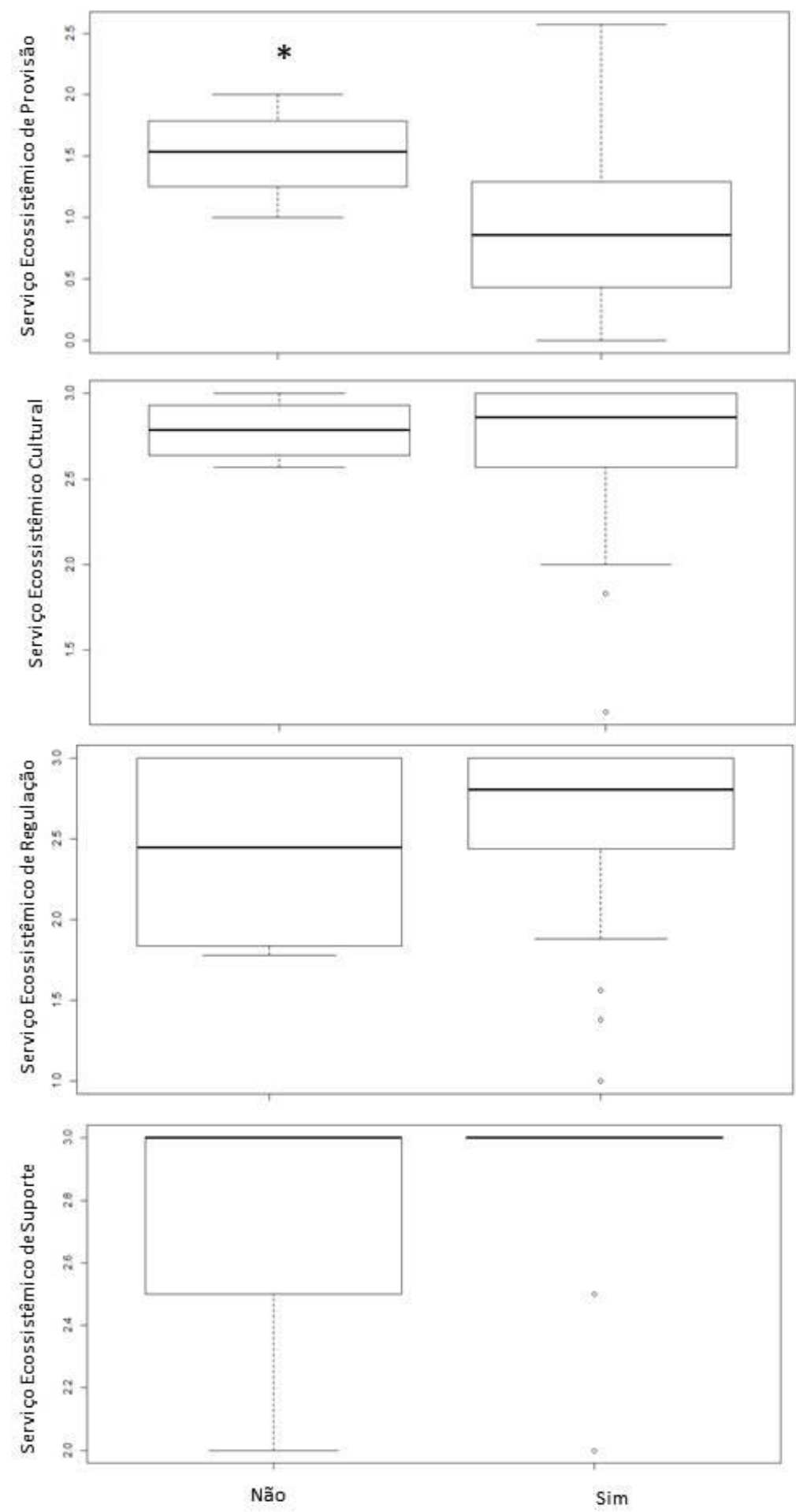

Figura 10: Boxplots com avaliações dos serviços ecossistêmicos de provisão, cultural, regulação e suporte (eixo vertical) pela variável "contato com a natureza ao longo da vida" respostas negativas (Não) e positivas (Sim) no eixo horizontal. A linha central dos retângulos representa a mediana das avaliações e as extremidades inferior e superior os limites do segundo e terceiro quartis dos dados respectivamente. A significância da diferença entre as medianas foi estimada por comparações pareadas com reamostragem em 10.000 aleatorizações cada. O símbolo $\left({ }^{*}\right)$ representa significância das diferenças entre as medianas dentro de cada serviço ecossistêmico (comparação no plano horizontal). 


\subsection{Tendência de declínio dos serviços ecossistêmicos}

Em nível regional, 42 entrevistados residiam no local há mais de 10 anos e participaram dessa etapa da entrevista. A provisão de habitat foi o SE que obteve $95,2 \%$ das respostas com percepção de declínio, seguido pela quantidade de água (83,3\%) e qualidade do ar (71,4\%). Relacionamos a quantidade de entrevistados que percebiam o SE como em declínio e a quantidade de entrevistados que classificaram esses mesmos serviços como importantes na etapa anterior (classificação dos serviços como importante, nota 2, ou muito importante, nota 3) (Figura 6). O teste de correlação de Spearman mostra que há correlação positiva significativa entre a percepção de declínio dos SE e a importância que o SE tem para os entrevistados $(p=0,01)$, ou seja, quanto maior a percepção de declínio, maior a percepção de importância daquele SE.

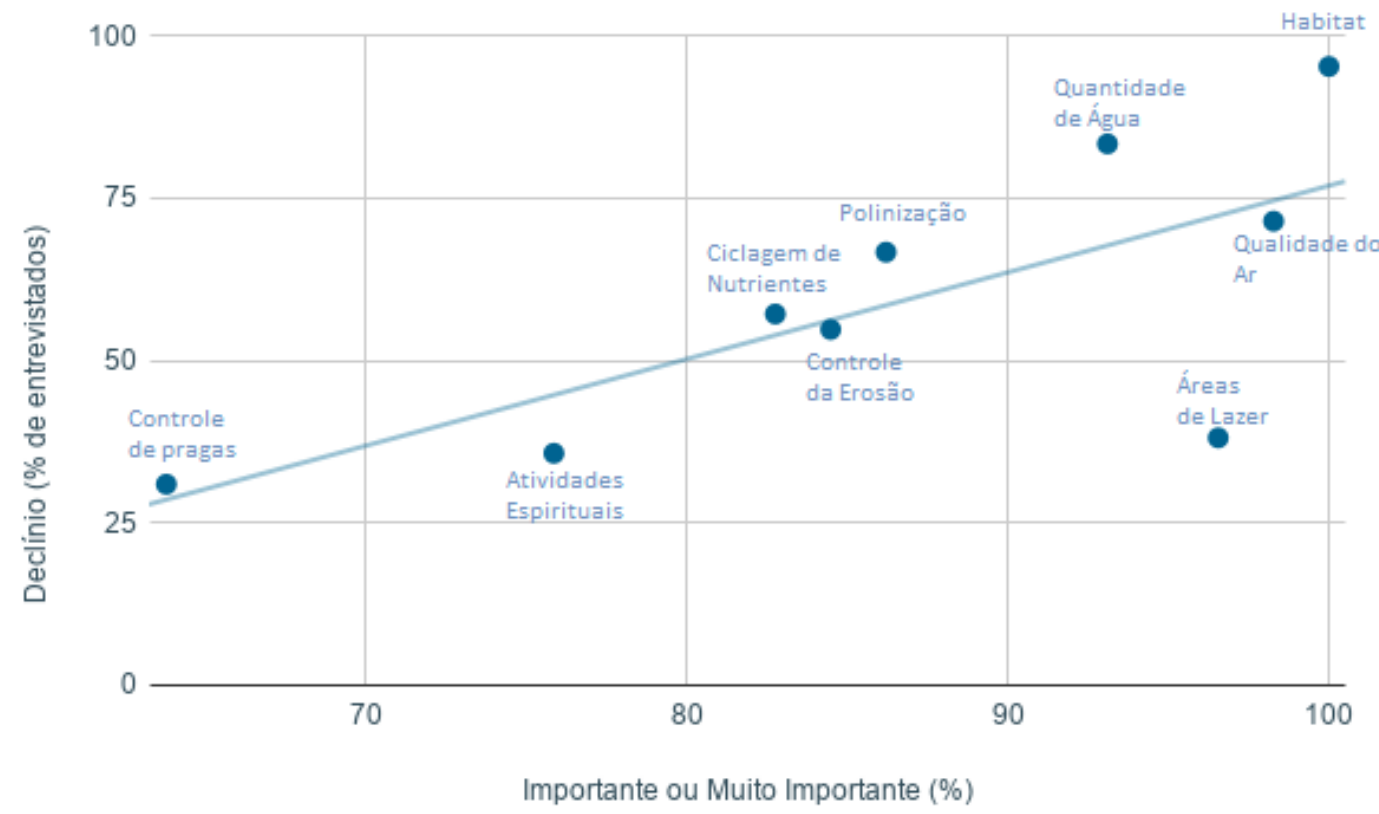

Figura 11: Analise de correlação entre a percepção de importância e declínio dos serviços ecossistêmicos. O eixo y retrata a porcentagem de entrevistados que classificou os diversos serviços ecossistêmicos (ponto azul) como em declínio, no eixo x encontra-se a porcentagem de entrevistados que classificou cada serviço ecossistêmico avaliado como importante ou muito importante.

\subsection{Visão dos gestores}

Os principais problemas atuais apontados pelos gestores incluem: conflitos com serviços de provisão (caça e pesca, extração de madeira, conflitos no uso da água), invasão de espécies exóticas (flora e fauna, principalmente pela invasão de animais domésticos como cachorros), atropelamento de fauna e afugentamento de fauna pelo impacto do entorno (barulho), falta de corredor ecológico ligando a outras áreas naturais e conflitos fundiários (invasão e regularização fundiária).

Todos os entrevistados do grupo "gestores" acreditam que a abordagem de serviços ecossistêmicos pode auxiliar na melhoria da gestão e resolução de conflitos, ajudando tanto para um planejamento com maior suporte de dados, como também como auxiliando no 
direcionamento para a tomada de decisão, facilitando a comunicação com a população e como uma ferramenta para educação ambiental.

\section{Discussão}

6.1. Valorização das áreas protegidas

Um dos principais riscos para as áreas protegidas deriva de um sistema de planejamento territorial polarizado, em que as áreas naturais, muitas vezes protegidas por 'cercas e muros', estão inseridas em uma matriz territorial ecologicamente degradada (de Fries et al. 2007). Uma questão de planejamento de importância crítica em muitas paisagens dominadas pelo homem é como organizar espacialmente áreas de cobertura natural dentro de uma matriz antropizada (Brosi et.al, 2008; Lin \& Fuller, 2013). Em nossa pesquisa, revelaram-se duas faces dessa matriz: a importância das áreas protegidas para promover o contato com a natureza, que muitas vezes é o único meio de se ter esses benefícios, principalmente para ambientes urbanos e, como consequência, aumentar o bem-estar da população, assim como os conflitos em relação às atividades permitidas na zona tampão e conflitos fundiários.

Os resultados das entrevistas com todos os stakeholders indicam que a provisão de habitat para as espécies foi percebida como o serviço ecossistêmico mais importante, o que é fundamental, pois um dos objetivos finais das áreas protegidas é a conservação da biodiversidade e seus habitats, de acordo com a Internacional Union for Conservation of Nature (IUCN, 2008) e a legislação brasileira (Lei 9985/2000).

A ênfase da importância foi principalmente para a categoria de SE culturais, tanto da etapa da entrevista aberta quanto da nota baseada na escala Likert. Alguns serviços ecossistêmicos tinham alto valor de importância mesmo por aqueles entrevistados que não eram beneficiários diretos (ex: pessoas que deram alto valor de importância para atividades de lazer e recreação, mas não frequentavam o PARNA Brasília). Scholte et.al. (2015) define que os valores socioculturais podem ser auto orientados ou orientados a outros: neste último caso, os indivíduos valorizam os objetos sem pensar em seu próprio bem, mas pensando no que é bom para a sociedade como um todo.

Ainda nesse sentido, outro SE que foi avaliado com alto grau de importância foi o de existência do PARNA Brasília, que é um valor intrínseco, onde a pessoa atribui valor por saber que o recurso existe, mesmo que ela nunca venha a utilizar esse recurso diretamente (MEA, 2003). Essa é uma consideração ética que envolve a ciência da conservação e que métodos de economia ambiental podem falhar em capturar. A avaliação monetária dos SE foca sua atenção nos SE que podem ser abordados com relativa facilidade por métodos baseados no mercado (especialmente os SE de provisão), enquanto os SE menos tangíveis acabam não recebendo a mesma atenção (Scholte et.al. 2015). No entanto, há grande complexidade na interação entre o funcionamento do ecossistema e suas contribuições para o bem-estar e o próprio bem-estar humano, razão pela qual cada vez mais autores pontuam a necessidade de uma abordagem pluralista ao realizar avaliações de SE (Chan et.al. 2016, Chan et. al., 2012b, Spangenberg and Settele, 2010, Kumar and Kumar, 2008). As avaliações socioculturais são importantes e necessárias para complementar os atuais métodos de avaliações monetárias de SE (Scholte et.al. 2015). 
De maneira geral, a população parece compreender e valorizar o PARNA Brasília conforme seus objetivos de criação e de maneira compatível com as atividades permitidas, tanto do ponto de vista dos SE Culturais, como também na importância para SE de Regulação e de Suporte, principalmente na provisão de habitat. Dentre os serviços de provisão, a água se destaca com alto grau de importância. De fato, o PARNA Brasília possui uma barragem de água e importantes nascentes que fazem parte do Sistema Santa Maria, responsável por abastecer $29 \%$ do Distrito Federal. Outro fato a ser destacado é que a região sofreu intensas secas nos últimos anos, evidenciando ainda mais a importância do local para este fim. O fato mostra como a abordagem de serviços ecossistêmicos pode ajudar na compreensão da importância desses espaços protegidos.

Os resultados também mostraram que, apesar de não estarem entre os serviços ecossistêmicos mais importantes, caça, extração de madeira e minerais, além de coleta de plantas medicinais, para artesanato e frutas apareceram como algum grau de importância, principalmente para o grupo urbano não frequente. Nenhum entrevistado se identificou como beneficiário da prática. Estas são atividades proibidas no local e revelam um importante tradeoff com outros serviços, como o de provisão de habitat, além da necessidade de maior conscientização sobre as atividades permitidas dentro da AP e seus limites territoriais. Dessa maneira, explicitamos a importância de se utilizar avaliações socioculturais de serviços ecossistêmicos como uma ferramenta incorporar uma ampla gama de SE nas avaliações (Iniesta-Arandia et.al. 2014), visto que o objetivo final não é ter uma medida específica sobre um serviço, mas sim, tornar explícito diferentes interesses (Chan et.al. 2012).

O fato dos SE menos percebidos serem controle de pragas, assoreamento e ciclagem de nutrientes pode estar relacionado com a tendência das pessoas a identificarem os SE que podem ser percebidas pelos sentidos (Lewan e Söderqvist, 2002), necessitando um maior grau de abstração no caso desses tipos de serviços ecossistêmicos. Lewan e Söderqvist (2002) discutem que tantos os percebidos pelos sentidos, como os que não o são, necessitam de conhecimento para serem entendidos. Mas, embora o conhecimento necessário para entender alguns dos SE possa se basear na experiência, o entendimento de outros depende do aprendizado teórico.

\subsection{Valores dos Stakeholders}

As análises revelaram que o valor de importância dado aos serviços ecossistêmicos é variável entre os stakeholders, ou seja, diferentes partes interessadas mantêm diferentes valores e percepções em relação aos serviços ecossistêmicos, como já encontrado anteriormente em outros trabalhos, como Bertín-Lopez et. al.(2012). Mas diferentemente desses autores, não houve um claro gradiente rural-urbano, sendo necessárias maiores informações para explorar essa questão (como uma amostra maior e mais balanceada em relação ao número de entrevistados entre os grupos).

A diferença entre os stakeholders ocorreu principalmente em decorrência dos valores relacionados aos SE de provisão percebidos pela população urbana não frequente. A maior importância dada aos SE de provisão pode estar relacionado tanto ao desconhecimento da legislação e das atividades permitidas - visto que alguns entrevistados não se declararam como beneficiários desses SEs - como também por práticas das atividades ilegais, sendo 
necessários maiores investigações sobre as motivações por essa demanda. Cabe destacar que a população rural, apesar de também não frequentar o PARNA, reconhece uma ampla gama de serviços ecossistêmicos e, mesmos os entrevistados que possuem moradia dentro dos limites do PARNA Brasília, não declararam a importância do uso de serviços ecossistêmicos de provisão. O grupo urbano não frequente é o grupo de moradores locais dos quais alguns entrevistados não tiveram contato com a natureza ao longo da vida. Campos Tisovec-Dufner et.al. 2019 constaram que o contato com a floresta pode ter um efeito indireto sobre a intenção de preservar, influenciando positivamente os usos da floresta. No caso deste grupo, o efeito pode ter sido o oposto, a falta de contato com a natureza faz com que se tenham percepções diferentes sobre a importância dos diferentes serviços ecossistêmicos, e como consequência, uma diferente conexão homem-natureza. No entanto, o número de entrevistados que tiveram respostas negativas em relação ao contato com a natureza ao longo da vida é restrito, sendo necessárias maiores investigações.

\subsection{Incorporando os stakeholders para priorizar ações de conservação}

Os resultados revelaram que a visão sobre a tendência de alguns SE possui uma alta correlação entre o valor de importância e a percepção do declínio. Levantamos a hipótese de que SE que estão em forte declínio e que são mais tangíveis, ou seja, mais percebidos pelos sentidos, possuem maior valor. Vale ressaltar que os resultados podem não refletir o que de fato está em maior ou menor declínio, visto que são baseados em uma percepção não técnicocientífica. Dessa forma, a abordagem participativa (gestores, especialistas e população) pode não determinar o declínio de um SE, mas sim, ser usada para indicar caminhos para a priorização de ações de manejo que conciliem expectativas da população com os objetivos da conservação e, com isso, obter o apoio dos diversos atores envolvidos na conservação ambiental. A promoção de um maior envolvimento dos usuários dos serviços ecossistêmicos no gerenciamento das áreas protegidas é fundamental, pois eles influenciam as decisões de conservação e são influenciadas por essas decisões, mas também é importante para alcançar planos mais inclusivos, apoiados, realistas e transparentes (Ban et al. 2013)

\section{Conclusões}

Nossos resultados mostram a importância do Parque Nacional de Brasília sob o ponto de vista de diferentes stakeholders, incluindo a população do entorno, que é diretamente afetada pela criação do Parque. Uma parte expressiva dos entrevistados teve o contato com a natureza durante a vida exclusivamente através de áreas protegidas, deixando ainda mais evidente a importância desses espaços para o bem-estar humano. A abordagem de serviços ecossistêmicos revelou trade-offs e alguns conflitos existentes, dados principalmente por serviços de provisão. Os resultados também revelaram que a percepção dos stakeholders varia pouco entre os grupos, com algumas divergências dado pelos SE de provisão.

Por outro lado, os entrevistados valorizam o PARNA Brasília em acordo com os objetivos da criação dessa área protegida, independentemente da frequência de visitação, como provisão de habitat e por valores intrínsecos (serviço ecossistêmico de existência), além das atividades de visitação. Além disso, houve valorização de serviços não somente por valores individuais, como também por valores coletivos, já que entrevistados deram alto valor de 
importância para SE em que não eram beneficiários diretos. Houve uma correlação expressiva entre o valor de importância e a percepção de declínio de alguns SE.

A abordagem de serviços ecossistêmicos pode ser promissora para facilitar a comunicação com a população, além de poder revelar trade-offs importantes. Além disso, abordar a importância e a tendência dos serviços ecossistêmicos em escala local sob o ponto de vista da população pode ser importantes informações na determinação de prioridades para a tomada de decisão sobre o manejo do ecossistema (Iniesta-Arandia et.al. 2014), alinhando as expectativas da população com os objetivos da conservação, podendo resultar em um importante apoio para essa estratégia de conservação.

\section{Agradecimentos}

Nós gostaríamos de agradecer o ICMBio e o Parque Nacional de Brasília pelo apoio dado à realização das pesquisas. Também agradecemos ao Dr. Leandro Reverberi Tambosi pelas opiniões para melhorar esta pesquisa. Este trabalho foi financiado pelo Conselho Nacional de Desenvolvimento Científico e Tecnológico (CNPq) [168722/2018-6]; Instituto de Pesquisas Tecnológicas (IPT) - Programa Novos Talentos Edital 01/2018; e Coordenação de Aperfeiçoamento de Pessoal de Nível Superior - Brasil (CAPES) - [88887.506471/2020-00].

\section{Bibliografia}

Allendorf, T. D., \& Yang, J. M. (2017). The role of gender in local residents' relationships with Gaoligongshan Nature Reserve, Yunnan, China. Environment, Development and Sustainability, 19(1), 185-198.

Ban, N. C., Mills, M., Tam, J., Hicks, C. C., Klain, S., Stoeckl, N., ... \& Chan, K. M. (2013). A socialecological approach to conservation planning: embedding social considerations. Frontiers in Ecology and the Environment, 11(4), 194-202.

Brosi, B. J., Armsworth, P. R., \& Daily, G. C. (2008). Optimal design of agricultural landscapes for pollination services. Conservation Letters, 1(1), 27-36.

Campos, M. T., \& Nepstad, D. C. (2006). Smallholders, the Amazon's new conservationists. Conservation Biology, 20(5), 1553-1556.

Campos Tisovec-Dufner, K., Teixeira, L., Marin, G. D. L., Coudel, E., Morsello, C., \& Pardini, R. (2019). Intention of preserving forest remnants among landowners in the Atlantic Forest: The role of the ecological context via ecosystem services. People and Nature, 1(4), 533-547.

Chan, K. M., Balvanera, P., Benessaiah, K., Chapman, M., Díaz, S., Gómez-Baggethun, E., ... \& Luck, G. W. (2016). Opinion: Why protect nature? Rethinking values and the environment. Proceedings of the National Academy of Sciences, 113(6), 1462-1465.

Chan, K. M., Guerry, A. D., Balvanera, P., Klain, S., Satterfield, T., Basurto, X., ... \& Hannahs, N. (2012). Where are cultural and social in ecosystem services? A framework for constructive engagement. BioScience, 62(8), 744-756. 
${ }^{b}$ Chan, K. M., Satterfield, T., \& Goldstein, J. (2012). Rethinking ecosystem services to better address and navigate cultural values. Ecological Economics, 74, 8-18.

CNUC, Cadastro Nacional de Unidades de Conservação, Brasil (2019) . Disponível em: $<$ https://app.powerbi.com/view?r=eyJrljoiMjUxMTUONWMtODkyNCOONzNiLWJiNTQtNGI3NTI 2NjlizDkzliwidCI6ljM5NTdhMzY3LTZkMzgtNGMxZi1hNGJhLTMzZThmM2M1NTBINyJ9> Acesso em: $27 / 03 / 2020$

Costanza, R., De Groot, R., Sutton, P., Van der Ploeg, S., Anderson, S. J., Kubiszewski, I., ... \& Turner, R. K. (2014). Changes in the global value of ecosystem services. Global Environmental Change, 26, 152-158.

Cumming, G. S., Allen, C. R., Ban, N. C., Biggs, D., Biggs, H. C., Cumming, D. H., ... \& Mathevet, R. (2015). Understanding protected area resilience: a multi-scale, social-ecological approach. Ecological Applications, 25(2), 299-319.

De Groot, R. S., Wilson, M. A., \& Boumans, R. M. (2002). A typology for the classification, description and valuation of ecosystem functions, goods and services. Ecological Economics, 41(3), 393-408.

DeFries, R., Hansen, A., Turner, B. L., Reid, R., \& Liu, J. (2007). Land use change around protected areas: management to balance human needs and ecological function. Ecological Applications, 17(4), 1031-1038.

DISTRITO FEDERAL. 2017. Plano integrado de enfrentamento a crise hídrica. Governo de Brasilia. Disponível em: <https://www.agenciabrasilia.df.gov.br/wpconteudo/uploads/2017/03/plano-integrado-de-enfrentamento-a-crise-hidrica-governo-debrasilia.pdf >. Acesso em julho de 2020.

Dudley, N. (Ed.). (2008). Guidelines for applying protected area management categories. IUCN.

Dudley, N., Higgins-Zogib, L., Hockings, M., MacKinnon, K., Sandwith, T., \& Stolton, S. (2011). National parks with benefits: how protecting the planet's biodiversity also provides ecosystem services. Solutions (Burlington): For a Sustainable and Desirable Future, 2(6), 87-95.

Folke, C. (2006). The economic perspective: conservation against development versus conservation for development. Conservation Biology, 20(3), 686-688.

Forzza, R. C., Baumgratz, J. F. A., Bicudo, C. E. M., Canhos, D. A., Carvalho Jr, A. A., Coelho, M. A. N., ... \&amp; Lohmann, L. G. (2012). New Brazilian floristic list highlights conservation challenges. BioScience, 62(1), 39-45.

García-Llorente, M., Harrison, P. A., Berry, P., Palomo, I., Gómez-Baggethun, E., IniestaArandia, I., ... \& Martín-López, B. (2018). What can conservation strategies learn from the ecosystem services approach? Insights from ecosystem assessments in two Spanish protected areas. Biodiversity and Conservation, 27(7), 1575-1597. 
García-Nieto, A. P., Quintas-Soriano, C., García-Llorente, M., Palomo, I., Montes, C., \& MartínLópez, B. (2015). Collaborative mapping of ecosystem services: The role of stakeholders' profiles. Ecosystem Services, 13, 141-152.

Iniesta-Arandia, I., García-Llorente, M., Aguilera, P. A., Montes, C., \& Martín-López, B. (2014). Socio-cultural valuation of ecosystem services: uncovering the links between values, drivers of change, and human well-being. Ecological Economics, 108, 36-48.

Kovács, E., Kelemen, E., Kalóczkai, Á., Margóczi, K., Pataki, G., Gébert, J., ... \& Mihók, B. (2015). Understanding the links between ecosystem service trade-offs and conflicts in protected areas. Ecosystem Services, 12, 117-127.

Kumar, M., \& Kumar, P. (2008). Valuation of the ecosystem services: a psycho-cultural perspective. Ecological Economics, 64(4), 808-819.

Lewan, L., \& Söderqvist, T. (2002). Knowledge and recognition of ecosystem services among the general public in a drainage basin in Scania, Southern Sweden. Ecological Economics, 42(3), 459-467.

Lin, B. B., \& Fuller, R. A. (2013). Sharing or sparing? How should we grow the world's cities?. Journal of Applied Ecology, 50(5), 1161-1168.

Liu, J., Linderman, M., Ouyang, Z., An, L., Yang, J., \& Zhang, H. (2001). Ecological degradation in protected areas: the case of Wolong Nature Reserve for giant pandas. Science, 292(5514), 98101.

Martín-López, B., Iniesta-Arandia, I., García-Llorente, M., Palomo, I., Casado-Arzuaga, I., Del Amo, D. G., ... \& González, J. A. (2012). Uncovering ecosystem service bundles through social preferences. PLoS One, 7(6).

Meyerson, L. A., Baron, J., Melillo, J. M., Naiman, R. J., O'Malley, R. I., Orians, G., ... \& Sala, O. E. (2005). Aggregate measures of ecosystem services: can we take the pulse of nature?. Frontiers in Ecology and the Environment, 3(1), 56-59.

Myers, N., Mittermeier, R. A., Mittermeier, C. G., Da Fonseca, G. A., \&amp; Kent, J. (2000). Biodiversity hotspots for conservation priorities. Nature, 403(6772), 853.

Millennium Ecosystem Assessment (2003). Ecosystems and human well-being: A framework for assessment. Report of the Conceptual Framework Working Group of the Millennium Ecosystem Assessment.

Millennium Ecosystem Assessment (2005). Ecosystems and human well-being: wetlands and water. World Resources Institute.

Oksanen, J., Blanchet, F. G., Friendly, M., Kindt, R., Legendre, P., McGlinn, D., ... \& Stevens, M. H. H. (2017). Vegan: community ecology package. 2017. R package version 2.4-5.

Oksanen, J., Blanchet, F. G., Kindt, R., Legendre, P., Minchin, P. R., O’hara, R. B., ... \& Oksanen, M. J. (2013). Package 'vegan'. Community ecology package, version, 2(9), 1-295. 
Palomo, I., Martín-López, B., Zorrilla-Miras, P., Del Amo, D. G., \& Montes, C. (2014). Deliberative mapping of ecosystem services within and around Doñana National Park (SW Spain) in relation to land use change. Regional Environmental Change, 14(1), 237-251.

Paul, S., \& Nagendra, H. (2017). Factors influencing perceptions and use of urban nature: Surveys of park visitors in Delhi. Land, 6(2), 27.

R Core Team (2017). R: A language and environment for statistical computing.

Scholte, S. S., Van Teeffelen, A. J., \& Verburg, P. H. (2015). Integrating socio-cultural perspectives into ecosystem service valuation: a review of concepts and methods. Ecological Economics, 114, 67-78.

Sodhi, N. S., Lee, T. M., Sekercioglu, C. H., Webb, E. L., Prawiradilaga, D. M., Lohman, D. J., ... \& Ehrlich, P. R. (2010). Local people value environmental services provided by forested parks. Biodiversity and Conservation, 19(4), 1175-1188.

Spangenberg, J. H., \& Settele, J. (2010). Precisely incorrect? Monetising the value of ecosystem services. Ecological Complexity, 7(3), 327-337.

Walde, J. F., Huy, D. T., Tappeiner, U., \& Tappeiner, G. (2019). A protected area between subsistence and development. International Journal of the Commons, 13(1), 175-204. DOI: http://doi.org/10.18352/ijc.844

Watson, J. E., Dudley, N., Segan, D. B., \& Hockings, M. (2014). The performance and potential of protected areas. Nature, 515(7525), 67-73. 
Material Suplementar S1 - Capítulo 2.

Roteiro I - Entrevista para levantamento da Percepção dos SE - População

\begin{tabular}{|c|l|}
\hline $\begin{array}{c}\text { Universidade de São Paulo } \\
\text { Instituto de Biociências }\end{array}$ & Data da entrevista: __o19 Entrevistador: \\
$\begin{array}{c}\text { Projeto: Áreas Protegidas como mantenedores de Serviços Ecossistêmicos em } \\
\text { sistemas socioecológicos: percepção e mapeamento no Cerrado }\end{array}$ & Ponto no GPS: \\
Lat: & UC:
\end{tabular}

\begin{tabular}{|l|l|}
\hline IDENTIFICAÇÃO DO ENTREVISTADO \\
\hline № & GRUPO: \\
\hline
\end{tabular}

Nota: os trechos em itálico são instruções ao entrevistador e não devem ser lido às pessoas entrevistadas.

Começar a entrevista com uma breve introdução. Lembre-se de se apresentar à pessoa. Ex:

1. Boa dia/tarde, sou/somos pesquisadores da Universidade de São Paulo (USP), falar NOMES! Estamos realizando esta entrevista pa ra entender como as pessoas se beneficiam das áreas protegidas da região. Hoje gostaríamos de conversar sobre a (nome da UC).

2. O senhor(a) teria um tempinho para nos ajudar? Nossa conversa deve demorar em torno de 10-15 minutos, mas se tiver muito ocupado(a) agora, podemos combinar um horário para retornar quando for melhor. $\quad$ NOME: 
NOTA: Se a pessoa topar, seguir próximos passos:

3. Gostaríamos de agradecer a participação. Pedimos licença para poder anotar e gravar durante a entrevista, porque são muitas coisas para conseguir lembrar de cabeça. E queremos que sua resposta seja exatamente o que foi dito. Sua identidade não será revelada no estudo.

NOTA: Lembre-se de sempre retomar o contato visual com o entrevistado, mesmo quando esteja anotando! Mostre que está prestando atenção. Retome coisas que já foram ditas e que parece interessante e tente encontrar coisas em comum entre o entrevistador e entrevistado para gerar confiança e semelhança.

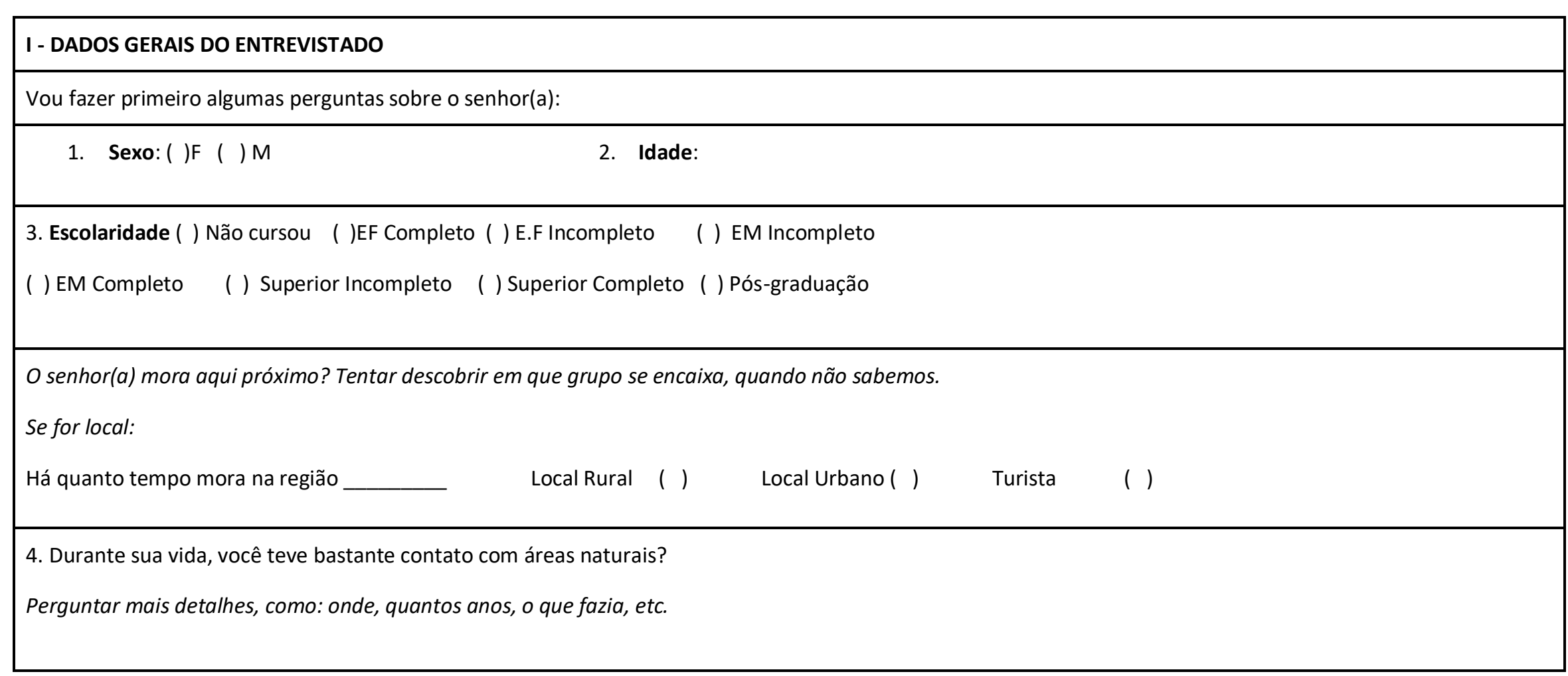




\section{CONTATO COM A UNIDADE DE CONSERVAÇÃO}

1. Você conhece a UC (falar o nome) ? Ou pelo menos já ouviu falar sobre ela?

SIM

NÃO

OUVI FALAR

Nota: Continuar apenas se a pessoa tiver algum conhecimento sobre o local. Se ela for local e não conhecer, mostrar no mapa, se mesmo assim não resolver, parar a entrevista e agradecer.

2. Você frequenta a UC (falar o nome) ? Com que frequência?

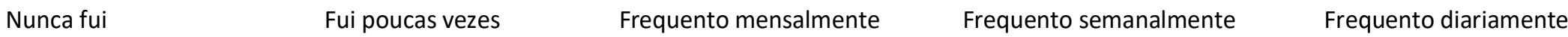

3. Qual o motivo da visita?

4. Você possui algum tipo de renda dependente da UC (falar o nome) ? Qual? O quanto da renda?

SIM

NÃO

5. Gostaria de substituir a UC por alguma outra coisa (pasto, lavoura, cidade, uma área natural não protegida, etc)? Por quê?

SIM

NÃO

Nota: Se a pessoa responder SIM, na próxima pergunta perguntar se ela gostaria de mais áreas como a UC mas em OUTRO LUGAR. 
5. Você gostaria que houvesse mais áreas assim como a UC para preservar o Cerrado? Por quê?

SIM

NÃO

\section{SERVIÇOS ECOSSISTÊMICOS}

1. Que benefícios você acha que o Parque traz por conservar a natureza?

NOTA: Primeiramente fazer a pergunta de forma aberta, e deixar o entrevistado falar. Anotando na tabela abaixo os que foram ditos na etapa 1 com um X na primeira coluna.

2. Agora vou citar alguns benefícios e os que já foram citados por você. Você poderia dar uma nota de 0-3 pensando na importância que esses benefícios trazem? Só responda para aqueles que você realmente percebe, sente ou faz uso.

0- Não é importante $\mathbf{1 - p o u c o ~ i m p o r t a n t e ~} \mathbf{2 - i m p o r t a n t e}$ 3-muito importante $\mathbf{X}$-não percebe

\begin{tabular}{|c|c|c|c|c|c|c|}
\hline Citado na 1 & & 0 & 1 & 2 & 3 & $\mathbf{X}$ \\
\hline \multicolumn{7}{|c|}{ SE CULTURAIS } \\
\hline & Lugar para se divertir (piquenique, cachoeiras, banho no rio, etc); & & & & & \\
\hline & Lugar para rezar; & & & & & \\
\hline & Lugar para caminhar & & & & & \\
\hline & Beleza para se ver (paisagem) & & & & & \\
\hline & Atividades Educativas & & & & & \\
\hline & Pesquisa Científica & & & & & \\
\hline
\end{tabular}




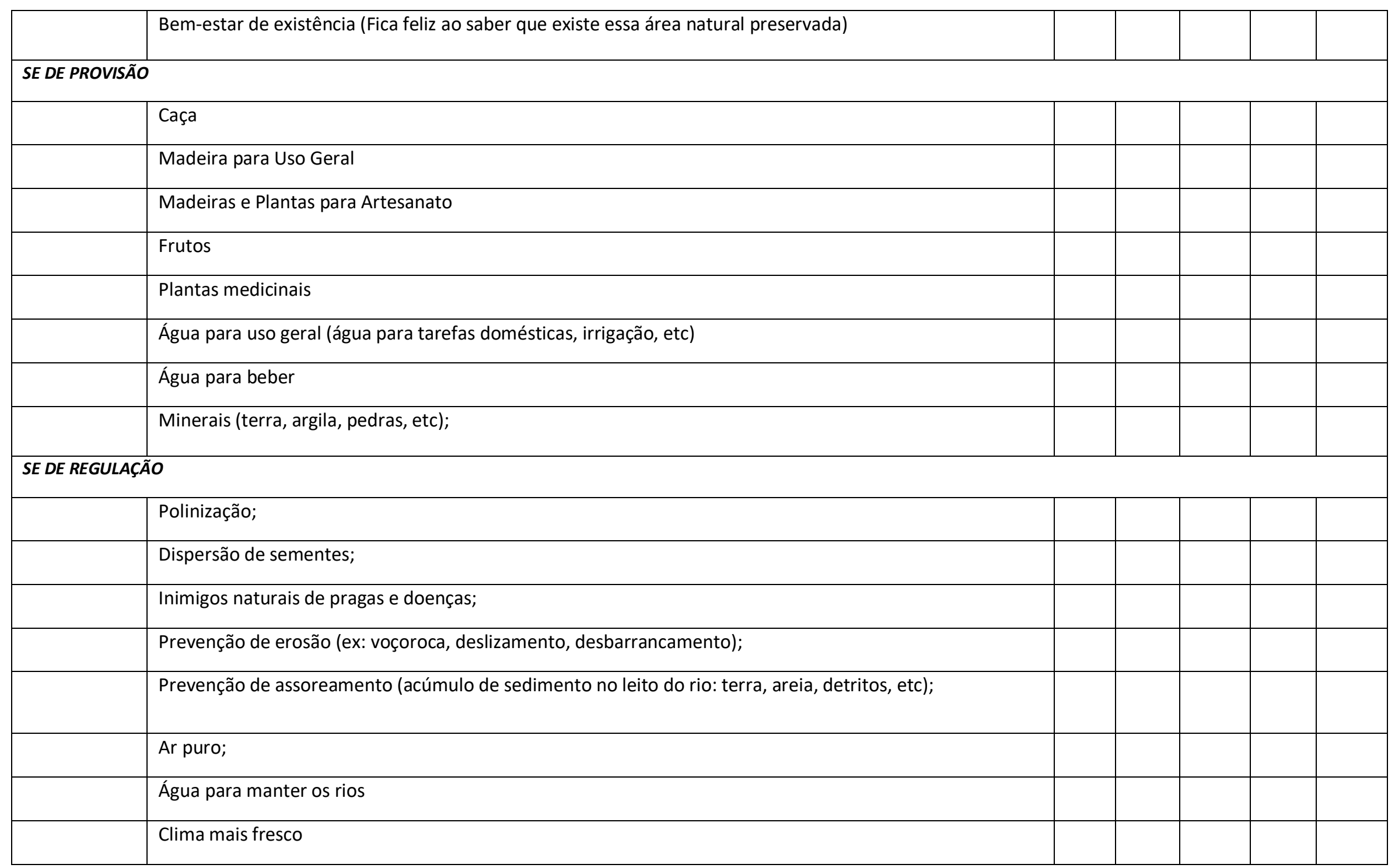




\begin{tabular}{|l|l|l|l|l|l|}
\hline \multicolumn{2}{|l|}{ Prevenção de Inundação } & & & \multicolumn{1}{l|}{} \\
\hline SE DE SUPORTE/APOIO & & & & \\
\hline & Deixa o solo mais fértil (decomposição e ciclagem) & & & & \\
\hline & Fornece habitat para espécies (Lugar para os animais morarem) & \\
\hline
\end{tabular}

\section{TENDÊNCIA DOS SERVIÇOS ECOSSISTÊMICOS \\ NOTA: somente faça essa pergunta se a pessoa for local.}

1. Agora eu vou fazer algumas afirmações e você dirá se CONCORDA, DISCORDA OU NÃO SABE. Vamos relembrar os últimos 10 anos...

\begin{tabular}{|l|l|l|l|}
\hline & Discordo & Concordo & Não sei \\
\hline Hoje em dia a água está mais suja & & & \\
\hline Diminuiu a quantidade de áreas naturais & & & \\
\hline Aumentou a quantidade de pragas e doenças na lavoura & & & \\
\hline Aumentou a quantidade de doenças nas pessoas & & & \\
\hline A seca está mais forte & & & \\
\hline Os rios têm menos água que antes & & & \\
\hline
\end{tabular}




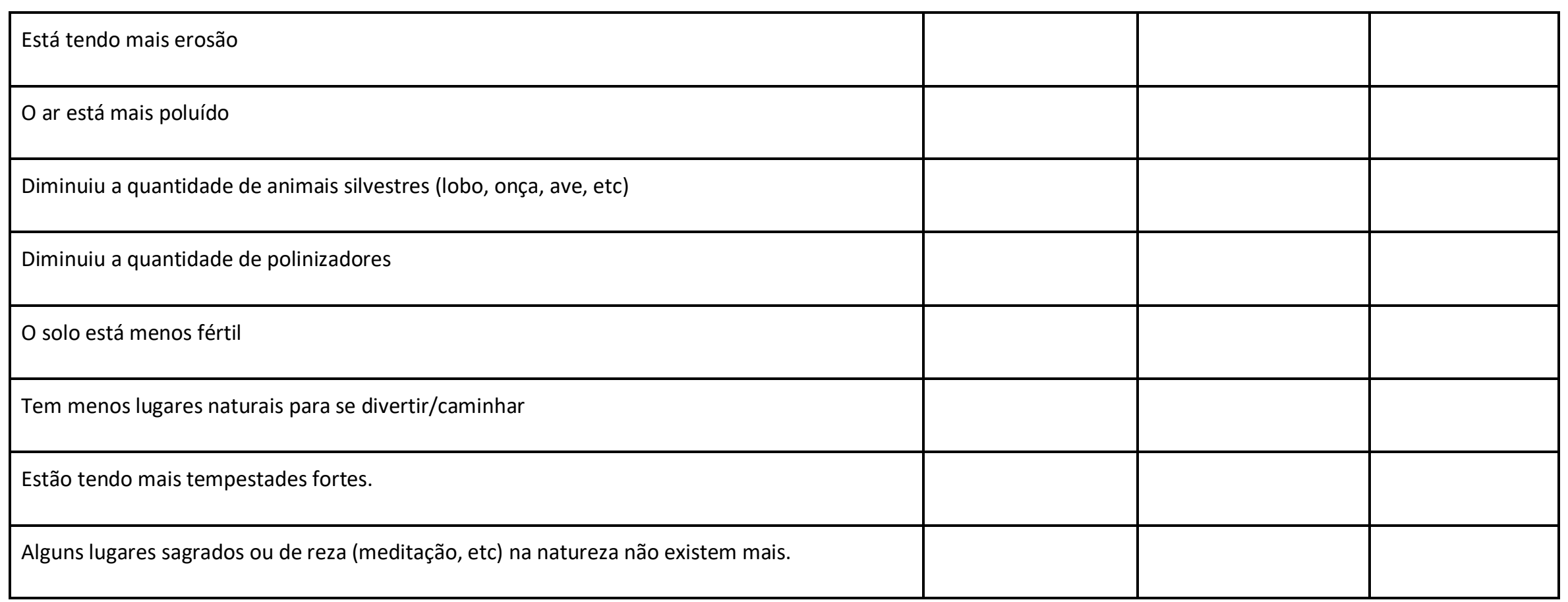

NOTA: Para finalizar : Gostaríamos muito de agradecer sua disposição em nos receber e nos responder. A sua participação é essencial para o sucesso do estudo. 
Roteiro II - Entrevista para levantamento da Percepção dos SE - Grupo de Especialistas

\begin{tabular}{|c|c|c|c|}
\hline $\begin{array}{l}\text { Universidade de São Paulo } \\
\text { Instituto de Biociências } \\
\text { Projeto: Áreas Protegidas como } \\
\text { mantenedores de Serviços } \\
\text { Ecossistêmicos em sistemas } \\
\text { socioecológicos: percepção e } \\
\text { mapeamento no Cerrado }\end{array}$ & $\begin{array}{l}\text { Data da entrevista: } \\
\text { Entrevistador: } \\
\text { UC: }\end{array}$ & $\begin{array}{l}\text { IDENTIFICAÇÃO DO ENTREVISTADO } \\
\text { GRUPO: Especialista } \\
\text { INSTITUIÇÃO: } \\
\text { CARGO: }\end{array}$ & № \\
\hline
\end{tabular}

Nota: os trechos em itálico são instruções ao entrevistador e não devem ser lido às pessoas entrevistadas.

Começar a entrevista com uma breve introdução explicando o projeto. Lembre-se de se apresentar à pessoa.

NOME: 
2. Pedimos licença para poder gravar a entrevista, não iremos divulgar as gravações e nomes.

\section{I - DADOS GERAIS DO ENTREVISTADO}

As primeiras perguntas serão de dados gerais:
1. Sexo: ( )F ( ) M
2. Idade:

3. Formação e área de atuação:

4. Há quanto tempo atua profissionalmente na região:

II - VISÃO GERAL DE PROBLEMAS E CONFLITOS

5. Quais são os principais problemas enfrentados pela UC? 
6. Você acha que a abordagem de Serviços Ecossistêmicos poderia ajudar a resolver? De que forma?

Nota: Para a próxima etapa entregue as fichas à seguir e explique. Deixe o entrevistado à vontade para preencher e tirar dúvidas. Deixe a alternativa de preenchimento e entrega depois, se assim ele preferir.

\section{SERVIÇOS ECOSSISTÊMICOS (SE)}

1. Nessa etapa, iremos avaliar os Serviços Ecossistêmicos que são fornecidos pela UC. Por favor, preencha a tabela dando uma nota de 0-3 de para os Serviços Ecossistêmicos citados de acordo com seu grau de importância. Coloque $\mathbf{X}$ quando você achar que não percebe ou que não há fornecimento do SE em questão.

0- Não é importante $\mathbf{1 - p o u c o ~ i m p o r t a n t e ~} \quad$ 2-importante $\quad$ 3-muito importante $\mathbf{X}$-não percebe/não fornece

\begin{tabular}{|l|l|l|}
\hline SERVIÇO ECOSSISTÊMICO & NOTA & \\
\hline Regulação do Clima & & \\
& & \\
& & \\
\hline
\end{tabular}




\begin{tabular}{|c|}
\hline Controle/Prevenção de Inundações \\
\hline Regulação da quantidade de água \\
\hline Regulação da qualidade da água \\
\hline Regulação da qualidade do ar \\
\hline Controle/Prevenção de assoreamento \\
\hline
\end{tabular}




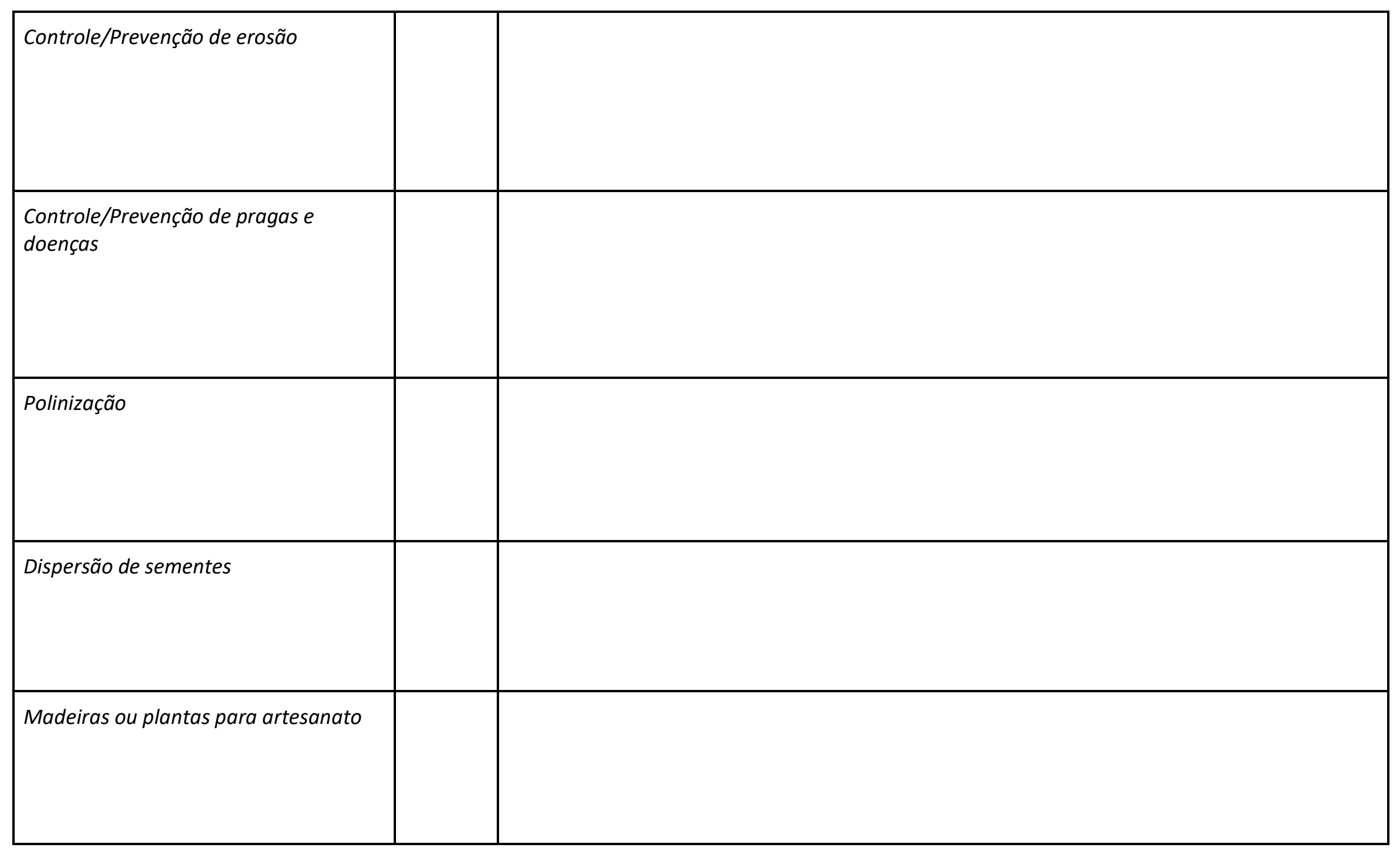

83 


\begin{tabular}{|c|}
\hline Frutos e outros alime \\
\hline Água para beber \\
\hline Água para uso geral \\
\hline Plantas medicinais \\
\hline Ciclagem de Nutrient \\
\hline Provisão de Habitat \\
\hline
\end{tabular}




\begin{tabular}{|l|l|l|}
\hline Recreação & & \\
\hline Caminhada & & \\
\hline Atividades Espirituais & & \\
\hline Atividades Educativas & & \\
\hline Pesquisa Cientifica & & \\
\hline
\end{tabular}


Valor de Existência (Bem-estar de

existência)

FIQUE À VONTADE PARA ANOTAR OBSERVAÇÕES, OUTROS SERVIÇOS ECOSSISTÊMICOS QUE GOSTARIA DE ACRESCENTAR OU SUGESTÕES: 


\section{Material Suplementar S2 Capítulo 2.}

Tabela 3: Frequência de respostas sobre o grau de importância dos serviços ecossistêmicos fornecidos pelo Parque Nacional de Brasília por stakeholders.

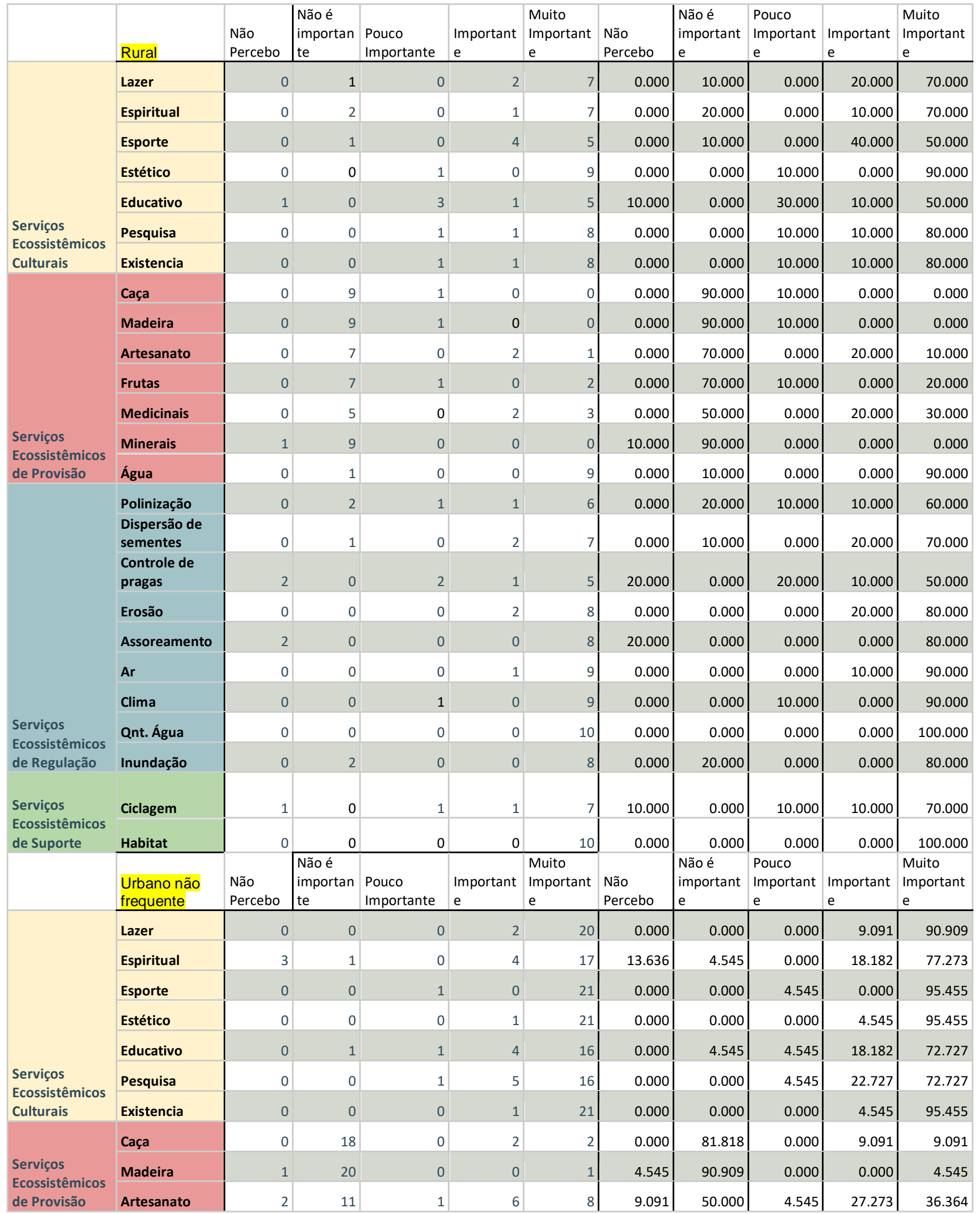




\begin{tabular}{|c|c|c|c|c|c|c|c|c|c|c|c|}
\hline & Frutas & 0 & 4 & 2 & 4 & 12 & 0.000 & 18.182 & 9.091 & 18.182 & 54.545 \\
\hline & Medicinais & 0 & 5 & 0 & 3 & 14 & 0.000 & 22.727 & 0.000 & 13.636 & 63.636 \\
\hline & Minerais & 2 & 15 & 1 & 1 & 3 & 9.091 & 68.182 & 4.545 & 4.545 & 13.636 \\
\hline & Água & 0 & 2 & 3 & 4 & 13 & 0.000 & 9.091 & 13.636 & 18.182 & 59.091 \\
\hline \multirow{9}{*}{$\begin{array}{l}\text { Serviços } \\
\text { Ecossistêmicos } \\
\text { de Regulação }\end{array}$} & Polinização & 0 & 2 & 0 & 6 & 14 & 0.000 & 9.091 & 0.000 & 27.273 & 63.636 \\
\hline & $\begin{array}{l}\text { Dispersão de } \\
\text { sementes }\end{array}$ & 0 & 0 & 1 & 2 & 19 & 0.000 & 0.000 & 4.545 & 9.091 & 86.364 \\
\hline & $\begin{array}{l}\text { Controle de } \\
\text { pragas }\end{array}$ & 3 & 2 & 2 & 5 & 10 & 13.636 & 9.091 & 9.091 & 22.727 & 45.455 \\
\hline & Erosão & 1 & 2 & 1 & 1 & 17 & 4.545 & 9.091 & 4.545 & 4.545 & 77.273 \\
\hline & Assoreamento & 2 & 1 & 1 & 3 & 15 & 9.091 & 4.545 & 4.545 & 13.636 & 68.182 \\
\hline & $\mathrm{Ar}$ & 0 & 0 & 0 & 0 & 22 & 0.000 & 0.000 & 0.000 & 0.000 & 100.000 \\
\hline & Clima & 0 & 0 & 0 & 2 & 20 & 0.000 & 0.000 & 0.000 & 9.091 & 90.909 \\
\hline & Qnt. Água & 0 & 1 & 1 & 1 & 19 & 0.000 & 4.545 & 4.545 & 4.545 & 86.364 \\
\hline & Inundação & 0 & 4 & 1 & 5 & 12 & 0.000 & 18.182 & 4.545 & 22.727 & 54.545 \\
\hline \multirow{3}{*}{$\begin{array}{l}\text { Serviços } \\
\text { Ecossistêmicos } \\
\text { de Suporte }\end{array}$} & Ciclagem & 0 & 0 & 1 & 2 & 19 & 0.000 & 0.000 & 4.545 & 9.091 & 86.364 \\
\hline & Habitat & 0 & 0 & 0 & 0 & 22 & 0.000 & 0.000 & 0.000 & 0.000 & 100.000 \\
\hline & $\begin{array}{l}\text { Urbano } \\
\text { frequente }\end{array}$ & $\begin{array}{l}\text { Não } \\
\text { Percebo }\end{array}$ & \begin{tabular}{|l|}
$\begin{array}{l}\text { Não é } \\
\text { importan } \\
\text { te }\end{array}$ \\
\end{tabular} & $\begin{array}{l}\text { Pouco } \\
\text { Importante } \\
\end{array}$ & $\begin{array}{l}\text { Important } \\
\mathrm{e}\end{array}$ & $\begin{array}{l}\text { Muito } \\
\text { Important } \\
\mathrm{e}\end{array}$ & $\begin{array}{l}\text { Não } \\
\text { Percebo }\end{array}$ & \begin{tabular}{|l|} 
Não é \\
important \\
e
\end{tabular} & $\begin{array}{l}\text { Pouco } \\
\text { Important } \\
\mathrm{e}\end{array}$ & $\begin{array}{l}\text { Important } \\
\mathrm{e}\end{array}$ & $\begin{array}{l}\text { Muito } \\
\text { Important } \\
\mathrm{e}\end{array}$ \\
\hline \multirow{7}{*}{$\begin{array}{l}\text { Serviços } \\
\text { Ecossistêmicos } \\
\text { Culturais }\end{array}$} & Lazer & 0 & 0 & 0 & 0 & 15 & 0.000 & 0.000 & 0.000 & 0.000 & 100.000 \\
\hline & Espiritual & 1 & 3 & 0 & 1 & 10 & 6.667 & 20.000 & 0.000 & 6.667 & 66.667 \\
\hline & Esporte & 0 & 0 & 0 & 0 & 15 & 0.000 & 0.000 & 0.000 & 0.000 & 100.000 \\
\hline & Estético & 0 & 0 & 0 & 2 & 13 & 0.000 & 0.000 & 0.000 & 13.333 & 86.667 \\
\hline & Educativo & 0 & 2 & 2 & 3 & 8 & 0.000 & 13.333 & 13.333 & 20.000 & 53.333 \\
\hline & Pesquisa & 0 & 0 & 0 & 1 & 14 & 0.000 & 0.000 & 0.000 & 6.667 & 93.333 \\
\hline & Existencia & 0 & 1 & 0 & 0 & 14 & 0.000 & 6.667 & 0.000 & 0.000 & 93.333 \\
\hline \multirow{14}{*}{$\begin{array}{l}\text { Serviços } \\
\text { Ecossistêmicos } \\
\text { de Provisão }\end{array}$} & Caça & 1 & 14 & 0 & 0 & 0 & 6.667 & 93.333 & 0.000 & 0.000 & 0.000 \\
\hline & Madeira & 0 & 15 & 0 & 0 & 이 & 0.000 & 100.000 & 0.000 & 0.000 & 0.000 \\
\hline & Artesanato & 0 & 13 & 1 & 1 & 0 & 0.000 & 86.667 & 6.667 & 6.667 & 0.000 \\
\hline & Frutas & 0 & 10 & 0 & 2 & 3 & 0.000 & 66.667 & 0.000 & 13.333 & 20.000 \\
\hline & Medicinais & 0 & 6 & 0 & 2 & 7 & 0.000 & 40.000 & 0.000 & 13.333 & 46.667 \\
\hline & Minerais & 0 & 15 & 0 & 0 & 이 & 0.000 & 100.000 & 0.000 & 0.000 & 0.000 \\
\hline & Água & 0 & 3 & 0 & 3 & 9 & 0.000 & 20.000 & 0.000 & 20.000 & 60.000 \\
\hline & Polinização & 0 & 2 & 1 & 0 & 12 & 0.000 & 13.333 & 6.667 & 0.000 & 80.000 \\
\hline & $\begin{array}{l}\text { Dispersão de } \\
\text { sementes }\end{array}$ & 0 & 0 & 0 & 0 & 15 & 0.000 & 0.000 & 0.000 & 0.000 & 100.000 \\
\hline & $\begin{array}{l}\text { Controle de } \\
\text { pragas }\end{array}$ & 3 & 2 & 1 & 2 & 7| & 20.000 & 13.333 & $6.667 \mid$ & 13.333 & 46.667 \\
\hline & Erosão & 1 & 3 & 0 & 1 & 10 & 6.667 & 20.000 & 0.000 & 6.667 & 66.667 \\
\hline & Assoreamento & 3 & 1 & 0 & 0 & 11 & 20.000 & 6.667 & 0.000 & 0.000 & 73.333 \\
\hline & Ar & 0 & 0 & 0 & 0 & 15 & 0.000 & 0.000 & 0.000 & 0.000 & 100.000 \\
\hline & Clima & 0 & 1 & 0 & 2 & 12 & 0.000 & 6.667 & 0.000 & 13.333 & 80.000 \\
\hline \multirow{2}{*}{$\begin{array}{l}\text { Serviços } \\
\text { Ecossistêmicos } \\
\text { de Regulação }\end{array}$} & Qnt. Água & 0 & 1 & 0 & 1 & 13 & 0.000 & 6.667 & 0.000 & 6.667 & 86.667 \\
\hline & Inundação & 0 & 2 & 0 & 3 & 10 & 0.000 & 13.333 & 0.000 & 20.000 & 66.667 \\
\hline Serviços & Ciclagem & 3 & 0 & 0 & 0 & 12 & 20.000 & 0.000 & 0.000 & 0.000 & 80.000 \\
\hline
\end{tabular}




\begin{tabular}{|c|c|c|c|c|c|c|c|c|c|c|c|}
\hline $\begin{array}{l}\text { Ecossistêmicos } \\
\text { de Suporte }\end{array}$ & Habitat & 0 & 0 & 0 & 0 & 15 & 0.000 & 0.000 & \begin{tabular}{|l|} 
\\
\end{tabular} & 0.000 & 100.000 \\
\hline & Turistas & $\begin{array}{l}\text { Não } \\
\text { Percebo }\end{array}$ & \begin{tabular}{|l|} 
Não é \\
importan \\
te
\end{tabular} & $\begin{array}{l}\text { Pouco } \\
\text { Importante }\end{array}$ & $\begin{array}{l}\text { Important } \\
\mathrm{e}\end{array}$ & \begin{tabular}{|l|} 
Muito \\
Important \\
e \\
\end{tabular} & $\begin{array}{l}\text { Não } \\
\text { Percebo }\end{array}$ & \begin{tabular}{|l|} 
Não é \\
important \\
e
\end{tabular} & $\begin{array}{l}\text { Pouco } \\
\text { Important } \\
\mathrm{e} \\
\end{array}$ & $\begin{array}{l}\text { Important } \\
\mathrm{e}\end{array}$ & $\begin{array}{l}\text { Muito } \\
\text { Important } \\
\mathrm{e} \\
\end{array}$ \\
\hline \multirow{7}{*}{$\begin{array}{l}\text { Serviços } \\
\text { Ecossistêmicos } \\
\text { Culturais }\end{array}$} & Lazer & 0 & 0 & 0 & 1 & 6 & 0.000 & 0.000 & 0.000 & 14.286 & 85.714 \\
\hline & Espiritual & 0 & 1 & 0 & 2 & 4 & 0.000 & 14.286 & 0.000 & 28.571 & 57.143 \\
\hline & Esporte & 0 & 0 & 0 & 1 & 6 & 0.000 & 0.000 & 0.000 & 14.286 & 85.714 \\
\hline & Estético & 0 & 0 & 0 & 0 & 7 & 0.000 & 0.000 & 0.000 & 0.000 & 100.000 \\
\hline & Educativo & 0 & 0 & 1 & 0 & 6 & 0.000 & 0.000 & 14.286 & 0.000 & 85.714 \\
\hline & Pesquisa & 0 & 0 & 1 & 0 & 6 & 0.000 & 0.000 & 14.286 & 0.000 & 85.714 \\
\hline & Existencia & 0 & 0 & 0 & 0 & 7 & 0.000 & 0.000 & 0.000 & 0.000 & 100.000 \\
\hline \multirow{7}{*}{$\begin{array}{l}\text { Serviços } \\
\text { Ecossistêmicos } \\
\text { de Provisão }\end{array}$} & Caça & 0 & 7 & 0 & 0 & 0 & 0.000 & 100.000 & 0.000 & 0.000 & 0.000 \\
\hline & Madeira & 1 & 6 & 0 & 0 & 0 & 14.286 & 85.714 & 0.000 & 0.000 & 0.000 \\
\hline & Artesanato & 1 & 4 & 0 & 2 & 0 & 14.286 & 57.143 & 0.000 & 28.571 & 0.000 \\
\hline & Frutas & 2 & 1 & 0 & 2 & 2 & 28.571 & 14.286 & 0.000 & 28.571 & 28.571 \\
\hline & Medicinais & 2 & 2 & 0 & 1 & 2 & 28.571 & 28.571 & 0.000 & 14.286 & 28.571 \\
\hline & Minerais & 1 & 4 & 0 & 1 & 1 & 14.286 & 57.143 & 0.000 & 14.286 & 14.286 \\
\hline & Água & 1 & 2 & 0 & 1 & 3 & 14.286 & 28.571 & 0.000 & 14.286 & 42.857 \\
\hline \multirow{9}{*}{$\begin{array}{l}\text { Serviços } \\
\text { Ecossistêmicos } \\
\text { de Regulação }\end{array}$} & Polinização & 0 & 0 & 0 & 1 & 6 & 0.000 & 0.000 & 0.000 & 14.286 & 85.714 \\
\hline & $\begin{array}{l}\text { Dispersão de } \\
\text { sementes }\end{array}$ & 1 & 0 & 0 & 0 & 6 & 14.286 & 0.000 & 0.000 & 0.000 & 85.714 \\
\hline & $\begin{array}{l}\text { Controle de } \\
\text { pragas }\end{array}$ & 0 & 1 & 1 & 1 & 4 & 0.000 & 14.286 & 14.286 & 14.286 & 57.143 \\
\hline & Erosão & 0 & 1 & 0 & 0 & 6 & 0.000 & 14.286 & 0.000 & 0.000 & 85.714 \\
\hline & Assoreamento & 0 & 0 & 0 & 1 & 6 & 0.000 & 0.000 & 0.000 & 14.286 & 85.714 \\
\hline & $\mathrm{Ar}$ & 1 & 0 & 0 & 0 & 6 & 14.286 & 0.000 & 0.000 & 0.000 & 85.714 \\
\hline & Clima & 0 & 0 & 0 & 0 & 7 & 0.000 & 0.000 & 0.000 & 0.000 & 100.000 \\
\hline & Qnt. Água & 1 & 0 & 0 & 1 & 5 & 14.286 & 0.000 & 0.000 & 14.286 & 71.429 \\
\hline & Inundação & 0 & 1 & 0 & 0 & 6 & 0.000 & 14.286 & 0.000 & 0.000 & 85.714 \\
\hline \multirow{3}{*}{$\begin{array}{l}\text { Serviços } \\
\text { Ecossistêmicos } \\
\text { de Suporte }\end{array}$} & Ciclagem & 2 & 0 & 0 & 1 & 4 & 28.571 & 0.000 & 0.000 & 14.286 & 57.143 \\
\hline & Habitat & 0 & 0 & 0 & 0 & 7 & 0.000 & 0.000 & 0.000 & 0.000 & 100.000 \\
\hline & Gestores & $\begin{array}{l}\text { Não } \\
\text { Percebo }\end{array}$ & \begin{tabular}{|l|} 
Não é \\
importan \\
te
\end{tabular} & $\begin{array}{l}\text { Pouco } \\
\text { Importante }\end{array}$ & $\begin{array}{l}\text { Important } \\
\mathrm{e}\end{array}$ & \begin{tabular}{|l|} 
Muito \\
Important \\
e \\
\end{tabular} & $\begin{array}{l}\text { Não } \\
\text { Percebo }\end{array}$ & $\begin{array}{l}\text { Não é } \\
\text { important } \\
\text { e }\end{array}$ & $\begin{array}{l}\text { Pouco } \\
\text { Important } \\
\text { e } \\
\end{array}$ & $\begin{array}{l}\text { Important } \\
\mathrm{e}\end{array}$ & $\begin{array}{l}\text { Muito } \\
\text { Important } \\
\mathrm{e}\end{array}$ \\
\hline \multirow{7}{*}{$\begin{array}{l}\text { Serviços } \\
\text { Ecossistêmicos } \\
\text { Culturais }\end{array}$} & Lazer & 0 & 0 & 1 & 0 & 3 & 0.000 & 0.000 & 25.000 & 0.000 & 75.000 \\
\hline & Espiritual & 0 & 1 & 2 & 0 & 1 & 0.000 & 25.000 & 50.000 & 0.000 & 25.000 \\
\hline & Esporte & 0 & 0 & 0 & 1 & 3 & 0.000 & 0.000 & 0.000 & 25.000 & 75.000 \\
\hline & Estético & 0 & 0 & 0 & 1 & 3 & 0.000 & 0.000 & 0.000 & 25.000 & 75.000 \\
\hline & Educativo & 0 & 0 & 0 & 0 & 4 & 0.000 & 0.000 & 0.000 & 0.000 & 100.000 \\
\hline & Pesquisa & 0 & 0 & 0 & 0 & 4 & 0.000 & 0.000 & 0.000 & 0.000 & 100.000 \\
\hline & Existencia & 0 & 0 & 0 & 0 & 4 & 0.000 & 0.000 & 0.000 & 0.000 & 100.000 \\
\hline \multirow{5}{*}{$\begin{array}{l}\text { Serviços } \\
\text { Ecossistêmicos } \\
\text { de Provisão }\end{array}$} & Caça & 0 & 4 & 0 & 0 & 0 & 0.000 & 100.000 & 0.000 & 0.000 & 0.000 \\
\hline & Madeira & 0 & 4 & 0 & 0 & 이 & 0.000 & 100.000 & 0.000 & 0.000 & 0.000 \\
\hline & Artesanato & 0 & 4 & 0 & 0 & 0 & 0.000 & 100.000 & 0.000 & 0.000 & 0.000 \\
\hline & Frutas & 0 & 4 & 0 & 0 & 0 & 0.000 & 100.000 & 0.000 & 0.000 & 0.000 \\
\hline & Medicinais & 0 & 4 & 0 & 0 & 0 & 0.000 & 100.000 & 0.000 & 0.000 & 0.000 \\
\hline
\end{tabular}




\begin{tabular}{|c|c|c|c|c|c|c|c|c|c|c|c|}
\hline & Minerais & 0 & 4 & 0 & 0 & 0 & 0.000 & 100.000 & 0.000 & 0.000 & 0.000 \\
\hline & Água & 0 & 0 & 0 & 0 & 4 & 0.000 & 0.000 & 0.000 & 0.000 & 100.000 \\
\hline \multirow{9}{*}{$\begin{array}{l}\text { Serviços } \\
\text { Ecossistêmicos } \\
\text { de Regulação }\end{array}$} & Polinização & 0 & 0 & 0 & 4 & 이 & 0.000 & 0.000 & 0.000 & 100.000 & 0.000 \\
\hline & $\begin{array}{l}\text { Dispersão de } \\
\text { sementes }\end{array}$ & 0 & 0 & 0 & 2 & 2 & 0.000 & 0.000 & 0.000 & 50.000 & 50.000 \\
\hline & $\begin{array}{l}\text { Controle de } \\
\text { pragas }\end{array}$ & 1 & 0 & 1 & 2 & 이 & 25.000 & 0.000 & 25.000 & 50.000 & 0.000 \\
\hline & Erosão & 0 & 0 & 0 & 2 & 2 & 0.000 & 0.000 & 0.000 & 50.000 & 50.000 \\
\hline & Assoreamento & 0 & 0 & 0 & 2 & 2 & 0.000 & 0.000 & 0.000 & 50.000 & 50.000 \\
\hline & Ar & 0 & 0 & 0 & 2 & 2 & 0.000 & 0.000 & 0.000 & 50.000 & 50.000 \\
\hline & Clima & 0 & 0 & 0 & 2 & 2 & 0.000 & 0.000 & 0.000 & 50.000 & 50.000 \\
\hline & Qnt. Água & 0 & 0 & 0 & 1 & 3 & 0.000 & 0.000 & 0.000 & 25.000 & 75.000 \\
\hline & Inundação & 0 & 1 & 0 & 2 & 이 & 0.000 & 25.000 & 0.000 & 50.000 & 0.000 \\
\hline Serviços & Ciclagem & 2 & 0 & 0 & 0 & 2 & 50.000 & 0.000 & 0.000 & 0.000 & 50.000 \\
\hline $\begin{array}{l}\text { Ecossistêmicos } \\
\text { de Suporte }\end{array}$ & Habitat & 0 & 0 & 0 & 0 & 4 & 0.000 & 0.000 & 0.000 & 0.000 & 100.000 \\
\hline
\end{tabular}

Tabela 4: Resultado do teste de significância por reamostragem para comparação par a par entre a diferença de mediana dos grupos (* diferença significativa, $p<0,05$ ). Tabela $A, B, C, D$ referem-se às comparações entre os grupos de stakeholders para a importância dada por grupo de serviços ecossistêmicos. E, F, G, H, I referem-se às comparações dentro dos grupos para avaliar a diferença entre a importância dada pelo grupo sobre os diferentes grupos de serviços ecossistêmicos.

\begin{tabular}{|c|c|c|c|c|c|}
\hline A) PROVISÃO & gestores & rural & turistas & urbano frequente & urbano não frequente \\
\hline gestores & & 0.31 & 0.21 & 1 & $0.04 *$ \\
\hline rural & & & 0.56 & 0.6 & 0.051 \\
\hline turistas & & & & 0.2 & 0.36 \\
\hline urbano frequente & & & & & $0.001 *$ \\
\hline urbano não frequente & & & & & \\
\hline
\end{tabular}

\begin{tabular}{|c|c|c|c|c|c|}
\hline B) CULTURAL & gestores & rural & turistas & urbano frequente & urbano não frequente \\
\hline gestores & & 0.6 & 0.4 & 0.31 & 0.06 \\
\hline rural & & & 1 & 1 & 1 \\
\hline turistas & & & & 1 & 1 \\
\hline urbano frequente & & & & & 1 \\
\hline urbano não frequente & & & & & \\
\hline
\end{tabular}

\begin{tabular}{|l|l|l|l|l|l|}
\hline \multicolumn{1}{|c|}{ C) REGULAÇÃO } & gestores & rural & turistas & urbano frequente & urbano não frequente \\
\hline gestores & & 0.15 & $0.02 *$ & 0.09 & 0.06 \\
\hline rural & & & 0.87 & & 1 \\
\hline turistas & & & & 0.83 & 0.34 \\
\hline urbano frequente & & & & & 0.38 \\
\hline urbano não frequente & & & & & \\
\hline
\end{tabular}

\begin{tabular}{|c|c|c|c|c|c|}
\hline D) SUPORTE & gestores & rural & turistas & urbano frequente & urbano não frequente \\
\hline gestores & & 1 & 1 & 1 & 1 \\
\hline rural & & & 1 & 1 & 1 \\
\hline turistas & & & & 1 & 1 \\
\hline
\end{tabular}




\begin{tabular}{|l|l|l|l|l|l|} 
urbano frequente & \multicolumn{2}{|l|}{} & \\
\hline urbano não frequente & \multicolumn{5}{|l|}{} \\
\hline \multicolumn{2}{|l|}{ E) GESTORES } & cultural & provisão & regulação & suporte \\
\hline cultural & & 0.14 & 0.28 & 0.14 \\
\hline provisão & & & 0.14 & 0.48 \\
\hline regulação & & & & 0.14 \\
\hline suporte & & & & \\
\hline
\end{tabular}

\begin{tabular}{|l|l|l|l|l|}
\hline \multicolumn{1}{|c|}{ F) RURAL } & cultural & provisão & regulação & suporte \\
\hline cultural & & $0.001^{*}$ & 0.89 & 0.22 \\
\hline provisão & & & $0.001^{*}$ & $0.005^{*}$ \\
\hline regulação & & & & 0.21 \\
\hline suporte & & & & \\
\hline
\end{tabular}

\begin{tabular}{|l|l|l|l|l|}
\hline \multicolumn{1}{|c|}{ G) TURISTAS } & cultural & provisão & regulação & suporte \\
\hline cultural & & 0.11 & & 0.27 \\
\hline provisão & & & $0.03^{*}$ & 0.2 \\
\hline regulação & & & & 0.26 \\
\hline suporte & & & & \\
\hline
\end{tabular}

\begin{tabular}{|l|l|l|l|l|}
\hline \multicolumn{1}{|c|}{$\begin{array}{l}\text { H) } \\
\text { FREQUENONTE }\end{array}$} & cultural & provisão & regulação & suporte \\
\hline cultural & & $0.0002^{*}$ & 0.74 & $0.013^{*}$ \\
\hline provisão & & & $0.0002^{*}$ & $0.001^{*}$ \\
\hline regulação & & & & $0.002^{*}$ \\
\hline suporte & & & & \\
\hline
\end{tabular}

\begin{tabular}{|l|l|l|l|l|}
\hline \multicolumn{1}{|c|}{ I) $\begin{array}{c}\text { URBANO NÃO } \\
\text { FREQUENTE }\end{array}$} & cultural & provisão & regulação & suporte \\
\hline cultural & & $0.0002^{*}$ & 0.12 & 0.06 \\
\hline provisão & & & $0.0003^{*}$ & $0.0002^{*}$ \\
\hline regulação & & & & $0.02^{*}$ \\
\hline suporte & & & & \\
\hline
\end{tabular}

Tabela 3: Resultado do teste de significância por reamostragem para comparação par a par entre a diferença de mediana entre gêneros ( ${ }^{*}$ diferença significativa, $p<0,05$ ). Tabela $A, B, C, D$ referem-se às comparações entre os gêneros para a importância dada por grupo de serviços ecossistêmicos.

\begin{tabular}{|c|l|}
\hline A) PROVISÃO & feminino \\
\hline masculino & 0.8 \\
\hline
\end{tabular}

\begin{tabular}{|l|l|}
\hline \multicolumn{1}{|c|}{ B) CULTURAL } & feminino \\
\hline masculino & 0.6 \\
\hline
\end{tabular}




\begin{tabular}{|c|l|}
\hline C) REGULAÇÃO & feminino \\
\hline masculino & 0.16 \\
\hline
\end{tabular}

\begin{tabular}{|l|l|}
\hline \multicolumn{1}{|c|}{ D) SUPORTE } & feminino \\
\hline masculino & 1 \\
\hline
\end{tabular}

Tabela 4: Resultado do teste de significância por reamostragem para comparação par a par entre a diferença de mediana das escolaridades (* diferença significativa, $p<0,05$ ). Tabela $A, B, C, D$ referem-se às comparações entre as diferentes escolaridades para a importância dada por grupo de serviços ecossistêmicos.

\begin{tabular}{|l|l|l|l|l|}
\hline \multicolumn{1}{|c|}{ A) PROVISÃo } & $\begin{array}{l}\text { Ensino } \\
\text { Fundamental }\end{array}$ & $\begin{array}{l}\text { Ensino } \\
\text { Médio }\end{array}$ & $\begin{array}{l}\text { Ensino } \\
\text { Superior }\end{array}$ & $\begin{array}{l}\text { Pós- } \\
\text { graduação }\end{array}$ \\
\hline Ensino Fundamental & & $0.02^{*}$ & 0.33 & \\
\hline Ensino Médio & & & 0.56 & $0.02^{*}$ \\
\hline Ensino Superior & & & & \\
\hline Pós-graduação & & & & 0.7 \\
\hline
\end{tabular}

\begin{tabular}{|l|l|l|l|l|}
\hline \multicolumn{1}{|c|}{ B) CULTURAL } & $\begin{array}{l}\text { Ensino } \\
\text { Fundamental }\end{array}$ & $\begin{array}{l}\text { Ensino } \\
\text { Médio }\end{array}$ & $\begin{array}{l}\text { Ensino } \\
\text { Superior }\end{array}$ & $\begin{array}{l}\text { Pós- } \\
\text { graduação }\end{array}$ \\
\hline Ensino Fundamental & & 0.2 & 1 & 0.6 \\
\hline Ensino Médio & & & 0.33 & 0.45 \\
\hline Ensino Superior & & & & \\
\hline Pós-graduação & & & & \\
\hline
\end{tabular}

\begin{tabular}{|l|l|l|l|l|}
\hline \multicolumn{1}{|c|}{ C) REGULAÇÃo } & $\begin{array}{l}\text { Ensino } \\
\text { Fundamental }\end{array}$ & $\begin{array}{l}\text { Ensino } \\
\text { Médio }\end{array}$ & $\begin{array}{l}\text { Ensino } \\
\text { Superior }\end{array}$ & $\begin{array}{l}\text { Pós- } \\
\text { graduação }\end{array}$ \\
\hline Ensino Fundamental & & 0.16 & 0.7 & \\
\hline Ensino Médio & & & 0.1 & 0.2 \\
\hline \\
Ensino Superior & & & & \\
\hline Pós-graduação & & & & \\
\hline
\end{tabular}

\begin{tabular}{|c|c|c|c|c|}
\hline D) SUPORTE & $\begin{array}{l}\text { Ensino } \\
\text { Fundamental }\end{array}$ & $\begin{array}{l}\text { Ensino } \\
\text { Médio } \\
\end{array}$ & $\begin{array}{l}\text { Ensino } \\
\text { Superior }\end{array}$ & $\begin{array}{l}\text { Pós- } \\
\text { graduação }\end{array}$ \\
\hline Ensino Fundamental & & 1 & 0.2 & 1 \\
\hline Ensino Médio & & & 1 & 1 \\
\hline Ensino Superior & & & & 1 \\
\hline Pós-graduação & & & & \\
\hline
\end{tabular}


Tabela 5: Resultado da regressão linear baseada na correlação de Spearman para avaliar a relação entre a idade as notas de importância dada às diferentes categorias de serviços ecossistêmicos.

\begin{tabular}{|l|l|l|}
\hline $\begin{array}{l}\text { Regressão } \\
\text { linear - idade }\end{array}$ & valor $p$ & $\mathrm{R}^{2}$ \\
\hline Provisão & 0.07 & 0.05 \\
\hline Cultural & 0.87 & 0.00 \\
\hline Regulação & $0.02^{*}$ & 0.09 \\
\hline Suporte & 0.2 & 0.01 \\
\hline
\end{tabular}

Tabela 6: Resultado do teste de significância por reamostragem para comparação par a par entre a diferença de mediana entre as respostas positivas e negativas para o "contato com a natureza ao longo da vida" (* diferença significativa, $p<0,05)$. Tabela $A, B, C, D$ referem-se às comparações entre as respostas sim e não para a importância dada por grupo de serviços ecossistêmicos.

\begin{tabular}{|c|l|}
\hline A) PROVISÃO & Sim \\
\hline Não & 0.02 \\
\hline
\end{tabular}

\begin{tabular}{|c|l|}
\hline B) CULTURAL & Sim \\
\hline Não & 0.53 \\
\hline
\end{tabular}

\begin{tabular}{|c|l|}
\hline C) REGULAÇÃO & Sim \\
\hline Não & 0.17 \\
\hline
\end{tabular}

\begin{tabular}{|c|l|}
\hline D) SUPORTE & Sim \\
\hline Não & \\
\hline
\end{tabular}


De maneira geral, no capítulo 1, a revisão revelou que as características socioculturais e econômicas, além do contexto geográfico, parecem ser importantes fatores relacionados à preferência das pessoas pelos serviços ecossistêmicos. SE compatíveis com os objetivos das áreas naturais estão entre os mais valorizados, mostrando que a população valoriza e entende a importância da criação desses espaços, enfatizando a importância dessa estratégia de conservação. Mas ainda é notável a presença da dependência de comunidades em relação a muitos tipos de serviços ecossistêmicos de provisão, destacando ainda um desafio a ser enfrentado.

Resultados semelhantes foram encontrados no capítulo 2 em nosso estudo de caso no PARNA Brasília. O resultado das 58 entrevistas revelou que os entrevistados valorizam o parque em acordo com os objetivos da criação dessa área protegida, independentemente da frequência de visitação, como provisão de habitat e por valores intrínsecos (serviço ecossistêmico de existência), além das atividades de visitação. Além disso, houve valorização de serviços não somente por valores individuais, como também por valores coletivos, já que entrevistados deram alto valor de importância para SE em que não eram beneficiários diretos. Houve uma correlação expressiva entre o valor de importância e a percepção de declínio de alguns serviços ecossistêmicos. Essa abordagem revelou trade-offs e alguns conflitos existentes, dados principalmente por serviços de provisão que possuem algum grau de importância para parte dos moradores do entorno. Além disso, uma parte expressiva dos entrevistados teve o contato com a natureza durante a vida exclusivamente através de áreas protegidas, deixando ainda mais evidente a importância desses espaços para o bem-estar humano, para além dos fins de conservação da biodiversidade.

Utilizar a abordagem de SE como uma ferramenta para facilitar a comunicação entre tomadores de decisão, pesquisadores e a população, mostra-se promissora para auxiliar nos esforços para a efetividade de áreas protegidas. Promover o envolvimento das partes interessadas em processos participativos reais possibilita a identificação de trade-offs e atividades incompatíveis, além da identificação das demanda da população local, buscando soluções win-win entre conservação da biodiversidade e bem-estar humano. 